This report was prepared as an account of work sponsored by an agency of the United States Government. Neither the United States Govermment nor any agency thereof, nor any of their yees, makes any warranty, express or implied, or assumes any legal liability or responsifor the accuracy, completeness, or usefulness of any information, apparatus, product, or process disclosed, or represents that its use would not infringe privately owned rights. Reference herein to any specific commercial product, process, or service by trade name, trademark, manufacturer, or otherwise does not necessarily constitute or imply its endorsement, recommendation, or favoring by the United States Government or any agency thereof. The views and opinions of authors expressed herein do not necessarily state or reflect those of the United States Government or any agency thereof.
Distribution Category UC-70

ORIII -2.50

DEE 011519

\title{
Porosity, Permeability, and Their Relationship in Granite, Basalt, and Tuff
}

\author{
Technical Report
}

April 1983

INTERA Environmental Consultants, Inc. 11999 Katy Freeway, Suite 610

Houston, TX 77079

The content of this report was effective as of October 1982. This report was prepared by INTERA Environmental Consultants, Inc. under Subcontract E512-02900 with Battelle Project Management Division, Office of Nuclear Waste Isolation under Contract No. DE-AC06-76RLO1830 and DE-AC02$83 \mathrm{CH} 10140$ with the U.S. Department of Energy. This contract was administered by the Battelle Office of Nuclear Waste Isolation. 


\section{DISCLAIMER}

This report was prepared as an account of work sponsored by an agency of the United States Government. Neither the United States Government nor any agency Thereof, nor any of their employees, makes any warranty, express or implied, or assumes any legal liability or responsibility for the accuracy, completeness, or usefulness of any information, apparatus, product, or process disclosed, or represents that its use would not infringe privately owned rights. Reference herein to any specific commercial product, process, or service by trade name, trademark, manufacturer, or otherwise does not necessarily constitute or imply its endorsement, recommendation, or favoring by the United States Government or any agency thereof. The views and opinions of authors expressed herein do not necessarily state or reflect those of the United States Government or any agency thereof. 


\section{DISCLAIMER}

Portions of this document may be illegible in electronic image products. Images are produced from the best available original document. 


\section{ACRNOWLEDGMENTS}

Discussion with a number of people has been helpful, including: G. Grisak, R. Lantz, F. Pearson, W. Marine, C. Davison, D. Snow and P. Witherspoon, although they in no way share responsibility for the conclusions presented here. 


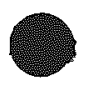

$\checkmark$ 


\section{ABSTRACT}

This report discusses the porosity, storage, and permeability of fractured (mainly crystalline) rock types proposed as host rock for nuclear waste repositories. The emphasis is on the inter-relationships of these properties but a number of reported measurements are included as well. The porosity of rock is shown to consist of fracture porosity and matrix porosity; techniques are described for determining the total interconnected porosity through both laboratory and field measurement. Permeability coefficient, as obtained by experiments ranging from laboratory to crustal scale, is discussed. Finally, the problem of determining the relationship between porosity and permeability is discussed. There is no simple, all encompassing relationship that describes the dependence of permeability upon porosity. However, two particular cases have been successfully analysed: flow through a single rough fracture, and flow through isotropic porous rock. These two cases are discussed in this report. 

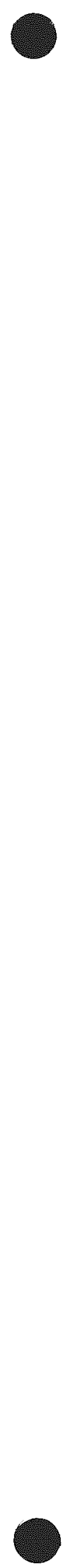
POROSITY . . . . . . . . . . . . . . . . . . . . 6

3.1 GENERAL . ........................ 6

3.2 INTERCONNECTED MATRIX POROSITY . . . . . . . . . . . . . . 8

3.3 FRACTURE POROSITY . . . . . . . . . . . . . . . . . 9 9

3.3 .1 Direct Observation .............. . . 9

3.3.2 Packer Tests in a Single Dril1 Hole . . . . . . . 11

3.3.3 Two-hel1 Tracer Tests . . . . . . . . . . . 12

3.3 .4 Comparison . . . . . . . . . . . . . . . . . 12

3.4 TOTAL POROSITY OF A ROCK MASS ................. 13

3.4.1 Total Porositv from Laboratory and Hvdrologic Measurements... . . . . . . . . . . . 13

3.4.2 Total Porositv from Field Flectrical

Measurements . . . . . . . . . . . . . . 14

3.5 CONCLUSIONS . . . . . . . . . . . . . . . . . . 14

4 STORAGE . . . . . . . . . . . . . . . . . . . . 16

4.1 LABORATORY DETERMINATION OF STORAGE . . . . . . . . . . . . 16

4.2 STORAGE FROM AQUTFER TESTS . . . . . . . . . . . . . . 17

5 PERMEABILITY . . . . . . . . . . . . . . . . . . . . . . . 18

5.1 GENERAL . . . . . . . . . . . .......... 18

5.2 MATRIX PERMEABILITY . . . . . . . . . . . ........ . . 19

5.2 .1 Methods of Measurements for Crystal1ine Rocks . . . 20

5.2.2 Laboratory studies of Temperatue and Pressure

Effects . . . . . . . . . . . . . . 22

5.2.2.1 Temperature Effects . . . . . . . . . 23

5.2 .2 .2 Pressure Effects ............ 31 
TABLE OF CONTENTS

(Continued)

Page

5.3 CONTROLLED LARGE SCALE TESTS . . . . . . . . . 36

5.3.1 Temperature and Pressure Effects in Controlled

Large-Scale Tests . . . . . . . . . 36

5.4 DRILL HOLE VALUES OF PERMEABILITY . . . . . . . . 42

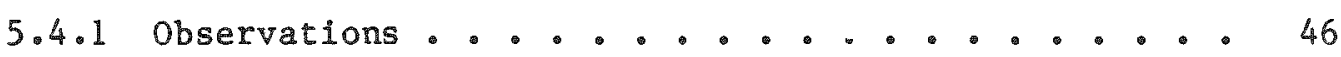

5.5 LARGE SCALE CRUSTAL PERMEABILITY . . . . . . . . 49

5.6 CONCLUSIONS ................... 50

6 DEPENDENCE OF PERMEABILITY ON PORE GEOMETRY . . . . . . . 58

6.1 INTRODUCTION . . . . . . . . . . . . 58

6.2 FRACTURE FLOW . . . . . . . . . . . 58

6.2 .1 Theory ................ 58

6.2.2 Experimental Test of the Cubic Law........ 59

6.3 MATRIX FLOW .................... 65

6.3 .1 Theory ................ 65

6.3.2 Experimental Tests of the Theory ......... 65

6.4 CONCLUSIONS ....................... 71

7 REFERENCES ................... 73

8 APPENDIX . . . . . . . . . . 85 
Figure 3-1. Discontinuities in a Fractured Rock Mass . . . . . . 7

Figure 3-2. Schematic Representation of Matrix Porosity showing Through-Going, Dead-ended and Isolated Pores . . . . 7

Figure 3-3. Fracture and Matrix Porosity . . . . . . . . . 10

Figure 5-1. Laboratory Measurement of Permeability of Intact Specimens ................ 21

Figure 5-2. Permeability of Water of Berea Sandstone as a Function of Temperature.............. 24

Figure 5-3. Permeability to Mineral Oil of Berea Sandstone vs Temperature ............... 24

Figure 5-4. Permeability to Mineral $0 i 1$ of Stainless steel vs Temperature ................ 26

Figure 5-5. Permeability to Water of Stainless Steel vs Temperature .............. 26

Figure 5-6. Plot of Average Permeability vs Time for Two Samples of Westerly Granite . . . . . . . . . . 27

Figure 5-7. Permeability of Los Alamos Granodiorite as a Function of Pressure and Temperature ........ 28

Figure 5-8. Permeability of Los Alamos Granodiorite as a Function of Pressure and Temperature .......... 29

Figure 5-9. Permeability of Westerly Granite vs Temperature . . . 30

Figure 5-10. (a) Change in Permeability with Stress for Westerly Granite, Darley Dale Sandstone and Ottawa Sand . . . . 34 (b) The Effect of Octahedral Shearing Stress upon Permeability for Various Mean Stresses . . . . . . 34 (c) The Effect of Mean Stress upon Permeability for Various Octahedral Shearing Stresses.... . . . . 34

Figure 5-11. Effect of Normal Stress on Flow Rate and on the Theoretical Smooth Wall Aperture . . . . . . . 38

Figure 5-12. Biaxial Loading at Elevated Rock Temperatures Facilitates Hydrothermo-Mechanical Coupling, Causing Dramatic Reductions in Flow Aperture . . . . . . . 
LIST OF FIGURES

(continued)

Figure 5-13. Joint Permeability-Normal Stress Relationships for In Situ Granite and In Situ Gneiss Show Close Agreement. 41

Figure 5-14. Guide to Selection of Well Test Techniques for Permeability Measurements . . . . . . . . 45

Figure 5-15. In Situ Measurements of Permeability . . . . . . . . 47

Figure 5-16. In Situ Measurements of $k$ for Crystalline Rocks . . . 48

Figure 5-17. In Situ Permeability Inferred from Various Large-Scale Phenomena ................. 51

Figure 5-18. Comparison of In Situ and Laboratory Measurements for the same Intervals at the Savannah River Plant . . 53

Figure 5-19. Comparison of Laboratory In Situ and Rock Mass Measurements of Permeability of Crystalline Rock at the Savannah River Plant . . . . . . . . . 54

Figure 5-20 Comparison of Intact and Fractured Rocks . . . . . . 56

Figure 6-1. Effect of Cyclic Loading on Permeability of Tension Fracture in Granite with Straight Flow . . . . . . . 61

Figure 6-2. Mechanical Properties of Fracture used in Determining Changes in Aperture with Stress .......... 63

Figure 6-3. Observed Fracture Flow Per Unit Head as a Function of Observed Aperture for Single Fracture . . . . . . 64

Figure 6-4. Density Distribution of 344 Cavity Widths for Westerly Granite Showing the Probability of Encountering a Cavity Belonging to the Width Range Indicated . . . 67

Figure 6-5. Comparison of Calculated and Measured Permeabilities . 70

LIST OF TABLES

Table 6-1. Calculated and Observed Permeability . . . . . . 68 
Of the several rock types proposed as host rock for nuclear waste repositories, granite, and basalt and, to a lesser extent, tuff and shale, have ground-water flow regimes dominated by fracture flow. Fvaluation of fracture porosity and permeability to permit modeling of flow and transport for performance assessment is less straightforward than for porous media. This report discusses a number of measured and inferred values of porositv, storage and permeability of fractured rock and reviews the mathematical relationships between porosity and permeability. It is intended to support those sections of the NhTS program concerned with rock in which fracture flow will be important.

Total porosity of a rock can be divided conveniently into two parts; namely, the matrix porosity and the fracture porosity. Fracture porosity as used herein is associated with joints and other large scale phenomena and can only be measured in situ. Matrix porosity contains portions which are interconnected and portions which are isolated; note that interconnected pore space could be dead-ended. That proportion of porosity which is of most use in modeling flow is referred to as the total interconnected porositv; the total interconnected porosity is domnated bo the interconnected matrix porosity. The total interconnected porosity can also be estimated hasef on deep resistivity surveys. In a general wav the results for crystalline Igneous and metamorphic rocks are in good agreement, and range from 0.01 down to 0.001 or lower. The results for basalts and tuffs are not as reliable, owing to a lack of elther drill hole measurements or deep resistivity survevs in these media. Laboratory tests suggest a total interconnected porositv value for tuff in the range of 0.05 to 0.40 ; for basalt, which is supported by a single field value, the range could be 0.01 to 0.1 .

The storage characteristics of porous media must be taken into consideration when analyzing data from transient flow tests or, converselv, when attempting to model transient flow phenomena. Storage behavior involves the porosity of the rock mass and what might be called the elasticity of the system, consisting of fluid density and fluid, rock and mineral compressibilities. Although very few measurements are available, there is general agreement of laboratory and field values of specific storage for crvstalline 
rocks; a value of around $3 \times 10^{-7} \mathrm{~m}^{-1}$ may be representative. Laboratory values of specific storage of sandstones range from $10^{-5}$ to $10^{-4} \mathrm{~m}^{-1}$ while field obtained values suggest a range of $10^{-3}$ to $10^{-6} \mathrm{~m}^{-1}$.

Laboratory values of permeability coefficient have been made on intact samples wrth dimensions typically less than $15 \mathrm{~cm}$. At least ten orders of magnitude separate the least permeable from the most permeable intact rock, with the widest variability to be found in the carbonates and volcanics. Shales, crystalline and metamorphic rock have permeabilities which can be as small as $10^{-10}$ darcy. Carbonates and volcanics can be as great as $10^{-2}$ darcy and salt and sandstone can exceed 10 darcy.

In the laboratory, permeability decreases dramatically with temperature increase for most, but not al1, rock specimens when the pore fluid is water. The cause of the change is not clearly understood; it may involve ourely thermal effects with complex changes in pore geometry due to temperatureInduced water-rock interactions. Because of this, the permeabilitv change with temperature, although large, is not quantitatively predictable at this trmé.

Permeability of porous media is very sensitive to pressure and stress; that this should be so can easilv be deduced from the relationship between permeability and pore dimension. Volumetric deformation of a sample is accomodated through system compressibility, and the pore space, being the least compressible part of the system, must undergo the greatest deformation. Porosity of sandstone, granite and sand decreased up to the onset of dilatancy; beyond that the porosity increases at an increasing rate.

Large tests under controlled conditions demonstrated that the effect of stress on the permeability of jointed media is equallv dramatic. Five fold changes in permeability with relatively small stress changes are not uncomon jointed media; significantly, the apparent minimum joint permeabilitv is still significantly greater than the matrix permeability for some crystalline rocks. Temperature effects in the one large scale test performed to date showed a non-linear decrease in permeability with both temperature and pressure increases. 
Large-scale permeability tests are performed in a borehole with no control over the boundary conditions except at the wellbore. The range of in situ values of permeability is even greater than that of the laboratory values, encompassing twelve orders of magnitude. Four to six orders of magnitude is typical at a particular site. There is a hint of a relationship between permeability and depth as suggested by some authors but the trend is obscure and does not justify the proposed exponential decrease. Nearly every site reported has at least one permeable zone (permeability of 1 to $100 \mathrm{md}$ ); this zone was deep in some areas $(1.8$ to $3.3 \mathrm{~km})$.

Various other physical phenomena were used to infer rock mass permeability; principal among these techniques were direct measurements of fracture spacings and apertures in situ, and observations of time and distance, quantities which relate phenomena thought to be controlled by hydraulic diffusion. The most interesting aspect of a compilation of data of this nature is the close agreement (between about 0.1 and $100 \mathrm{md}$ ) of any of the values. Not surprisingly, data obtained by measuring aperture width and fracture spacing lead to higher calculated permeabilities. The significance of these data is that large volumes of rock, up to cubic kilometers in size, are being sampled.

One data set for crystalline bedrock is especially illuminating for nuclear waste storage studies. Measurements made at the Savannah River Plant comprise what is probably the most complete data set, hydrologically speaking, available today. One indication is that fracture zones in the metamorphic rocks are not infinite in extent but terminate in virtually impermeable rock. Thus, the regional average permeability is dominated by that of the impermeable rock, which in turn is close to laboratory values. In this case, laboratory values of permeability appear to provide values that, within an order of magnitude, are applicable to calculations of regional flow.

Permeability depends on interconnected porosity and pore or fracture width and spacing. In the case of flow through fractures, the controlling factor is the cube of the aperture width. This relationship has been shown to hold in the laboratory for rough fractures in crystalline rock. For matrix flow, on the other hand, permeability depends upon hydraulic radius and porosity or hydraulic radius and formation factor. The theory developed has been tested on two granites and several sandstones. 


\section{INTRODUCTION}

Performance assessment calculations for a waste repository in geologic media are based heavily upon mathematical modeling of ground-water flow in porous and fractured media. Satisfactory modeling requires proper values of input parameters and may require including the effects of thermomechanical loading and the constraints of geochemical equilibrium. Anong the required parameters, values of porosity and permeability are perhaps the most difficult to select owing to the great range of values reported in the literatire, and to their sensitivity to environmental conditions such as stress and temperature.

A number of rock types have been proposed as repository host rocks, including basalt, granite, salt, shale and tuff. Ground-water flow in basalt, and granite, and to a lesser extent, in shale and tuff, occurs mainly through fractures in the rock masses rather than through the rock matrix. Evaluation of fracture porosity and permeability as will be required for modeling flow in such rocks, is less straightforward than the evaluation of these parameters for porous media. To assist those portions of the NWTS effort concerned with assessing performance of repositories which might be constructed in fractured media, this report discusses a number of measured and inferred values of porosity, storage, and permeability of fractured rocks, and reviews the mathematical relationships between porosity and permeability. A significant portion of the document emphasizes the effects of scale on the hydrologic behavior of fractured rock masses and thus discusses the relation between laboratory and in situ measurements.

This document is organized so as to stress behavioral principles rather than to serve simply as a compilation of measured values arranged by rock type. Such a compilation has recently been published by Wolff (1981), and the reader seeking simply tabulated data is referred there. This report is intended rather to provide principles of behavior for those whose performance assesssment tasks will require them to estimate parameter values where none are available or to choose array often disparate sets of measurements. 
These principles are discussed in the four chapters of this report titled:

- Porosity;

- Storage;

- Permeability; and

- Dependence of Permeability on Pore Geometry.

The chapter devoted to porosity discusses laboratory measurements of porosity in both unfractured and fractured samples with part of the discussion emphasizing the effects of microcracks. Porositv values of typical rocks are tabulated to emphasize the proportion of cotal porosity contributed by fracture, interconnected and residual pore space. The problems of analyzing non-interconnected pore space are discussed.

Storativity values are required for transient flow problems. Their dependence on both rock mass porosity and elastic behavior is discussed in the chaper on storage.

We next turn to laboratory and field measurements of permeabilitv coefficients and present graphical compilations of measurements made at laboratory, in situ, and regional scales. Permeability changes in response to changes in such external stimuli as stress or temperature are discussed as are some chemical deposition phenomena.

The final substantive chapter is devoted to the problem of expressing, In a quantitative manner, the relationshios that exist between porosity and permeability coefficient in various rock types. 


\subsection{GENERAL}

Porosity is defined as the ratio of the volume of voids to the total volume. Porosity is significant because it is a measure of the amount of fluid which is stored in a saturated rock. Porosity is also needed, in addition to permeability, to determine the average true velocity of elements in the fluid under a given hydraulic gradient. This information will be needed to estimate the time required for radionuclides to travel given distances away from a repository.

Porosity is associated with many scales of discontinuity (Figure 3-1). The solid rock contains grain boundary cracks and interstitial voids; intragranular cracks on all scales contribute pore space. The latter include faults, joints, shear zones and bedding plane partings (Fig. 3-1).

Like many rock properties, porosity and permeability are scale-dependent and the concept of a representative elemental volume (Witherspoon et al 1981) is useful. The REV, like the unit cell in crystallography, can be considered to be the smallest volume of sample which has properties representative of all larger sizes. In a laboratory range of sizes, samples having dimensions of more than 10-grain diameters are probably representative. Most laboratory samples probably meet this condition. However, on a drill-hole or crustal scale, the size of the REV is not yet known and it is not known how relevant such measurements are for rock masses. Hydrologic studies need to address this question in order to obtain valid rock mass characteristics for repository design.

Because of the way porosity is measured, it is convenient to divide total porosity, $n_{\mathrm{T}}$, into two parts:

$$
\eta_{T}=\eta_{M}+\eta_{F} \quad E q \cdot 3 \cdot 1
$$

where $\eta_{M}$ is matrix and $\eta_{F}$ is fracture porosity. Matrix porosity is that associated with intact, laboratory-sized samples, usually $5 \mathrm{~cm}$ or less in size. Fracture porosity is that associated with any discontinuity larger than this; fracture porosity is only accurately measured in situ. 


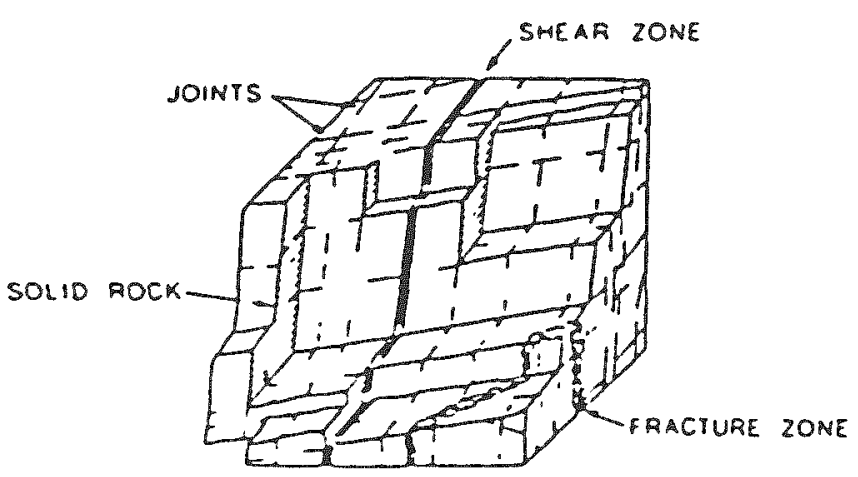

Figure 3-1. Discontinuities in a Fractured Rock Mass. (Witherspoon et al, 1977)

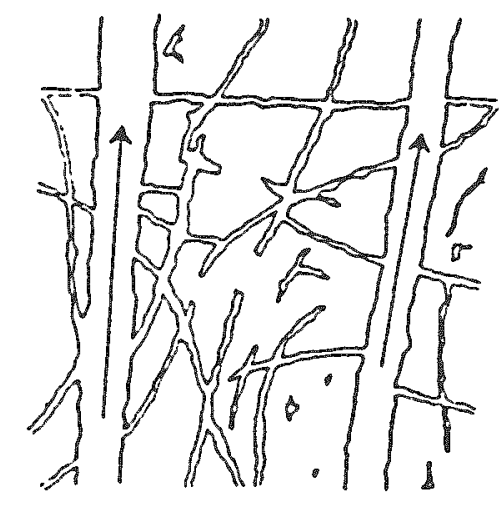

Figure 3-2. Schematic Representation of Matrix Porosity Showing Through-Going, Dead-Ended and Isolated Pores.

(Norton and Knapp, 1977) 
Matrix porosity may be subdivided further (Norton and Knapp, 1977) into residual and interconnected porosity:

$$
\eta_{\mathrm{M}}=\eta_{\mathrm{I}}+\eta_{\mathrm{R}} \quad \mathrm{Eq} \cdot 3.2
$$

Residual porosity, $n_{R}$, is completely isolated within a crystalline or glass matrix. $n_{I}$ is pore space which is interconnected throughout, and may include that which is both through-going and dead-ended (Fig, 3-2). A11 of $\eta_{I}$ is accessible to fluids in the major discontinuities. $\eta_{I}$ and $\eta_{F}$ together form the flow network in a rock mass. We are primarily concerned here with the magnitude of $\eta_{I}$ and $n_{F}$; we will discuss them separately only because they are measured in different ways.

\subsection{INTERCONNECTED MATRIX POROSITY}

nI of crystalline rocks, basalt or tuff is usually measured by (a) immersion or (b) mercury porosimeter. Immersion methods are based on obtaining three quantities: dry weight in air, $W_{D}$; sample total volume, $\mathrm{V}_{\mathrm{T}}$; and $\mathrm{W}_{\mathrm{S}}$, the weight immersed in a fluid of known density, $\rho$ (Brace, 1965, for example). Since the solid material plus residual porosity has a volume equal to:

$$
\left(w_{D}-w_{S}\right) / 0
$$

then, by definition, and neglecting buoyancy in air,

$$
\eta_{I}=\frac{V_{T}-\left(W_{D}-W_{S}\right) / \rho}{V_{T}}=1-\frac{W_{D}-W_{S}}{\rho V_{T}}
$$

Dreyer (1958) in a classic study of porosity, showed that $n_{I}$ can be measured to about \pm 0.001 , if care is taken with drying, immersion, and purity of immersion fluid. A gas or fluid pycnometer can be used in conjunction with measurement of $V_{T}$ and $W_{D}$ to give total matrix porosity, $\eta_{M} \cdot$ 
The mercury porosimeter (Rootare and Prenzlow, 1967) is designed to measure not only $n_{I}$, but also to give porosity associated with different pore sizes. Accuracy is hard to estimate since it depends on pore size and ability of the apparatus to inject mercury into the smaller pores. For typical crystalline rocks, accuracy of $\eta_{I}$ is probably poorer than the values obtained by immersion.

Measured $\eta_{I}$ is shown in the lower part of Figure $3-3$; values of basalt, tuff and various crystalline rocks are grouped separately. Data come from DeWiest (1969), Stesky and Brace (1973), Morrow and Brace (1981), and Brace (unpublished, 1981).

Granite and other felsic plutonic rocks, metamorphic rocks (slate, gneiss, quartzite, marble) range in $\eta_{I}$ from about 0.004 to 0.01 . Among the mafic rocks, most dunites and gabbros are less than 0.003 ; the lower limit is uncertain, as 0.001 is about the limit of measurement. Some serpentinized ultramafic rocks have porosity which ranges up to 0.15 (Stesky and Brace, 1973).

$r_{I}$ of tuff ranges from 0.004 to nearly 0.40 . The association of low porosity with degree of welding of the tuff is suggested (DeWiest, 1969), but further work is clearly needed on this material. $\eta_{I}$ of basalt ranges very widely, from less than 0.001 to 0.25 , depending on position in the flow. The lowest values come from the interior of sills or from thick flow units.

\subsection{FRACTURE POROSITY}

$\eta_{F}$ is typically measured in situ, because of the obvious difficulty with sampling a large natural "fracture". Several techniques are used: (a) direct observation of fracture aperture and spacing, (b) packer tests in a single drill hole, and (c) tracer tests between drill holes.

\subsubsection{Direct Observation}

Villas (1975), Bianchi and Snow (1969), and Norton and Knapp (1977) have reported fracture spacing and aperture in several granites and granitic orebodies. For a single set of parallel planar fractures of uniform spacing, $J$, and aperture, $B$, fracture porosity becomes: 


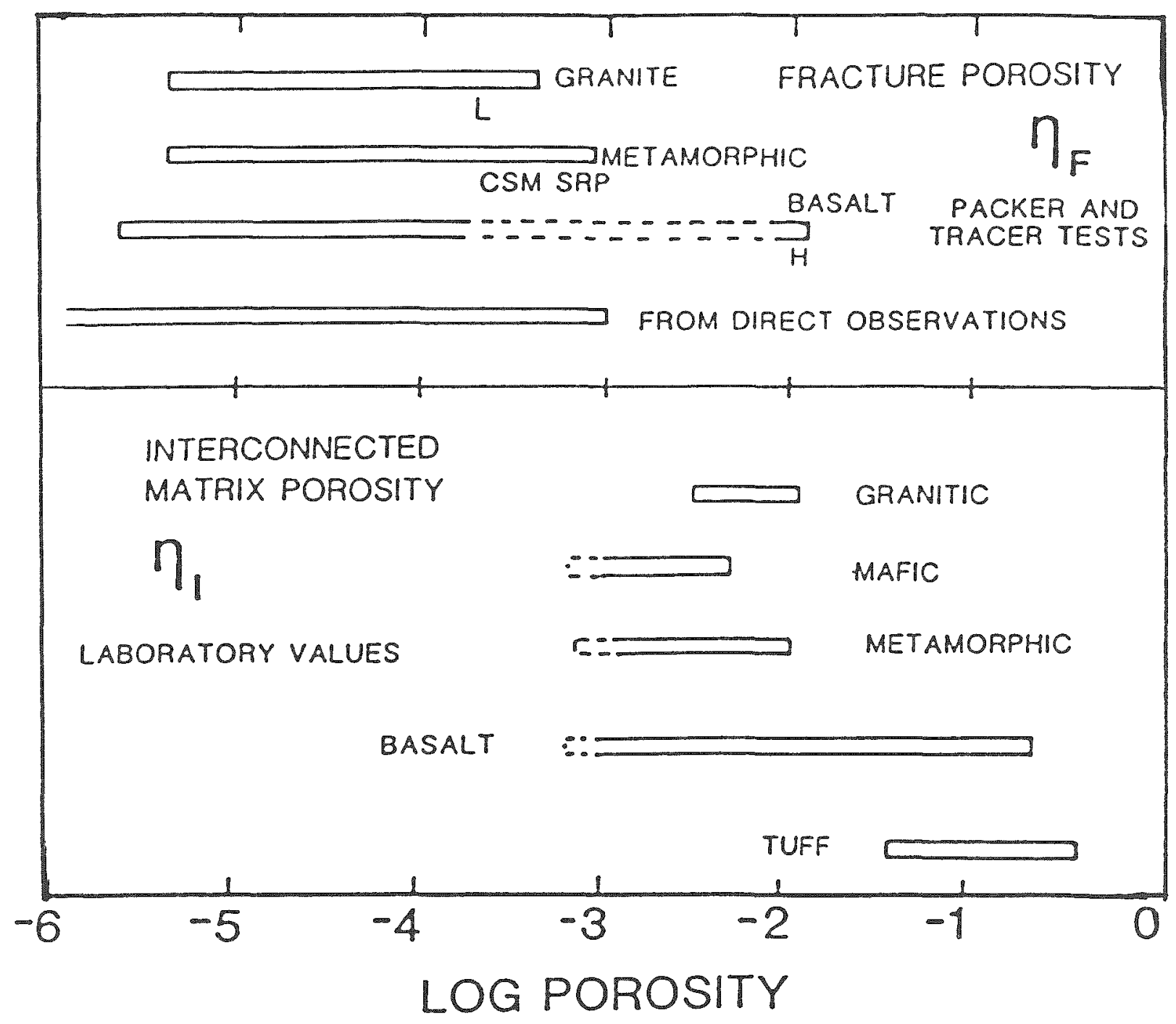

Figure 3-3. Fracture and Matrix Porosity. [Bars indicate range of reported values of porosity. See text for source of the data. SRP refers to rocks from the Savannah River Project (Marine 1979) CSM from Voegele et al (1981), L from Pratt et al (1977) and H from Science Applications, Inc. (1980).] 


$$
\eta_{\mathrm{F}}=\mathrm{B} / \mathrm{J}
$$

$\mathrm{Eq} \cdot 3.4$

$\eta_{F}$ so calculated from field measurements of $B$ and $J$ ranges from $5 x$ $10^{-6}$ to $10^{-3}$ (Norton and Knapp, 1977). These directly observed values are shown in Figure $3-3$.

\subsubsection{Packer Tests in a Single Drill Hole}

$\eta_{F}$ has also been estimated from packer tests in fractured crystalline racks (Snow, 1968a). Similar assumptions are made; namely, that the fractures form plane parallel sets perpendicular to the hole. From the packer test, both fracture spacing and an apparent aperture, $b$, can be obtained (Snow, 1968a), subject to a number of further assumptions:

1. the number of open fractures obey a Poisson distribution;

2. all fluid flow is along open fractures, which are rigid and inert;

3. fracture permeability is isotropic, fluid flow is laminar; and

4. permeability can be calculated as though the rock were continuous homogeneous porous medium.

Fracture porosity can then be obtained from the calculated values of spacing, $J$ and apparent aperture, $b$, from

$$
\begin{array}{ll}
n_{F}=b / J & E q \cdot 3.5
\end{array}
$$

Snow (1968a, 1969) has analyzed the fracture porosity from drill hole measurements at 36 dam sites predominantly in crystalline rocks. His data, collected in Figure 3-3, vary systematically with depth. $\eta_{F}$ to depths of $20 \mathrm{~m}$ ranged from 1 to $4 \times 10^{-3}$. At depths of 50 to $200 \mathrm{~m}, \eta_{\mathrm{F}}$ ranged from 2 to $4 \times 10^{-6}$.

At least two additional effects need to be considered for the Snow values collected in Figure 3-3. (1) According to assumption 2 above, all flow is along the fracture and none is through the rock matrix. Brace (1971) found that tight and conductive intervals in crystalline rocks differed in most cases by 3 to 4 orders of magnitude; this assumption will, therefore, in 
most situations be justified. (2) Voegele et al (1981) showed that B and b could differ significantly, due to fracture tortuosity and roughness. For $b$ in the range 50 to $200 \mu m$ as in the snow examples, B/b ranged from a factor of 2 to 4. This would have the effect of shifting the Snow values in Figure 3-3 to higher porosities; at the shallow end, they would be twice as high, and at the deep end, 4 times as high.

A few other measurements of fracture porosity are available, from so-called block tests, conducted in mines or surface outcrops. Apparent aperture, $b$, of the joint tested in metamorphic rocks at the CSM mine (Voegele et al 1981) was about $40 \mu \mathrm{m}$. Assuming all the joints in the block had the same value of $b$, and applying their $B / b$ correction factor of 3 , joint porosity would be $5 \times 10^{-4}$ (CSM in Figure 3-3). The porosity for the Pratt et al (1977) block test in a surface outcrop of granite was $10^{-4}$ (L in Figure $3-3)$.

\subsubsection{Two-we11 Tracer Tests}

Marine (1967) has used the between-wells tracer test (Pickens and Grisak, 1981) to estimate porosity of a conductive interval at about $500 \mathrm{~m}$ depth in precambrian metamorphic rocks beneath the Savannah River Plant (SRP), Aiken, S.C. He reported a value of about $10^{-3}$ (Figure $3-3$ ). A single tracer test in basalt at around $1 \mathrm{~km}$ depth at the Hanford Reservation, Richland, Washington gave a porosity of a transmissive interflow of $10^{-2 *}$ (Science Applications, Inc., 1980).

\section{3 .4 Comparison}

It is of interest to compare fracture porosity derived from the three methods above and collected in Figure 3-3. Results of the first two methods, the packer tests and the direct measurements overlap we11, particularly if the packer results of Snow are corrected as suggested above. Data from the block tests agree with values obtained in shallow packer tests, a result to be expected since the block tests are in essence surface tests. In contrast, both of the values obtained in the two-hole tracer tests are higher than

* preliminary data 
those obtained in the two other procedures. The tracer tests were designed for relatively transmissive intervals, however. In the precambrian rocks at the SRP, these intervals represent intensely fractured zones; at Hanford they correspond to porous interflow units*. Perhaps the high porosities obtained in the tracer tests are, therefore, quite reasonable.

\subsection{TOTAL POROSITY OF A ROCK MASS}

According to Eq. 3.1 and 3.2 , the total porosity, $n_{\mathrm{T}}$, of a rock mass wil1 be

$$
n_{T}=n_{F}+n_{I}+n_{R}=n+n_{R}
$$

The fracture porosity and interconnected matrix porosity are shown in Figure 3-3 and have been discussed above. The sum of these, the total interconnected porosity, $n$, constitutes the total pore space in a rock mass through which fluids might move.

\subsubsection{Total Porosity from Laboratory and Hydrologic Measurements}

$\eta$ is clearly dominated by $\eta_{I}$, the interconnected matrix porosity (Figure 3-3). This was previously suggested on the basis of a more limited data set by Brace (1977) and Norton and Knapp (1977). The matrix porosity is typically greater than $10^{-3}$, whereas fracture porosity is less than $5 \times 10^{-4}$. Since $10^{-3}$ is just about at the resolution of the laboratory measurement, some very tight rocks may have matrix porosities less than this; nevertheless, to judge from present observations, most are much more porous.

We conclude that for granitic, unaltered mafic, and metamorphic rocks, total interconnected rock mass porosity ranges from 0.001 to 0.01 . No fracture porosities are available for tuff. If we assume that $\eta_{F}$ is about the same as for other rocks, then $n$ will again be dominated by $n_{I}$. Rock mass values of $\eta$ for tuff will therefore range from 0.05 to 0.50 . Basalt may be a special case. Accepting the single data point from Hanford and

* preliminary data 
combining it with Snow's dam site values, $\eta_{F}$ can evidently range enormously, from $10^{-6}$ to $10^{-2}$ (Figure 3-3). Simlarly matrix values range very widely. For basalt $1 t$ may be necessary to have an accurate profile of the rock units in a particular rock mass to estimate even an average $\eta$.

\subsubsection{Total Porosity from Field Electrical Measurements}

For water-saturated rock which contains no metallic minerals or graphite, total interconnected porosity correlates closely with electrical conductivity (Brace, 1971). Thus, so-called deep resistivity surveys, which yield a conductivity-depth profile, can be used to estimate $\eta$. Such survevs have been made in several parts of the U.S., in Africa, and in Europe (Brace, 1971; Nekut et a1, 1977). Rocks to depths of about $25 \mathrm{~km}$ have resistivities which range from $10^{3}$ to $10^{5}$ ohm meters. These values are consistent with and, in fact, require that the rocks be saturated with ground water. The porosity required to provide this much electrical conduction ranges from $10^{-3}$ to $10^{-2}$ (Brace, 1971). This is also a rock mass value since the electrical surveys sample volumes of rock many kilometers in dimension. Most of the survevs have involved anorthosite, or various precambrian crvstalline rocks. For later sections of this paper, it is worth noting that resistivitv surveys tell nothing about rock mass permeability.

In contrast to resistivity measurements made for crystalline rock terrains noted above, values for basalt are much lower. The most complete studies have been made in Iceland (Bjornnson, 1976, Thaver et a1, 1981). To about 1 to $3 \mathrm{~km}$ depth, resistivity ranges from $10^{2}$ to $10^{3}$. This reaures an $\eta$ of 0.02 to 0.05 (Bjornnson, 1976).

\subsection{CONCLUSIONS}

Rock mass porosity has been estimated in two very different ways; the results for crustalline igneous and metamorphic rocks are in good agreement. Thus, both deep electrical resistivity surveys, and a combination of hydrologic and laboratory tests suggest that interconnected rock mass porosity is in the range of 0.01 to 0.001 from depths of a few tens of meters to several kilometers. The single electrical survey for basalt ques 0.02 to 


\section{STORAGE}

For steady-state flow of fluids around a repository, porosity of the host rock and the elasticity of the rock water system need not be considered. However, for transient flow, these factors become important; along with the other hydrologic parameters, they determine how rapidly pressure will change near the site and the magnitude of the change in a given period of time. Porosity was reviewed above; here we look at elasticity of the system. Elasticity is usually expressed as one of two quantities, storage coefficient, $\mathrm{S}$ (also called storativity), or specific storage, $\mathrm{S}_{\mathrm{S}}$.

$S_{S}$ may be defined as the change in porosity of a water-filled rock per unit change in head (DeWiest, 1965). It can be expressed in terms of other rock and fluid properties (Brace et al, 1968) as

$$
s_{s}=o g\left(\beta_{e}-\beta_{s}+n\left(\beta-\beta_{s}\right)\right) \quad E q \cdot 4 \cdot 1
$$

$S$ is the amount of water in storage released from a column of aquifer of unit cross-section, per unit decrease in head. Thus $S$ is just $S_{S}$ times the aquifer thickness.

Equation 4.1 reduces to that found in standard works such as DeWiest (1965),

$$
S_{s}=\rho g\left(B_{e}+n \beta\right) \quad E q \cdot 4 \cdot 2
$$

When mineral compressibility is set equal to zero. For many common minerals and rocks this approximation is valid; $\beta_{\mathrm{s}}$ is typically a tenth or less of $B_{e}$ at the low pressure of interest here.

\subsection{LABORATORY DETERMINATION OF STORAGE}

Equation 4.1 can be used to calculate $S_{S}$ from laboratory determined compressibility and porosity. There are very limited data for crystalline rocks. Using the rock properties in Brace et al (1968), $\mathrm{s}_{\mathrm{s}}$ of Westerly granite is $10^{-7} \mathrm{~m}^{-1}$ at a confining pressure of $10 \mathrm{MPa}$. If we take 
a range of other crystalline rocks (Brace, 1965 and unpublished, 1981) using measured porosities and compressibilities, $S_{S}$ ranges from 3 to $7 \mathrm{x}$ $10^{-7} \mathrm{~m}^{-1}$. Pierre shale is $3 \times 10^{-5} \mathrm{~m}^{-1}$ and sands and san dstone range from $10^{-5}$ to $10^{-4} \mathrm{~m}^{-1}$ (Bredehoeft and Hanshaw, 1968).

\subsection{STORAGE FROM AQUIFER TESTS}

Storage in situ is determined through the use of an aquifer test, as outlined by Walton (1970) or Davis and DeWiest (1966). In the case of fractured rock of low permeability, packer tests may be more accurate than a standard pumping test. Transient equations for flow in fractured media have been outlined by Papadopulos (1967).

The most complete data set has been obtained by Marine (1969) at the Savannah River Plant from a number of holes which penetrate the precambrian at depths of 300 to $500 \mathrm{~m}$. His values are collected in the table below.

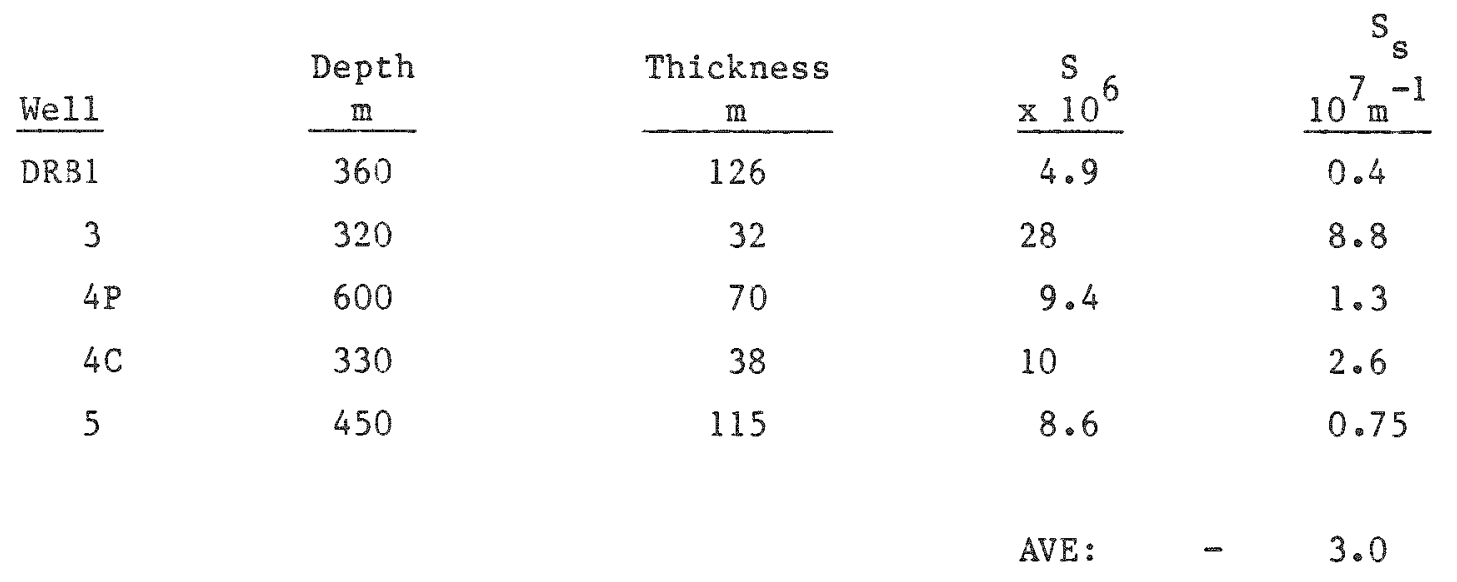

Although the data for crystalline rocks are far too few to generalize, it is of interest that there is fair agreement between laboratory and the SRP values, at around $3 \times 10^{-7} \mathrm{~m}^{-1}$. Aquifer tests on sandstone yield very different values. Values obtained for Entrada, Wingate, and Morrison formations (Jacob and Lohman,, 1952) range from $10^{-3}$ to $10^{-6} \mathrm{~m}^{-1}$, overlapping somewhat the values given above for laboratory samples. 


\section{PERMEABILITY}

\subsection{GENERAL}

The flow of fluids in rock masses is determined by fluid pressure gradient sand by a single rock mass parameter, the permeability. Although deep disposal of radioactive waste material provides, through physical inaccessibility, a high degree of protection against human intervention or natural events, transport of radioactive material to the biosphere is still possible by ground-water movement. For waste storage studies, regional permeability characterization is thus an important goal; depths of from a few hundred meters to several kilometers are of interest.

on the scale of the repository and its regional environment, characterization of the permeability at an arbitrary location is valid only if the value so obtained is characteristic of permeability on a regional scale. It is plausible that the regional permeability coefficient could be either greater or smaller than that measured locally. In the first case, conductive fractures could exist on a scale larger than the volume of material sampled during a packer test; in the second case, fractures which were conductive on the scale of the test might not be pervasive enough to be conductive on the scale of the repository. In either case, inhomogeneities in the rock mass itself act to determine the regional permeability behavior, though these inhomogeneities might not be detectable on the scale of the permeability test.

This chapter discusses values of permeability measured at various scales, ranging from laboratory samples to the drill hole. These values are compared when both are available from a given site. Variation of drill-hole permeability with depth is also explored. Several large-scale phenomena, such as reservoir induced earthquakes can be used to infer permeability on an even larger scale than the drill hole. Values obtained by such methods are compared with laboratory and dri11-hole values.

Additional effects discussed in this chapter include the observed dependence of permeability on temperature and pressure. Both these parameters may be significant for repository design. Some temperature increases near the repository are expected. Excavation, thermal expansion and other changes may induce stress and pressure changes. 


\subsection{MATRIX PERMEABILITY}

Flow of fluid through a porous matrix like rock is analogous to diffusion or heat flux. Thus, flow is governed by a tensor, analogous to diffusivity or thermal conductivity. The basic form for fluid flow is

$$
\begin{array}{ll}
q_{i}=-K_{1 j} \frac{\partial P}{\partial x} & E q \cdot 5.1
\end{array}
$$

This is an empirical relationship, known as Darcy's Law, and is mathematically equivalent to Ohm's Law or Fick's first law. Experiments show that even in scalar form, where $\mathrm{K}_{i j}$ becomes simply $\mathrm{K}$, both fluid and medium characteristics are involved. We wish to focus solely on medium properties so that an alternative form of Equation 5.1 is used:

$$
\begin{array}{lll}
q_{1}=\frac{-k_{i j}}{\mu} \frac{\partial P}{\partial x_{j}} & & \\
q=-\frac{k}{\mu} \frac{d p}{d x} & \text { in scalar form, } & \text { Eq. } 5.2
\end{array}
$$

Permeability, $k$, depends solely on characteristics of the medium. This paper is concerned with the magnitude of $k$ for rocks. Although $k$ varies with direction in rocks (Bianchi and Snow, 1969; Gale and Witherspoon, 1979), principal values are rarely available; we will therefore have to treat it as a scalar.

The units and even the dimensions of $k$ are a source of confusion. We have tried to clarify this in the Appendix where some of the different units are compared. We will use the darcy, both for historical reasons and because the perneability of most rocks falls within that range of values in darcies covered by the familiar decimal prefixes. Thus, most values of $k$ we will discuss range from a nanodarcy $\left(10^{-21}\right.$ meters $\left.^{2}\right)$ to a darcy. The darcy $\left(10^{-8} \mathrm{~cm}^{2}\right)$ is conveniently expressed in SI units using

1 darcy $=1$ (micrometer $)^{2}=10^{-12}$ meters ${ }^{2}$ 


\subsubsection{Methods of Measurements for Crystalline Rocks}

Laboratory measurements are usually made on intact samples 2.5 to $15 \mathrm{~cm}$ in minimum dimension. Two techniques are used, depending on the anticipated permeability. Above about a microdarcy, a steady-state measurement is made, in which volume of fluid is measured per unit time for fixed pressure gradient. This is a traditional method of soil and rock mechanics (Scott, 1963; Ohle, 1951). For rocks with permeability less than about a microdarcy, the transient method is more convenient (Brace et al, 1968). In this method, the decay of a pressure pulse suddenly applied to one end of the sample is observed. Thus, only pressure and time need to be measured; this method readily adapts itself to high pressure measurement. Recent refinements in the transient method (Lin, 1978; Heard et al, 1979) have lowered the detection level to around $10^{-12}$ darcy.

A number of laboratory permeability measurements for rocks are sumarized in Figure 5-1, together with typical values for soil, for comparison. The bars for each rock or soil type reflect the range of values reported. Some wel1-known rocks and field sites are identified alongside the bars. For all the measurements in Figure 5-1, stress was approximately hydrostatic.

A number of aspects of laboratory permeability (Figure 5-1) are worth noting:

(i) Some ten orders of magnitude separate the least from the most permeable rocks. Since it is not clear that our present detection limit coincides with the minimum permeability of rocks, this range could be even wider.

(ii) The widest variability among the rock types is observed for the carbonates and volcanics. This might have been predicted just on petrologic grounds (compare coquina and lithographic limestone, for example!).

(iii) However, permeability does not necessarlly correlate with porosity. This is a fact well-known is soil mechanics (Scott, 1963; Scheidegger, 1974); some clay is considerably more porous 


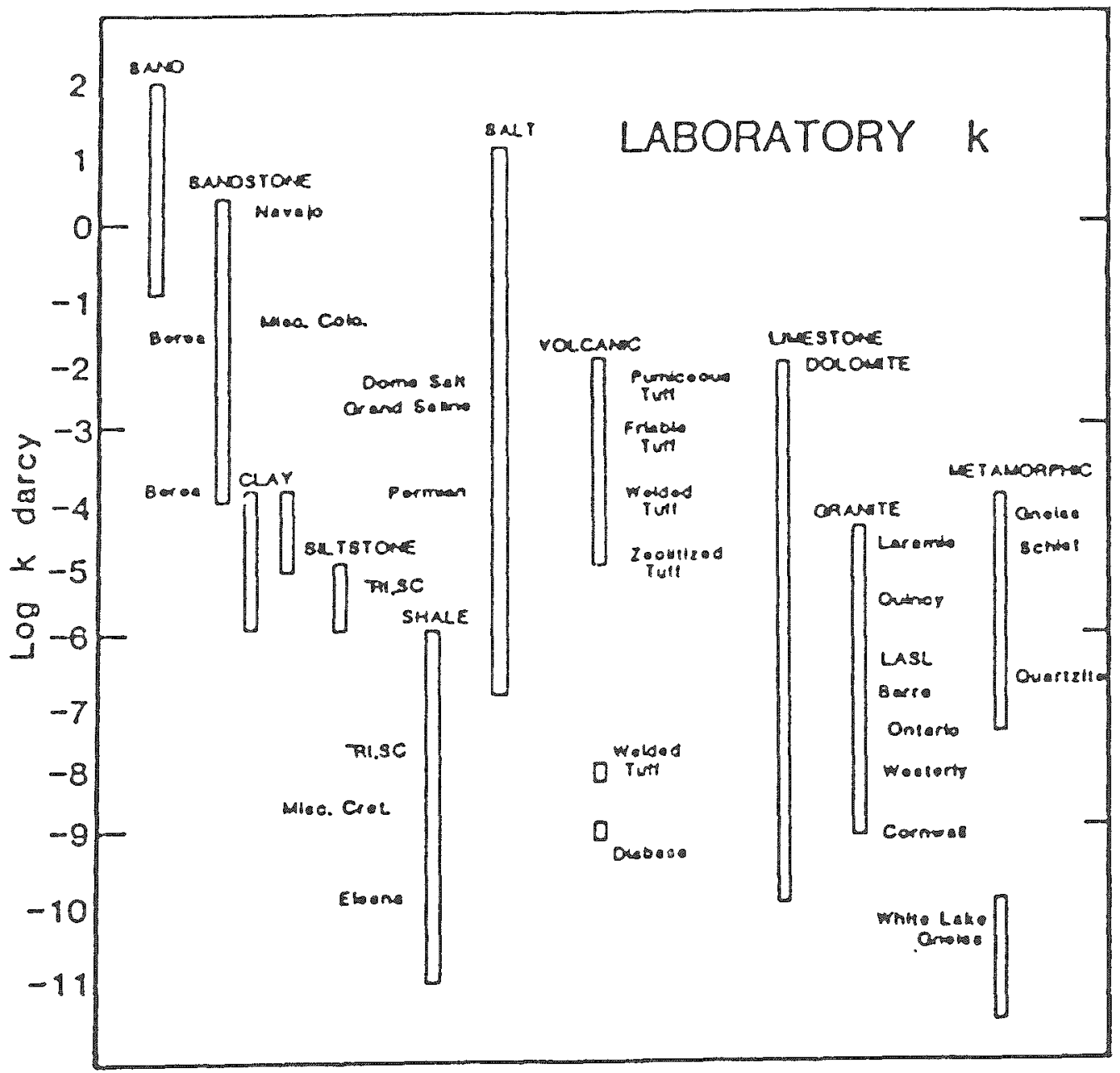

Figure 5-1. Laboratory Measurement of Permeability of Intact Specimens. [Boxes show range of measured values. Pressure was hydrostatic and less than $10 \mathrm{MPa}$ and temperature about 25 C. Data from Brace (1980), Gloyna and Reynolds (1961), and Keller (1960).] 
than sand; yet the relative permeabilities are reversed (Figure 5-1). Also, typical crystalline rocks have an interconnected porosity of 0.01 or less (Brace, 1965) and yet their permeability is equivalent to shale which rarely has a porosity less than 0.10 (Rubey and Hubbert, 1959).

(iv) If we assume that the term "crystalline rocks" applies to the rocks grouped in Figure 5-1 under "granite" and "metamorphic", then for crystalline rock, $k$ of intact specimens is approximately equivalent to that of clay and shale.

\subsubsection{Laboratory Studies of Temperature and Pressure Effects}

Satisfactory isolation of nuclear waste requires understanding not only in situ permeability and hydraulic gradient but also how these characteristics depend on temperature and pressure. Values of these parameters in and surrounding the repository may be significantly altered by emplacement of the waste. While recent work suggests that very dramatic changes in permeability result from heating to temperatures of 150 to $200^{\circ} \mathrm{C}$, the studies provide no general criteria useful for design of repositories. In this section we will review the studies that have been made to date and draw conclusions as to the status of knowledge regarding the effects of temperature on the permeability of various rock types.

A slightly different situation exists with regard to the effects of stress on the matrix permeability. The in situ stress state, which correlates fairly well with the depth of the repository, and the layout of the repository are the primary parameters which affect the stress state. Thus, the repository depth, over which we have some control, defines the stress induced response of the permeability behavior with which we are interested. Although crystalline rocks are of primary interest here, much interesting work has been done with porous media, some of the results of which may be applicable to rocks like granite. Therefore, both porous and crystalline rocks are discussed in this section. 


\subsubsection{Temperature Effects}

As observed in the laboratory, permeability is affected in many different ways when the temperature is increased. Temperature affects fluid viscosity, too, but this effect is already accounted for in our definition of $\mathrm{k}$ (see Equation 5.2). Temperature might be expected to affect $\mathrm{k}$ through purely physical effects, like thermal expansion, or thermal cracking. In addition, however, a variety of water-rock interactions seem to play a role. As we show below, these processes evidently alter pore geometry, and have profound effects on $k$. Although not purely temperature effects, they are induced when temperature is increased.

In a study of a geothermal area (Piwinskii and Netherton, 1977), two sandstones of 15-20\% porosity were investigated under about 100 bars confining pressure. The effect of up to $90^{\circ} \mathrm{C}$ on steady-state flow was investigated for a fluid described as a siliceous brine. Permeability, initially in the millidarcy range, dropped by up to a factor of 1,000 in 1 to 2 hours. Chemical effects were noted; namely that silica came out of solution, and the $\mathrm{pH}$ increased during flow through these rocks. The reduction of flow was believed due to silica deposition.

In another study of three porous sandstones (Casse and Ramey, 1979), flow of nitrogen, helium, oil, and water was studied under confining pressures to 140 bars. The permeability to water dropped by as much as 65 percent at a temperature of $300^{\circ} \mathrm{F}$ (Figure 5-2). The drop was more pronounced the higher the confining pressure. In the case of flow of mineral oil (Figure 5-3), no change was detected over the same temperature interval. Thus, the cause of the permeability change was specific to water, and the authors suggested that fluid-solid surface effects were responsible for the change. In a somewhat earlier, rather broader-ranging study (Weinbrand et al, 1975), similar results for water were observed to a temperature of $175^{\circ} \mathrm{F}$; permeability dropped by 50 percent.

other studies of the flow of water or oil in different porous materials provide additional insight into temperature effects. For example, no changes with temperature were observed for flow of water through limestone (Danesh et a1, 1978). On this basis, the reaction of water with silicate minerals such as quartz or feldspar seems to be identified as the source of the temperature effects. A very interesting result (Danesh et a1, 1978) was obtained for 


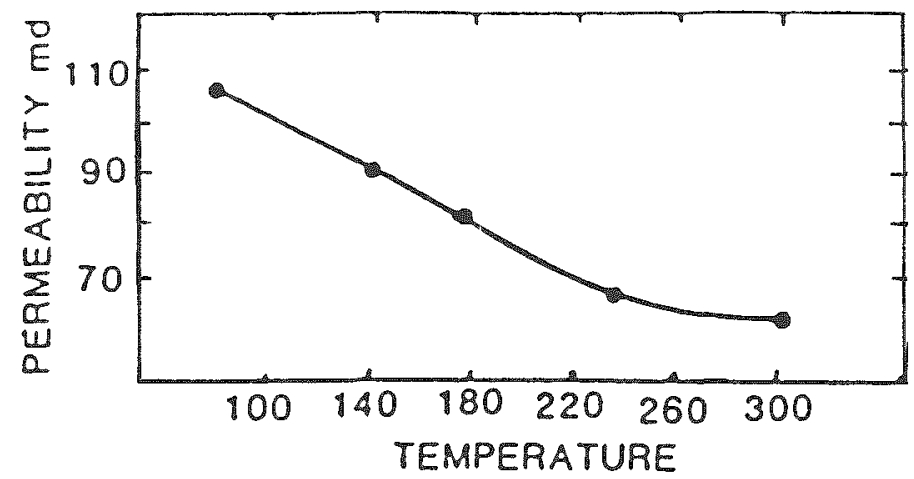

Figure 5-2. Permeability to Water of Berea Sandstone as a Function of Temperature. [Confining pressure equals 2000 psi. Mean pore pressure equals 125 psi. Casse and Ramey (1979).]

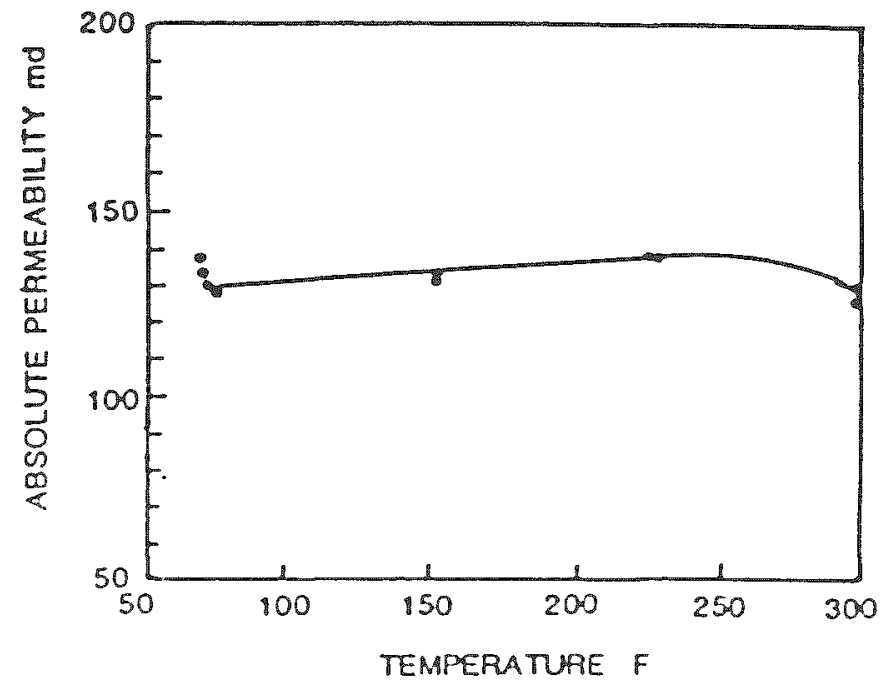

Figure 5-3. Permeability to Mineral 011 of Berea Sandstone vs Temperature. [Confining pressure equals 2000 psi. Mean pore pressure equals 200 psi. Casse and Ramey (1979).] 
flow through porous stainless steel. Although the oil showed no effect (Figure 5-4) when water flowed through stainless steel, the permeability dropped as it did for sandstone, although the changes were not quite as dramatic (Figure 5-5). The particular reaction involving water and steel was not identified.

The role of additional parameters has been investigated (Somerton and Mathur, 1976), although the effects were unclear. Stress did not appear to affect the way permeability varied with temperature. Varlous concentrations of $\mathrm{KCl}$ produced unsystematic changes in the terperature effect.

Lockner et al, (1978) studied permeability changes along temperature gradients in fractured samples of granite. Confining pressure was either 300 or 600 bars, and whether flow was up or down the temperature gradient, permeability dropped dramatically (Figure 5-6).

An extensive study was made (Potter, 1978) of temperature effects for both Westerly granite and the Los Alamos granodiorite (GT). The method used, like the previous study, was the transient technique. The temperature range was $200 \mathrm{C}$, and confining pressure ranged up to 400 bars. The pressure vesse 1 was externally heated. Here the pressure gradient along the specimen was only a few bars, unlike a previous study (Summers et al, 1978). Effective pressure, $\bar{p}$, is just $\left(P_{c}-P_{p}\right)$ during the experiments. For samples of $G T$, permeability to water dropped by about a factor of 10 for temperature samples at $200^{\circ} \mathrm{C}$ (Figure 5-7); the effect was sightly less at higher pressure. Permeability recovered upon cooling almost perfectly. After an extended period of flow ( 120 hours), permeability actually increased significantly (Figure 5-8). The behavior of Westerly granite dramatically contrasted with that of GT, and also conflicted with other studies above. Permeability increased with temperature (Figure 5-9) and recovered to a higher permanent value. A careful study was made of the reasons for the observed temperature effects and two processes were identified; namely, themal cracking, and water-rock chemical reactions. Thermal cracking was regarded as the predominant mechanism here. Study of sections using the SEM revealed that the cracks were intergranular. Autoradiography using $6{ }^{3} \mathrm{Ni}$ isotope supported this conclusion. The limited chemical effects consisted of some dissolution of the quartz. The marked difference between the two rocks studied was believed due to their different equilibration states. The GT rock was thought to have reached equilibration at a higher temperature than 


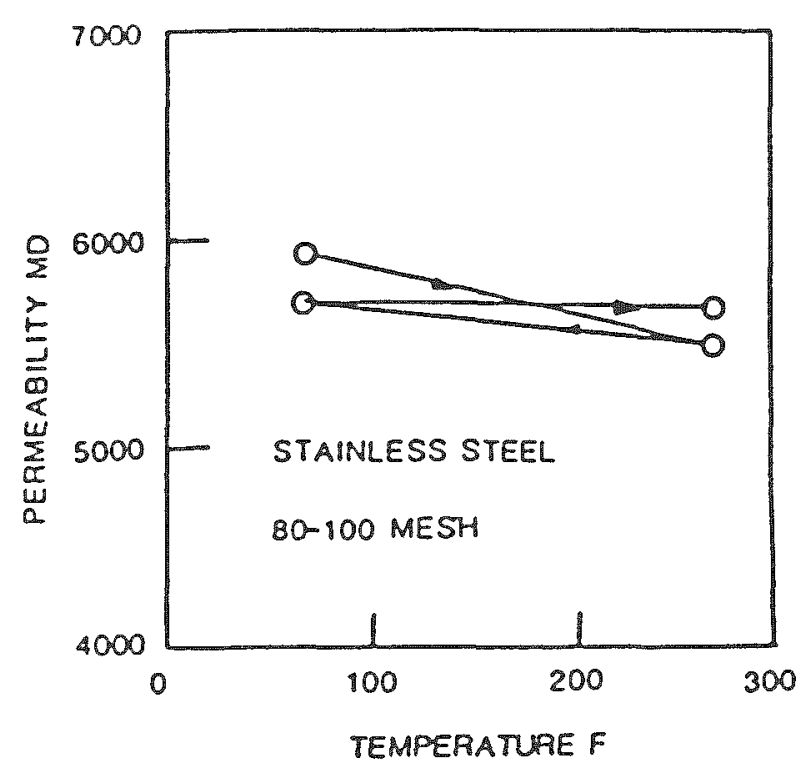

Figure 5-4. Permeability to Mineral 0il of Stainless steel vs Temperature. (Danesh et al, 1978).

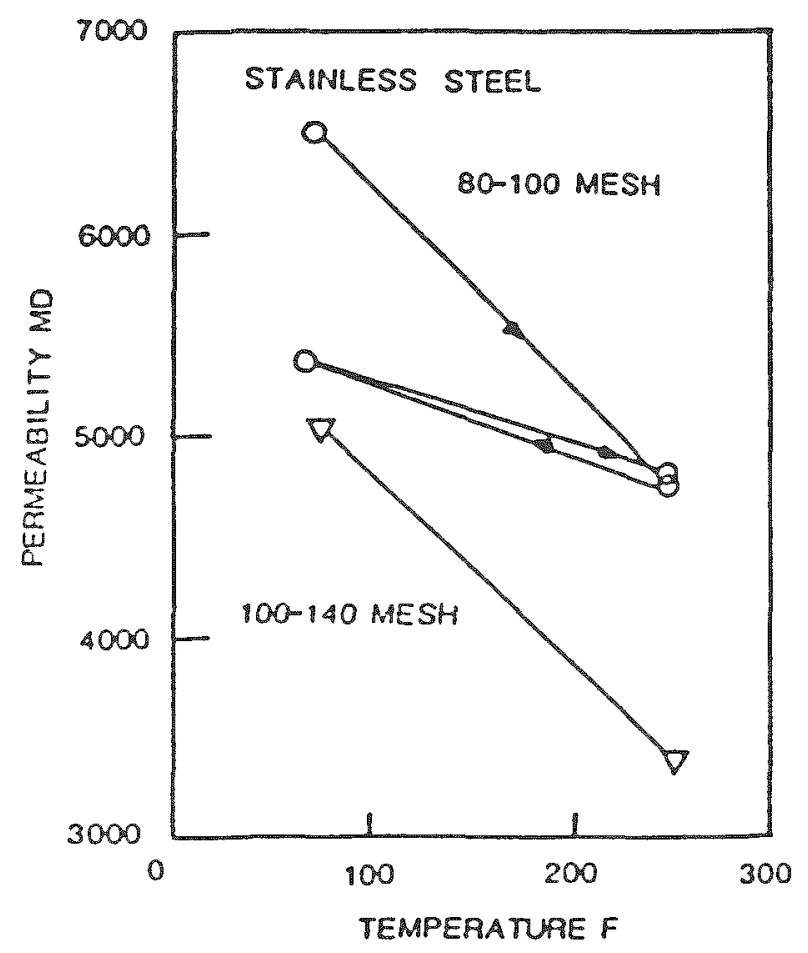

Figure 5-5. Permeability to Water of Stainless Steel vs Temperature. (Danesh et al, 1978). 


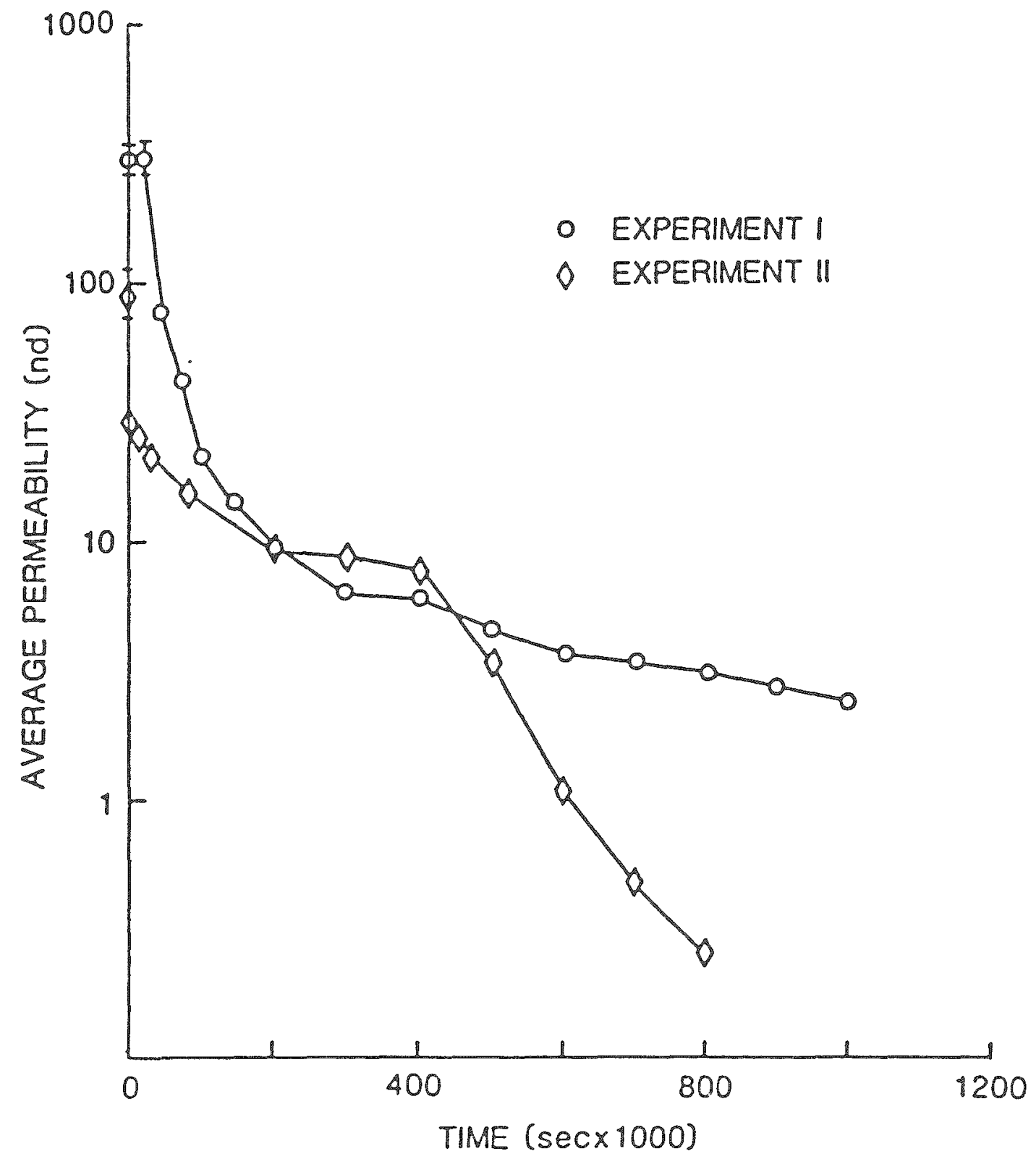

Figure 5-6. Plot of Average Permeability vs Time for Two Samples of Westerly Granite. [In experiment I, water cooled as it flowed away from the borehole. In experiment II, water flowed towards the borehole, increasing in temperature. In both experiments, permeability decreased with time. Lockner et al (1978).] 


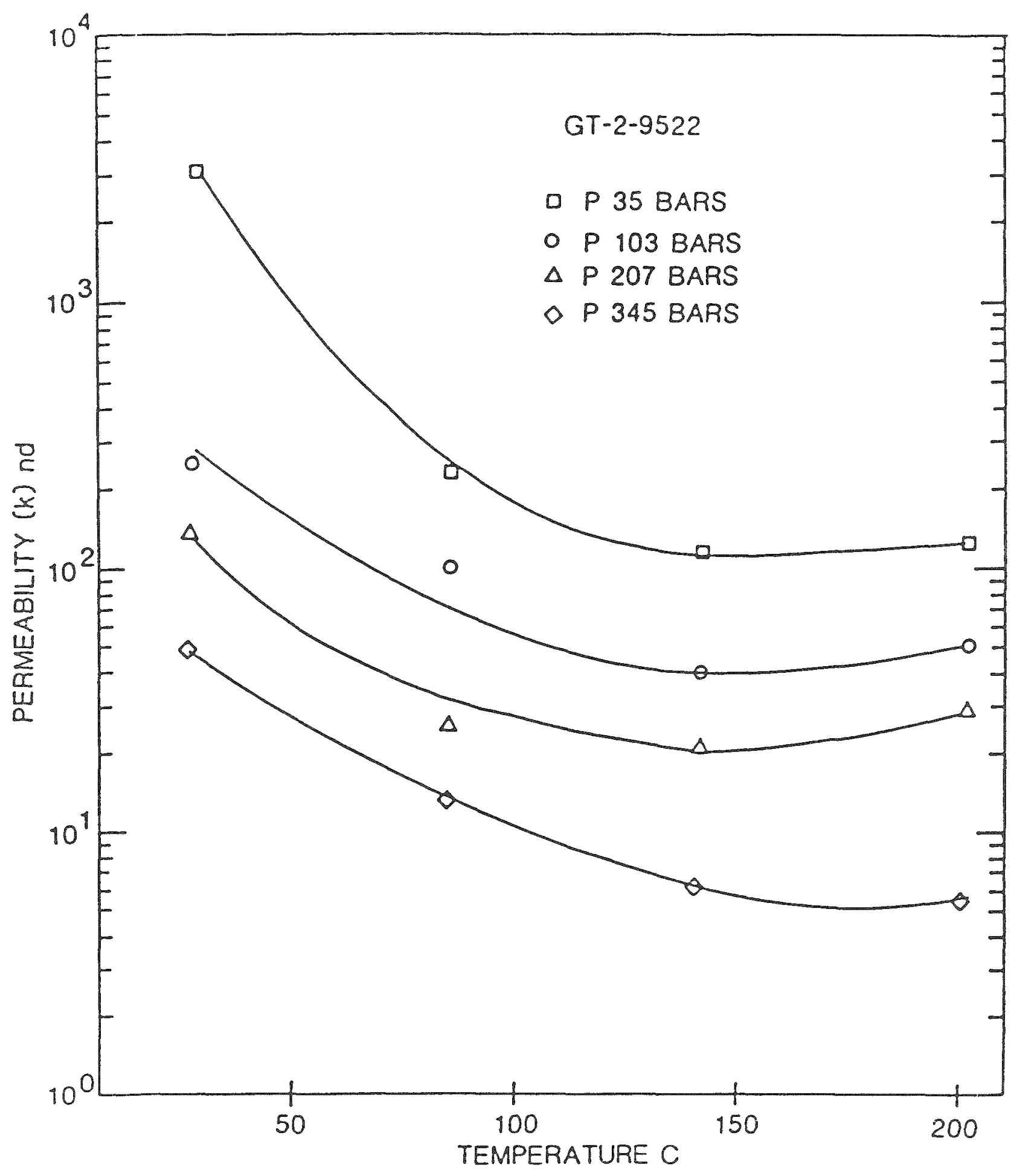

Figure 5-7. Permeability of Los Alamos Granodiorite as a Function of Pressure and Temperature. Permeabilitv Recovers Almost Perfectly During Cooling. Potter (1978). 


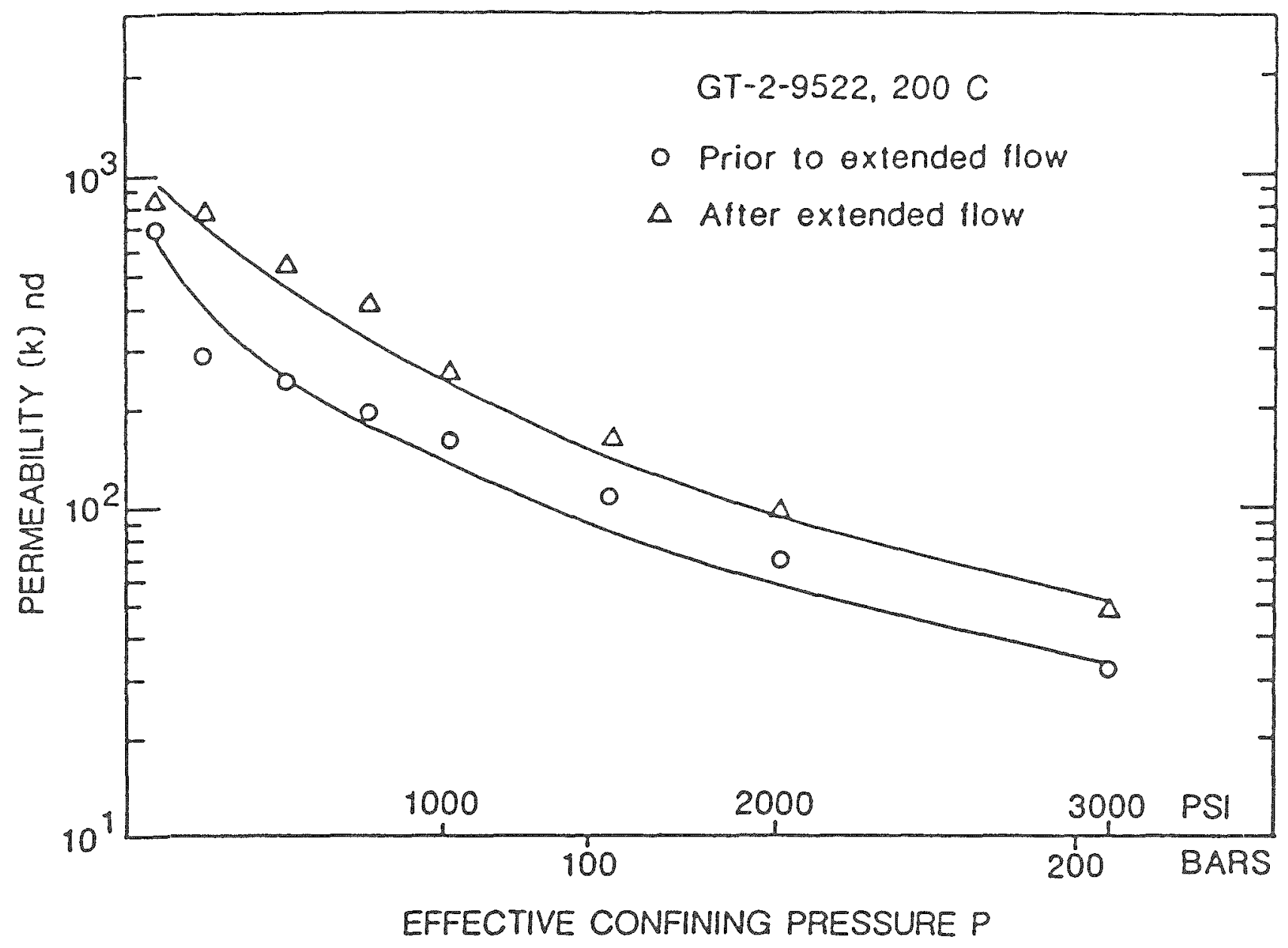

Figure 5-8. Permeability of Los Alamos Granodiorite as a Function of Pressure and Temperature, Showing Effect of Flow for 120 Hours. Potter (1978). 


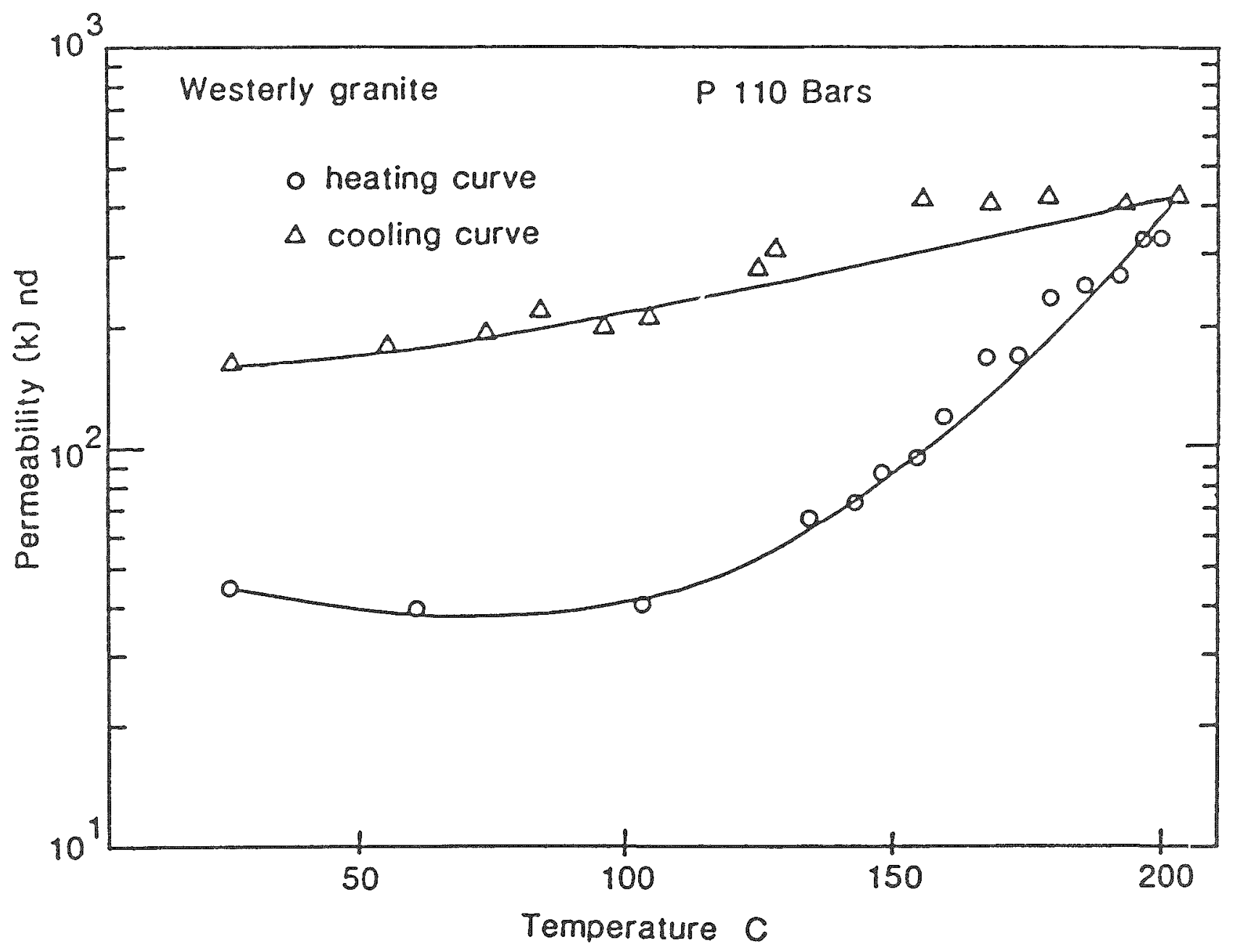

F1gure 5-9. Permeability of Westerly Granite vs Temperature. A Heating Cycle Here Probably Required 0.4 days. Potter (1978). 
the Westerly granite. The cooling to laboratory conditions with subsequent heating seems to explain qualitatively the temperature effects found.

A final pair of studies (Charles, 1978; Charles, 1979) focused on the chemical reactions which ensue when heated water flows past a rock like granite at elevated temperature. The changes are complex and varied: quartz and microcline reacted extensively; plagioclase became more calcic; relative reactivity was quartz > plagioclase > microcline > biotite; development of secondary phases was extensive, as was dissolution of quartz.

Several general conclusions are suggested by present work on the effects of temperature on permeability.

(i) In most, but not all experiments, permeability dropped dramatically with temperature increase or with the time of flow at temperature, as long as the fluid involved was water. The effects seemed limited to silicate minerals, except for one study where steel reacted similarly. For one silicate rock, permeability actually increased with temperature and time. The results to data are thus somewhat inconsistent.

(ii) The permeability change with temperature, although large, was not quantitatively predictable.

(iii) The mechanisms cited were thermal cracking and fluid-rock chemical reactions. Usually these two had an opposite effect--the former increased flow, the latter, because of precipitation of new phases, produced a clogging effect.

(iv) Confining pressure, stress, and ion concentration all seemed to have some small but unsystematic effect on the way permeability varies with temperature.

\subsubsection{Pressure Effects}

Permeability of porous media is known to depend on pore dimensions. Pore dimensions, particularly the aperture, or width, change with stress, so that it is not surprising to find that permeability is quite stress-dependent. 
Few measurements have been made for geologic materials or for granular aggregates at geologic stresses (see review by witherspoon et al, 1977), although there is an extensive literature for rocks and soils under engineering conditions (DeWiest, 1965). Although data relevant to geologic conditions are limited, some general trends are discernible for (a) unjointed rocks with porosity less than 2 percent, (b) unjointed rocks or granular aggregates with high porosity, and (c) jointed rocks like granite or coal.

In most experiments we will describe, the stress state had axial symetry. $k_{\|}$refers to permeability parallel with, and $k_{\perp}$ perpendicular to the unique stress direction. Thus, the bulk of this data is strictly only applicable to unidirectional stress-induced permeability changes.

Among rocks with porosity less than about 0.02 , only Westerly granite has been investigated under simulated geologic conditions (Zoback and Byerlee, 1975). At around 80 percent of the fracture stress in confined compression tests, $k_{\|}$increased by a factor of 3 to 4 (Figure 5-10(a)) over $k_{p}$, the value at $39 \mathrm{MPa}$ effective hydrostatic pressure and zero stress. Brace (1977) showed that this change in $k$ was predictable from crack paraneters and electrical resistivity changes for this rock at the same effective confining pressure.

Mordecai and Morris (1971) observed changes in $k_{\|}$in Darley Dale sandstone (porosity 11 percent) prior to fracture at confining pressures up to 40 MPa. At low pressure, behavior was similar to granite although the actual increase in $k_{\|}$was only 20 percent (Figure 5-10(a)). At $41 \mathrm{MPa}$, $k_{\|}$actual1y underwent a 5 percent overall decrease prior to fracture.

Zoback and Byerlee investigated two granular aggregates, crushed Westerly granite (1976a) and ottawa sand (1976b). At effective confining pressures of 20 and $50 \mathrm{MPa}$, the starting porosities of the granite sand were 31 and 22 percent, respectively. In both cases, $k \|$ had dropped by a factor of 50 at peak stress. Although there appeared to be a small amount of dilatancy prior to peak stress, permeability fell monotonically. Three porous sandstones behaved similarly over smaller ranges of stress.

$k_{\|}$of Ottawa sand dropped even more (Figure 5-10(a)); at 750 bars effective pressure, it fell by a factor of nearly 100 at peak stress. 1 was also obtained, from experiments done in extension; $k$ decreased by a factor of 10 to 20 at peak stress. 
Zoback and Byerlee (1976a, b) observed that the effective stress law did not hold for $k$ of sandstone and sand with either hydrostatic compression or triaxial stress. Small departures from this law have been evident before (Brace, 1977), although not for permeability and electrical resistivity. The new studies show that for sandstone, for example, permeability under hydrostatic pressure is proportional to $\left(A_{P} P^{-P_{C}}\right)$ where $A$ is constant with a value of 2 to 4 depending on direction, $P_{P}$ is pore pressure, and $P_{C}$ is confining pressure. A is close to 1 for equilbrium and transport properties which obey the effective stress law (Brace, 1977). Engelder and Scholz (personal communication, 1977) have also found that $A$ is not equal to 1 for flow through a sand-filled sawcut in Barre granite; here, however, A was apparently less than 1 .

The trends suggested by available measurements (Figure 5-10(a)) reflect interplay of the two factors, porosity, $\eta$, and hydraulic radius, $m$, upon which permeability depends. Both $n$ and $m$ in turn depend on stress, in a way which evidently varies among the different materials shown in Figure $5-10(a)$.

For intact rocks, the following relationship is widely applicable:

$$
\begin{array}{ll}
k=\frac{\mathrm{m}^{2}}{k_{0}} \eta^{3} & \text { Eq. } 5.3
\end{array}
$$

where $k_{0}$ is a dimensionless constant which can vary between 2 and 3 (Brace, 1977), In is one-quarter of the diameter of a cylindrical pore and half the aperture, a, of a flat rectangular slot. For dilatant microcracks in low porosity rocks, permeability in the direction of the microcracks, $k_{j}$, has a different form (Brace et al, 1968):

$$
\begin{array}{ll}
\mathrm{k}_{j}=\frac{\mathrm{m}^{2}}{\mathrm{k}_{0}} \mathrm{n} & \mathrm{Eq} \cdot 5.4
\end{array}
$$

From either equation (5.3) or (5.4), $k$ depends on $r$ and $m$, and both of these may, in general, be affected by stress. Of the three materials in Figure 5-10(a), changes in $r$ and with stress are only understood for an intact, unjointed granite (Brace, 1977). Based on other measurements, mas found to change very little with stress, so that most of the change in $k$ shown must be due to change in porosity, $\eta$. Evidently, $n$ decreases up to the onset of 


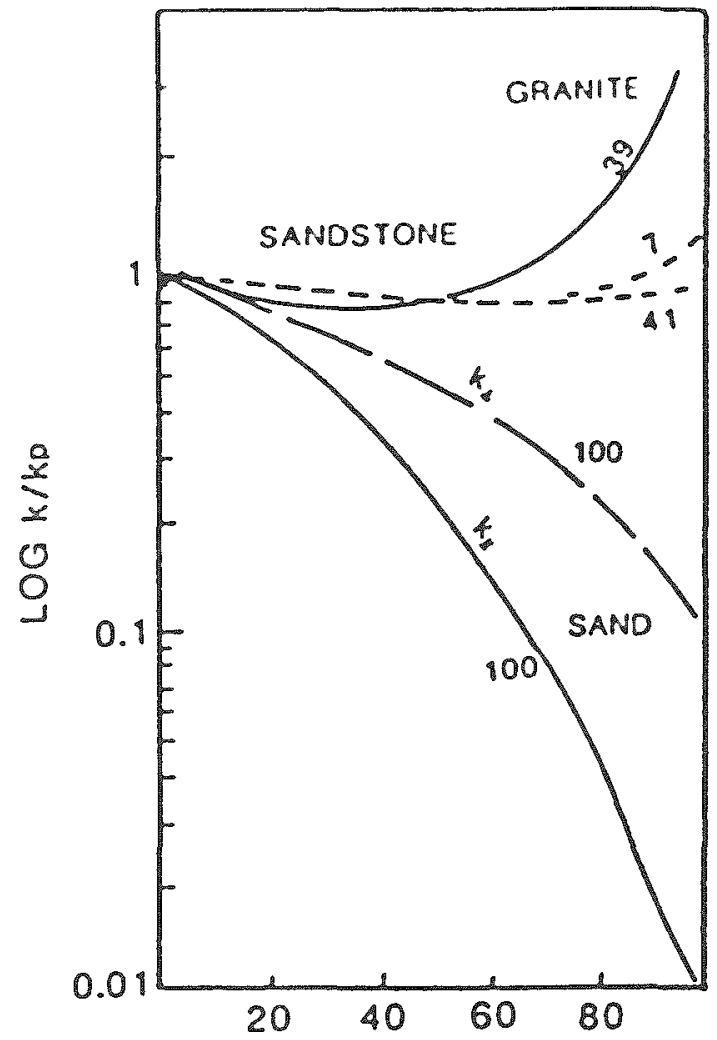

PERCENT OF FRACTURE STRESS

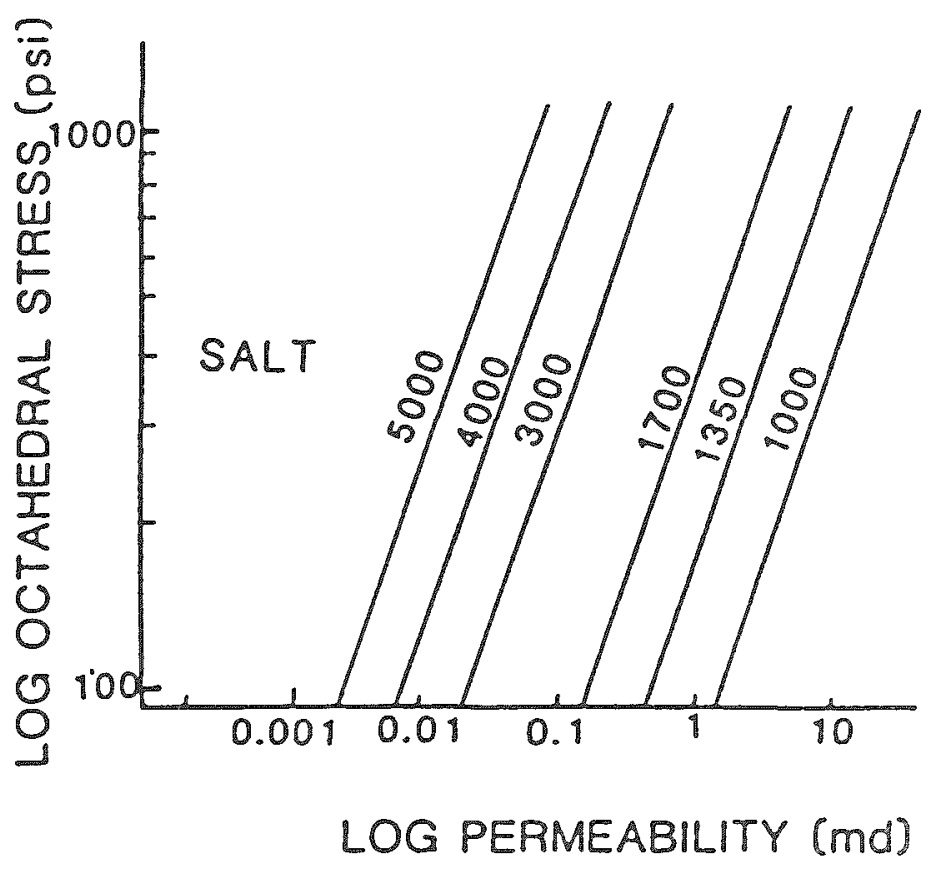

(b)

(a)

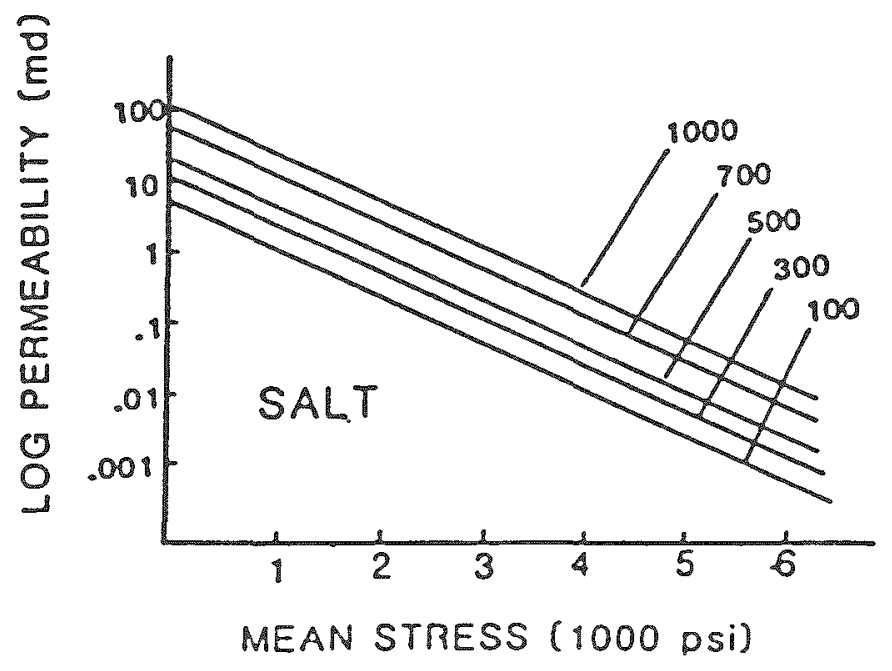

(c)

Figure 5-10. (a) Change in Permeabilitv with Stress for Westerlv

Granite, Darlev Dale Sandstone and Ottawa Sand; Confining

Pressure is Indicated (Brace, 1978). (b) The Fifect of

Octahedral Shearing Stress upon Permeablitity for Various

Mean Stresses (Lai, 1971). (c) The Effect of Mean

Stress upon Permeability for Various Octahedral Shearing

Stresses (Lai, 1971). 
dilatancy; beyond that $\eta$ increases, at an increasing rate. For the sand and sandstone in Figure 5-10(a) changes of $\mathrm{m}$ and $\eta$ with stress are not known; the change in $k$ shown could be due to either or both.

It is interesting to note that in the dilatant region, relative change in porosity due to dilatancy of all three materials is about the same. For granite, it was about 30 to 35 percent, for sandstones similar to Darlev Dale, about 10 to 30 percent and, for the sand, 20 percent; thus, the relative changes in $n$ are comparable. In contrast, $k$ of granite increased nearly fourfold, $k$ of sandstone increased about 10 to 20 percent, and $k$ of sand decreased strongly. These striking differences must reflect the different way $m$ responded to stress in the three materials.

The permeability of rock salt as a function of stress has been extensively studied by La1 (1971), who performed numerous triaxial, high-pressure tests to examine the effects of stress-state, strain-state, and fluid flow. The permeability of the salt was evaluated in terms of mean stress and octahedral shearing stress; these parameters are auite logical owing to the plastic nature of deformation of salt at appreciable pressures.

Experimental evidence indicates that vielding and plastic deformation are essentially independent of the apolied mean stress where bv definition the mean stress is simply the arithmetic average of the three princidal stresses. This quantity is also related to the first stress invariant, so the mean stress an be computed as well by the average of the normal stresses on any three mutually perpendicular planes. Most plasticity theories nostulate that the plastic behavior of materials is related primarilv to that part of the stress tensor which is independent of the mean stress. This deviatoric stress is, in a sense, a measure of the deviation of the stress from a spherically symetric or hydrostatic stress state.

The value of the octahedral shear stress is perhaps the most frequent ly utilized method to express the deviatoric stress. If, at a point in a body a surface which makes equal angles with the principal stress directions is examined, it will be found that the normal stress on this plane is numerically equal to the mean stress. There are eight such planes and in space they form an octahedron; thus, the teminology. It also can be shown that the magnitude of the shear stress on these octahedral planes equals the intensitv of the deviatoric stress and is, therefore, a measure of the stress tending to cause plastic deformation. 
In sumary, then, mean stress causes, ideally, symmetric volumetric deformation while permanent plastic deformation is due to the octahedral shear stress.

Typical tests results from Lai (1971) are shown in Figure 5-10 (b) and (c). Figure 5-10 (b) illustrates that the effect of increasing octahedral shear stress for various mean stresses is to increase the permeability. Increasing the mean stress at a constant octahedral shear stress, on the other hand as illustrated in Figure 5-10 (c) leads to a decrease in the permeability.

\subsection{CONTROLIED LARGE SCALF TESTS}

\subsubsection{Temperature and Pressure Effects in Controlled Large-Scale Tests}

We next consider a group of tests which fall midway between smal1-scale laboratory tests and large-scale borehole tests. Although these tests are large scale, they also have in common the fact that they are performed with controlled boundary conditions. The tests are thus large-scale "1aboratory" tests.

In rocks like granite, joints and other planar fractures provide the prinicpal flow paths (witherspoon and Gale, 1977; Snow, 1968a; snow, 1958h). The effect of stress on permeability of jointed media is quite dramatic.

Somerton et al (1975) showed that $k$ of finely jointed coal dropped 1 to 2 orders of magnitude of 75 percent of the fracture stress in confined compression. No difference between $k_{1}$ and $k_{\perp}$ was apparent.

Pratt et al (1977), studied permeability of a 3-meter block of granite contaning a jount, as stress was applied normal or parallel with the joint. Uniaxial stress of $12 \mathrm{MPa}$ parallel with the ioint raised $k_{j}$ twofold, whereas $3 \mathrm{MPa}$ normal to the joint decreased $k_{j}$ to half the starting value. The constant value of $k_{j}$ reached at high stress $(1.2 \mathrm{md})$ was still 10 times greater than $k$ of the matrix granite under $10 \mathrm{MPa}$ confining pressure (Brace, 1977).

Gale (1975) observed changes in $\mathrm{k}_{\mathrm{j}}$ in a large (approximately $1 \mathrm{~m}$ ) granite core containing joints. Flow rates along a joint could be varied by a factor of 4 to 5 by changes of only 0.5 to $1 \mathrm{MPa}$ in the effective normal stress acting across the joint. As Pratt et al (1977) observed, flow through the joint could not be cut off by high normal stress across the joint. Even at 
$100 \mathrm{MPa}$ normal stress, permeability of granite with a sawcut remained $10^{3}$ greater than matrix permeability in laboratory experiments (Engelder and Scholz, personal communication, 1977).

Voegele et al (1981) presented the results of a large-scale in situ fracture permeability study in granitic gneiss in which both temperature and stress could be controlled. The results of the ambient portion of this test are illustrated in Figure 5-11.

The numbers 1 through 8 indicate the order of testing. Theoretical smooth wall apertures (b) and permeabilities $\left(b^{2} / 12\right)$ can be calculated from the following well-known equation for linear flow between parallel plates:

$$
q=-\frac{b^{3}}{12 u} \frac{d p}{d x}
$$

$\mathrm{Eq} \cdot 5.5$

The permeability of the joint when it was stress relieved by drilling four slots around the sides of the block was equivalent to that of a smooth wall aperture (b) of 60.7 microns. Each of the three ambient load paths reduced this to between 27.1 and 30.3 microns at the highest stress level. Subsequent biaxial loading to $6.9 \mathrm{MPa}$ prior to heating the block also produced an equivalent aperture of the same magnitude; 30.0 microns. It is of more interest, however, to examine the combined effects of temperature and pressure. The three variables: flow (or aperture), rock temperature, and total normal stress show remarkable interdependence, as shown in Figure 5-12. The highest smooth wall aperture of 30.0 microns achieved at ambient temperature (12 C) and under a total normal stress of $6.9 \mathrm{MPa}$ was reduced to 18.3 at $41.4 \mathrm{C}$ and to $9.1 \mathrm{~m}$ at $73.6 \mathrm{C}$. Thus, increased temperature alone reduced joint permeability by an order of magnitude from 75 darcys to 6.8 darcys.

It is unlikely that a reduction of flow aperture of this magnitude could have been achieved at ambient temperature. The clear implication is that the mating of the joint surfaces was improved at elevated temperature.

The inversion of the load cycle at $74 \mathrm{C}$ (points 16, 17, and 18) is further evidence that temperature may have a more powerful influence on aperture (b) than pressure. After unloading to $3.45 \mathrm{MPa}$, a reloading to 


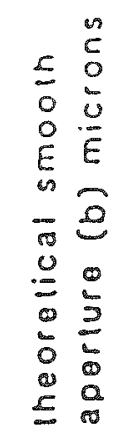

$\begin{array}{ll}5 & 0 \\ 0 & \\ E & E \\ \sim & 0 \\ 0 & 0 \\ 0 & 0 \\ 0 & 0 \\ 0 & 0\end{array}$

60

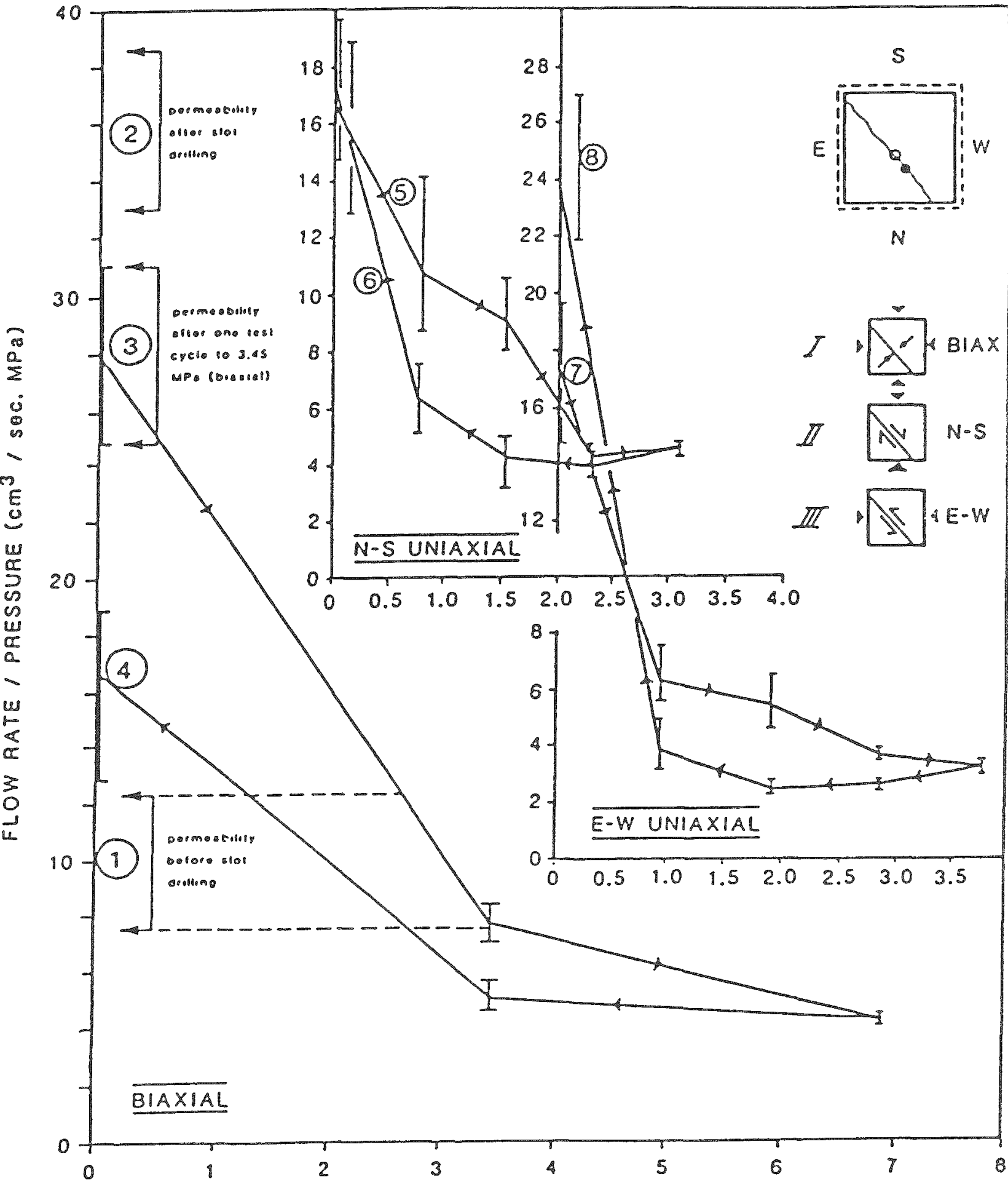

NORMAL STRESS ON JOINT (MPa)

Figure 5-11. Effect of Normal Stress on Flow Rate and on the Theoretical Smooth Wall Aperture (3). (1 micron=0.0n $1 \mathrm{~mm}$ )

Ambient Temperature. From Voegele, et al., 1981. 


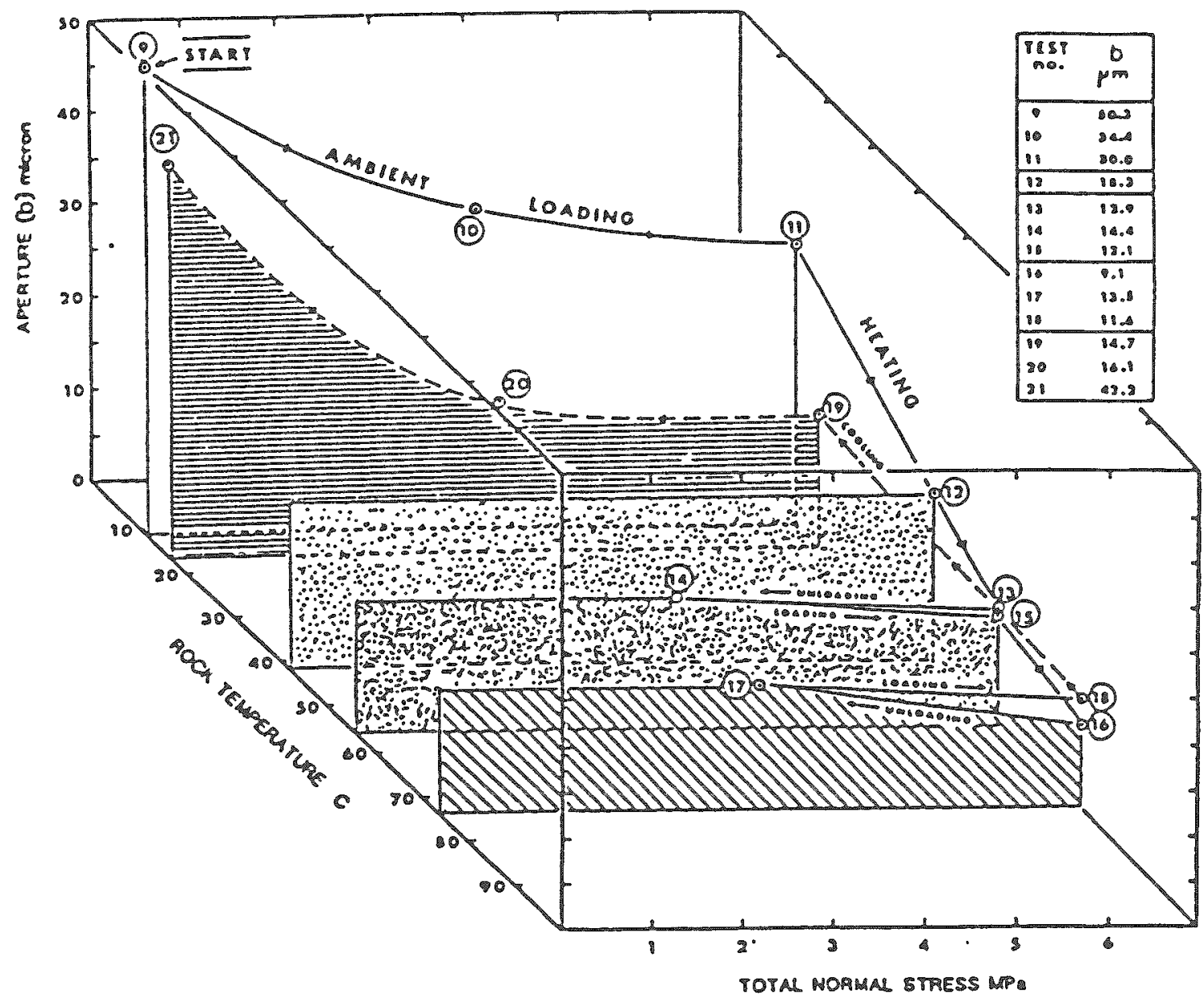

Figure 5-12. Biaxial Loading at Elevated Rock Temperatures Facilitates Hydrothermo-Mechanical Coupling, Causing Dramatic Reductions in Flow Aperture. From Voegele, et a1. 1981 . 
6.9 $\mathrm{MPa}$ was insufficient to "reclose" the joint to the same extent. The scatter of flow data is insufficient to invalidate this conclusion, despite the diminutive aperatures involved.

Witherspoon et al (1979) considered that the four thick curves shown in Figure 5-13 were potential evidence of a scale effect on fracture permeability. The in situ ambient of Voegele et al (1981) for the natural minalized joint shows close agreement with the pratt et al (1977) in situ data for a joint in granite, and apparently lends support to this scale effect hypothesis.

However, several aspects of the hypothesis are suspect. Chief of these is the attempt to compare artificial, unweathered tension fractures (Iwai, 1976 and witherspoon et al 1979) with natural weathered joints. Bandis (1980) has shown that joint apertures tend to be larger when joints are weathered.

An interesting point emerges from the comparison of joints and artificial fractures illustrated in Figure 5-13. The artificial fractures were generated and presumably flow tested at nearly the same ambient conditions in the laboratory. In contrast, it is not likely that the natural joints in the Eield were tested at the temperature and pressure conditions at which they formed. The fracture upon which Voegele et al (1981) concentrated their efforts showed significant weathering. Their results suggest that when joints are flow tested at elevated temperature and pressure, the mating of the joint walls apparently improves. The test series reported by voegele et a1 (1981) certain1y does not refute the suggestion of a scale effect in fracture permeability, but it does provide another plausible explanation for the observed behavior.

Witherspoon et al (1981), described a novel large-scale permeability experiment which enabled measurement of the average permeability of a large (approximately $10^{6} \mathrm{~m}^{3}$ ) volume of rock. A section of drift at stripa was sealed and equipped with a ventilation system which could be utilized to evaporate all water which was seeping into the sealed room. By measuring air flow rate, temperature, and humidity changes, they determined an average permeability coefficient of $10^{-6}$ darcy.

It is difficult to compare data for jointed and unjointed rocks, since stress levels for the former did not approach those for fracture of intact material. It is significant that stress effects are much more dramatic for 


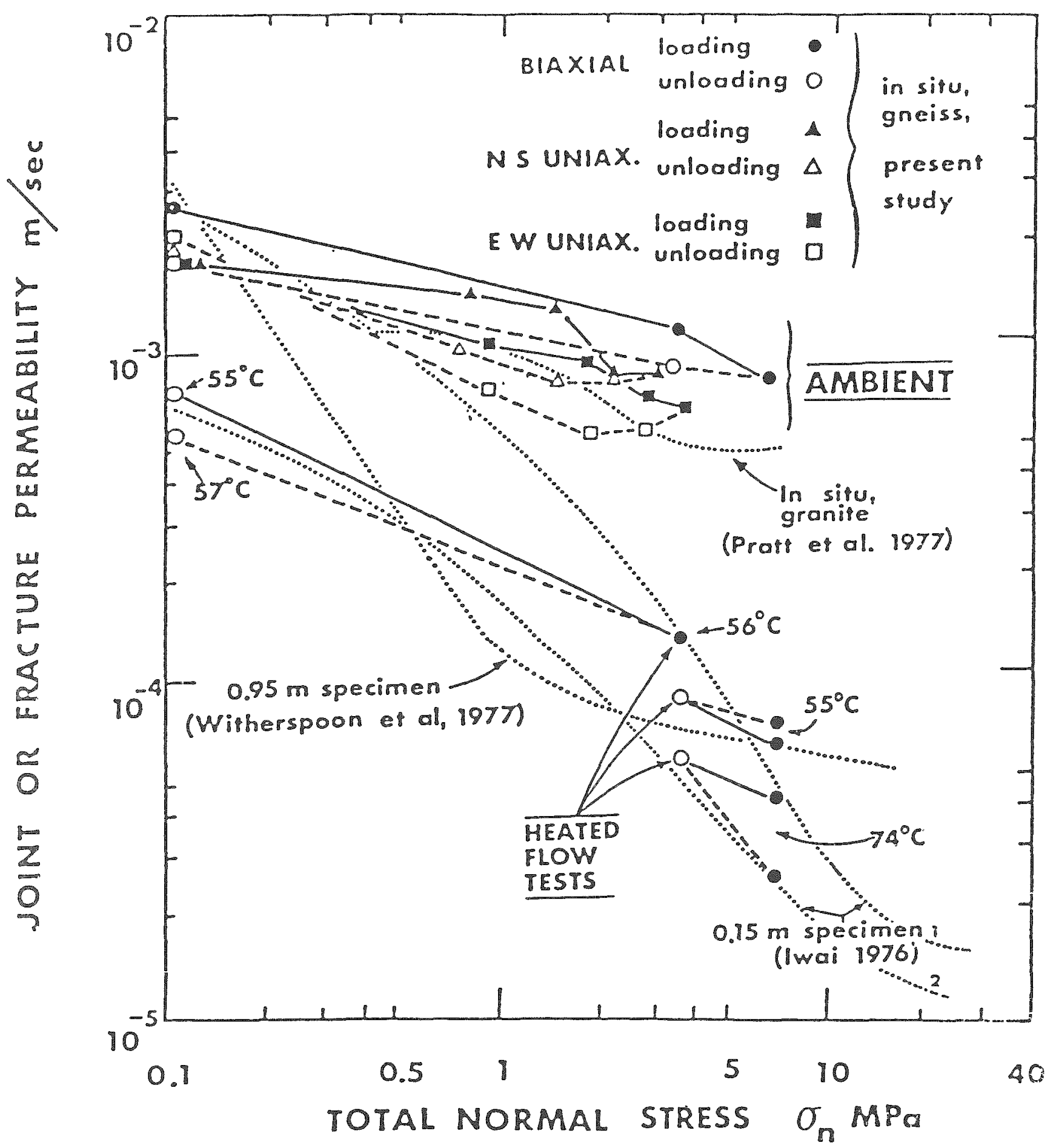

E1gure 5-13. Joint Permeability - Normal Stress Relationships for In

Situ Granite (Pratt, et al., 1977) and In Situ Gneiss

(Ambient) Show close Agreement. The Steeplv Inclined

(Dotted) Curves for Artificial Tension Fractures in

Granite (Witherspoon, et al., 1977 and Iwai, 1976)

Tested Under Ambient Conditions Show Similar Permeabil-

1tv-Stress Coupling to the Heated Flow Tests Conducted

at $59^{\circ}-57^{\circ}$ and 74 C. From Voesele, et al., 1981. 
$\mathrm{k}_{j}$, however. Twofold to fourfold changes in $k$ were produced by a stress of 1 to $10 \mathrm{MPa}$; twofold to threefold changes in $k$ required $100 \mathrm{MPa}$ for granite. It is interesting to compare permeabilitv and strain changes for the jointed granite. Joint closure at $3 \mathrm{MPa}$ normal stress was about $10 \mathrm{\mu m}$ (Pratt et al, 1977). Jornt spacing is about $1 \mathrm{~m}$, so that the strain was $10^{-4}$. Therefore, change in $k_{j}$ was more than $10^{4}$ times greater than the linear strain perpendicular to the joints. This is comparable to the amolification report ed by Snow (1968a) and Witherspoon and Gale (1977).

Controlled, large-scale tests provide a method for examining the transition in behavior between laboratory tests where typically all boundarv conditions can be monitored and controlled and large scale field tests where typically the boundary conditions at one point are controlled and, perhaps, conditions are monitored at a few other points. Controlled, large-scale tests are set up such that boundary conditions can be controlled on as large a sample as is practical; stress and temperature effects on permeability have been studied in these tests but admittedly, the data base is small.

The controlled, large-scale tests have shown, primarily, that the permeability of joints is extremely sensitive to temperature and pressure effects. That data which exists suggests a decrease in permeability with increasing pressure or increasing temperature. The data also suggest that It is not possible to reduce, through pressure alone, the joint permeabilitv to that of the intact rock.

\subsection{DRILL HOLE VALUES OF PERMEABILITY}

Drill hole measurements refer to values obtained, typicallv in drill holes, for rock, undisturbed and in place, with no control over boundarv conditions except at the wellbore. There is a variety of methods (Witherspoon and Gale, 1977), all of which give an averaged value for some interval--the interval being the length of exposed rock along the drill hole where the test is performed.

Drill hole methods for permeability testing can be grouped conveniently into four basic types (Kilson et al, 1979). 
Steady-state, constant-head injection tests are the most commonly used tests in evaluating crystalline rock permeability for engineering investigations because they may be rapidly performed in single small-diameter boreholes. The test procedure consists of injecting water between packers at constant pressure. When the flow rate becomes essentially constant, it is assumed steady state has been reached and the pressure is increased to obtain another steady-state flow. Three to six such points are obtained. Ideally, the pressure-flow rate curve should be linear; nonlinearity may be caused by fracture deformation, turbulent flow, or packer leakage (Louis and Maini, 1970). Permeability should be calculated based on the slope of the linear portion of the curve. The lower limit of detection is a function of flowmeter resolution; for a 10-m packer spacing, a permeability of $10^{-5}$ darcy is about the lowest practical limit.

Slug tests consist of the instantaneous addition or withdrawal of water from a well or the packed-off zone of a well and monitoring the transient head response (Cooper et al, 1967). Type curves vary only slightly with storativity; hence, permeability is the only value that can be accurately computed.

Because slug tests are generally of short duration, the results, as with constant-head injection tests, tend to be representative of the materials close to the we11. It is, therefore, important that the well be fully developed. Slug tests in formations of very high permeability tend to decay so rapidly that meaningful data cannot be obtained, while those performed in formations of low permeability may require an exceptionally long time to decay. A 70 percent decay is considered necessary for a confident fit to the type curves used in analysis. For tight formations, test time can be 1ong; a $10 \mathrm{~m}$ zone with a permeability of $10^{-5}$ darcy would require about 6 days to test. This may be compared with a testing time of about 1 minute for the same single fracture using the pulse test.

The pulse test was specifically designed (Wang et al, 1977) for rapidly measuring hydraulic conductivity within single fractures of very small aperture. The test involves monitoring the decay of an instantaneous increase in pressure within a small isolated interval of the wellbore containing a single fracture. This test differs from the standard slug test in that the pressure decay being measured is that of a small volume of water within the isolated interval of the wellbore rather than the slowly declining 
head of a larger column of water feeding into the test interval. For perfectly rigid fractures and test equipment the pressure decay in the pulse test is due solely to the compressibility of water stored within the isolated interval of the wellbore. The time required for pulse decay is a function of permeability. The amount of decay sufficient to determine permeability, with fracture apertures of about 1 m can in practice be achieved in about one hour.

Pump tests are the most widely used type of permeability test. Standard pump tests analysis follows the classic solution of Theis (1935) for confined aquifers and Hantush (1956) for leaky confined aquifers. The procedure involves withdrawing water from a well, maintaining either a constant discharge rate or a constant drawdown. Levels are monitored in the pumped well and in one or more observation wells. Tests involving either stepped, or continuously varying discharge can also be analyzed by superposition of the standard analyses. After pumping is ended, water-level recovery can be monitored and an additional measure of permeability can be obtained.

standard pumping tests yield data on horizontal permeability, and, if an observation well is available, storativity may also be measured. If the permeability of a particular stratigraphic zone is required, the part of the well within that zone must be isolated, such as with packers, and water must be pumped only from that zone. The same zone must also be isolated in the observation well if a meaningful measure of storativity is to be made. These procedures are most successful if the stratigraphic zone being tested is relatively more permeable than the zones immediately above and below.

A generalized guide to the selection of well tests based upon the anticipated permeability and length of the test zone is shown on Figure 5-14 for the four basic wellbore tests described above. Assumptions used in defining test limitations and include both equipment and time constraints. Transient tests were required to be completed within seven days, but no test was accepted which ran for less than one minute. No upper limit of measurement was established for either the pump test or the constant head injection test.

In terms of range, the constant head injection test is shown to be the most versatile. Permeabilities can be measured over more than 8 orders of magnitude, ranging from greater than 10 darcies to as 10 as $10^{-7}$ darcies assuming a 10-m test zone. The slug test has the smallest range of 

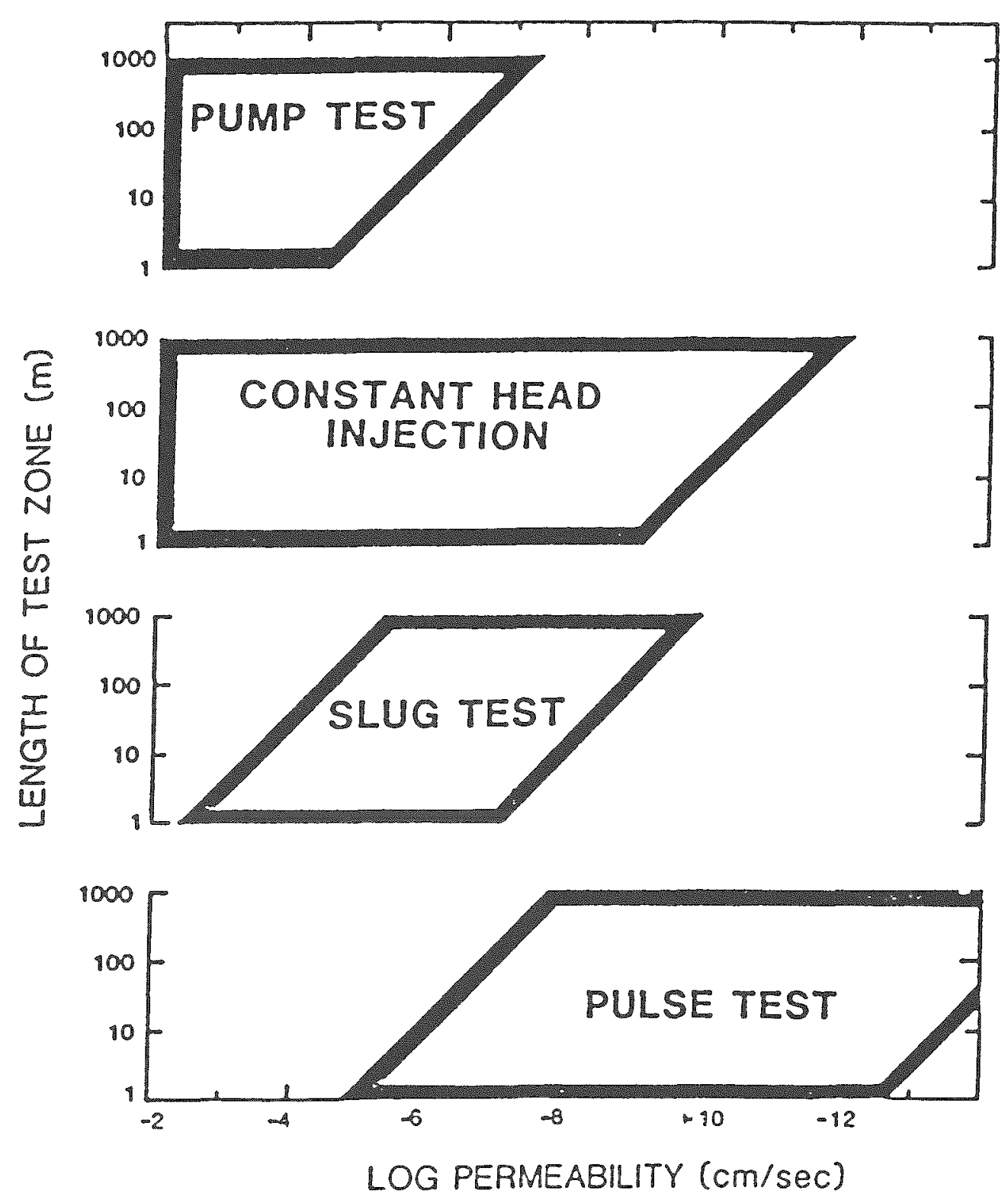

Figure 5-14. Guide to Selection of hell Test Techniques for Permeability Measurements. Limits are Sensitive to Equipment, We11 Geometry and Test Time.

(W1 son, et al., 1979) 
applicability (about 4 to 5 orders of magnitude) and is therefore less versatile than the other tests.

The pulse test is also apolicable over about 8 orders of magnitude, from about $10^{-3}$ darcies to $10^{-11}$ darcies for a $10-\mathrm{m}$ test zone.

The above methods yield quantities like "coefficient of transmissibility", "hydraulic conductivity", or, in some cases, permeability as defined here.

\section{4 .1 Observations}

In situ measurements of $k$ are shown in Figure 5-15 are again grouped roughly according to rock type. Conversion to permeability has been made here using the factors given in the Appendix; special oroblems which have arisen in conversion are indicated in the Notes accompanying Figure 5-15. As noted above, we have taken published or verbally communicated values to he correct and have made no attempt to assign probable errors to the field measurements. Crystalline, igneous, and metamorphic rocks gave the values across the middle of the figure; a few important oil-producing rocks are given at the far left, for contrast. Measurements in clav rich rocks are glven on the right side of Figure 5-15. Approximate depths and the interval are grven where known.

The range of $1 n$ situ values of permeability is even greater than the range of laboratory values, spaning some 12 orders of magnitude. Four to six orders of magnitude variation is typical at a particular site, such as the LASL well or the SRP wells, or at the Climax granite (Figure 5-15). For irystalline rocks in general, in situ $k$ evidently ranges from about $1 \mathrm{\mu d}$ to $100 \mathrm{md}$. The argillaceous rocks such as shales, siltstone, and shaley sandstones are generally less permeable than the crystalline rocks by one or two orders of magnitude.

It is instructive to examine in situ permeability of crystalline rocks as a function of depth. Recause data are still very limited, only three depth zones have been chosen (Figure 5-16), the surface to $50 \mathrm{~m}$, 50 to $500 \mathrm{~m}$, and below $500 \mathrm{~m}$. Several features are evident.

(1) Permeabiluty varies by over four orders of magnitude at a partxcular site, within the same depth interval. 


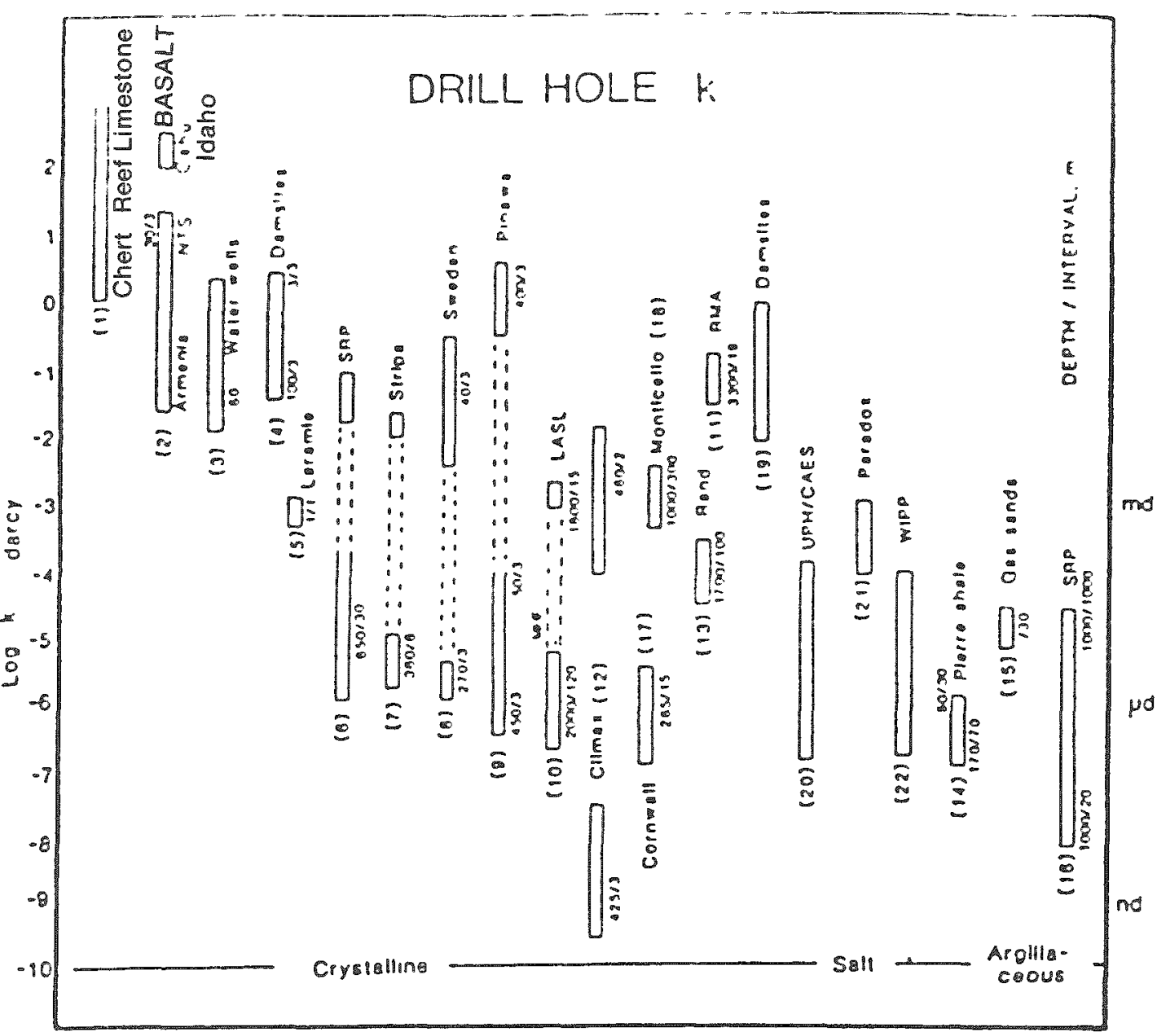

Figure 5-15. In Situ Measurenents of Permeability. Deoth and Inter-

val Lengths Given in Meters where Known. Numbers in

Parentheses Refer to Accompanving Notes. Modified from

Brace, 1980 with Additional Data from (19) Mundi and

Wallace, 1973; (21) Thackston, 1981; (22) Peterson and

Lagus, 1981; and (20) Voegele, et al., 1981.

1 Fractured chert in shale. fractured limestone, coralline reef limestone

2 Armenan basalt Nevada Test Site basalt. Oahu, Idaho basalts

3 Calculated from observed flow rates from water wells up to $60 \mathrm{~m}$ deep in fractured metamorphic rocks of northern Colorado

4 Pumping tests at 38 damsites in crystalline rocks in western United States

5 Pumping tests in a surface outcrop of granite near Laramie. Wyoming

6 Pumbing and swaboing tests in crystalline basement rocks at the Savannah River Plant near Aiken, South Carolina $1 \mu$ was the detection limit

7 Pumping test in the Stripa mine, Sweden

8 Over 500 pumping tests at 5 sites in grantes and gneiss. Sweden

9 Pumping and drill stem tests in the Lac du Bonnet batholith, near Pinawa. Manitoba $05 \mu$ was the detection limit

10 Drill stem tests at 5 depths in geothermal test nole No 2 , in grandodionte, near Los Alamos. New Mexico (LASL) MHF refers to a measurement made of water loss into the sides of the hydrofracture

11 The Rocky Mountain Arsenal (RMA) well near Denver. during injection into $18 \mathrm{~m}$ of open hole in crystalline rocks Values shown here calculated from an average transmissibility of $500 \mathrm{md}$-ft/cp or 5 darcy-ft using interval of $70 \mathrm{ft}$ and viscosity of $1 \mathrm{cp}$

12 Two values from nearby sltes in the Climax granttic stock. the high value came from both pressure decay and constant pressure tests and the low value from constant pressure tesis using air The upper values came from a region which may have been affected by the Piledriver nuclear explosion. permeablity was probably enhanced by the damage

13 Based on average water inflow into a tunnel in quartzite

14 Packer tests made in several drill holes in the thick sections of the Pierre shale

15 Pumping tests in Rulison and Gasbuggy sites (gas sands)

16 From Triassic siltstone and mudstone near Aiken. South Carolina

17 The range of a number of measurements using injection and pulse methods in the Carnmenellis granite. Cornwall Engiand

18 Packer tests at Monticelio Reservorr. South Carolina 


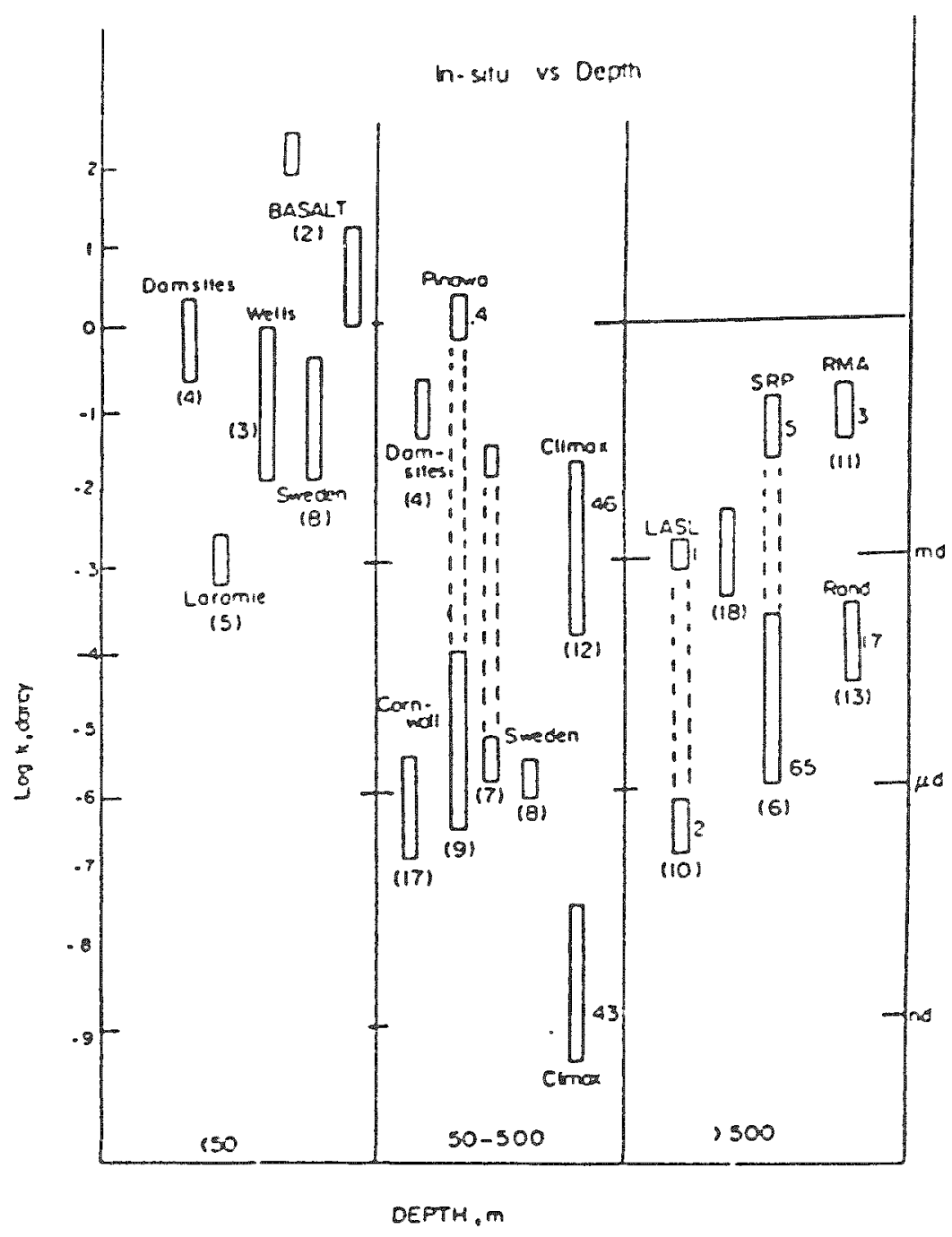

Figure 5-16. In Situ Measurements of Permeahility for Crvstalline

Rocks from Figure 5-15 Arranged Accordang to Depth.

Several Depths are Given in Kiloneters. From Brace, 1990. 
(ii) There is a hint of decrease of permeability with depth but, as also pointed out by Maini and Hocking (1979), hardly enough to justify the exponential law suggested (Carlsson and 011son, 1977; Rice and Simons, 1976). Compare particularly the values from depths greater than $500 \mathrm{~m}$; no systematic variation with depth is evident.

(iii) At nearly every site, some portion of the rock sampled by the drill holes has a permeability of 1 to $100 \mathrm{md}$. This relatively permeable zone may be as deep as $1.8 \mathrm{~km}$ (LASL) or $3.3 \mathrm{~km}$ (RMA). Similar zones were noted in a survey of 25 Canadian mines to 1.7 $\mathrm{km}$ (Raven and Gale, 1977).

\subsection{LARGE SCALE CRUSTAL PERMEABILITY}

Rock-mass permeability has been inferred a number of ways; the two principal methods require (i) measurements of fracture spacing and aperture of conducting fractures, or (ii) observations of time and distance which relate phenomena thought to be controlled by hydraulic diffusion.

Water flow in fractured rock may occur principally through joints, faults, and other planar fractures (Witherspoon and Gale, 1977). Assuming plane parallel sets of such fractures, then rock-mass permeability can be calculated from

$$
k=b^{3} / 12 J
$$

where $\mathrm{b}$ is fracture aperture and $\mathrm{J}$ fracture spacing (Witherspoon and Gale, 1977; Snow, 1968b).

Flow of fluids through rocks, like chemical diffusion or heat flow, is gaverned in the transient regime by

$$
t \sim L^{2} / \alpha
$$

Eq. 5.7

where $t$ and $L$ refer to time and distance, respectively, of a moving front of pressure, and $\alpha$ is hydraulic diffusivity. Here,

$$
a=k / n \mu R
$$

$\mathrm{Eq} \cdot 5.8$ 
where $k$ is permeability, $\eta$ is porosity, $\mu$ is viscosity, and $\beta$ is compressibility of the fluid. Given some phenomenon thought to be due to transient flow, $t$ and $L$ can be found. One example is an earthquake believed due to pumping of fluid at a nearby well (Ohtake, 1974). t would be the time between pumping and the earthquake, and $\mathrm{L}$ the distance between well and epicenter. can then be obtained from Equation 5.8 if porositv of the rocks and $\mu$ and $k k$ of the fluid are known. Large scale permeability values inferred in various ways are collected in Figure 5-17; additional exolanations of the methods used are given in the notes which accompany the figure. One rather remarkable feature of Figure 5-17 is the close agreement of many of the values, between about 0.1 and $100 \mathrm{md}$. Not surprisingly, the values obtained for joints were much higher. Perhaps the aperture, $b$, had become widened by surface processes like weathering or stress relaxation. The values for the mine fractures could have been complicated by aqueous solution reations; apertures might have been widened or even reduced by reactions with the wall rock. In any event, these effects would strongly influence $k$, because of its third-power dependency on $b$ (Equation 5.6).

Many of the crustal permeabilities gathered in Figure 5-17 represent values averaged over distances of kilometers (Skaergaard, Matsushiro, oceanic crust, for example). The volumes of rock represented are therefore much larger than sampled either in a laboratorv measurement or in a typical in situ test. careful comparison of these three data sets for particular sites may provide a better future understanding of the scale effect on permeahility (Witherspoon et a1, 1979).

Marine (1981) used the helium content of ground water to determine a bound on $k$ over a $50 \mathrm{~km}$ path which terminated at the SRP. His value, representing an upper bound, was based on assumptions about radioactivity of the basement rocks along the path, and about a lack of leakage of helium through overlying formations. The value, about $1 \mu d$, is close to the relatively impermeable intervals at the SRP (Figure 5-17).

\subsection{CONCLUSIONS}

We first compare observations from the SRP (Savannah River Project), and then turn to a general comparison of the three sets of values given in 


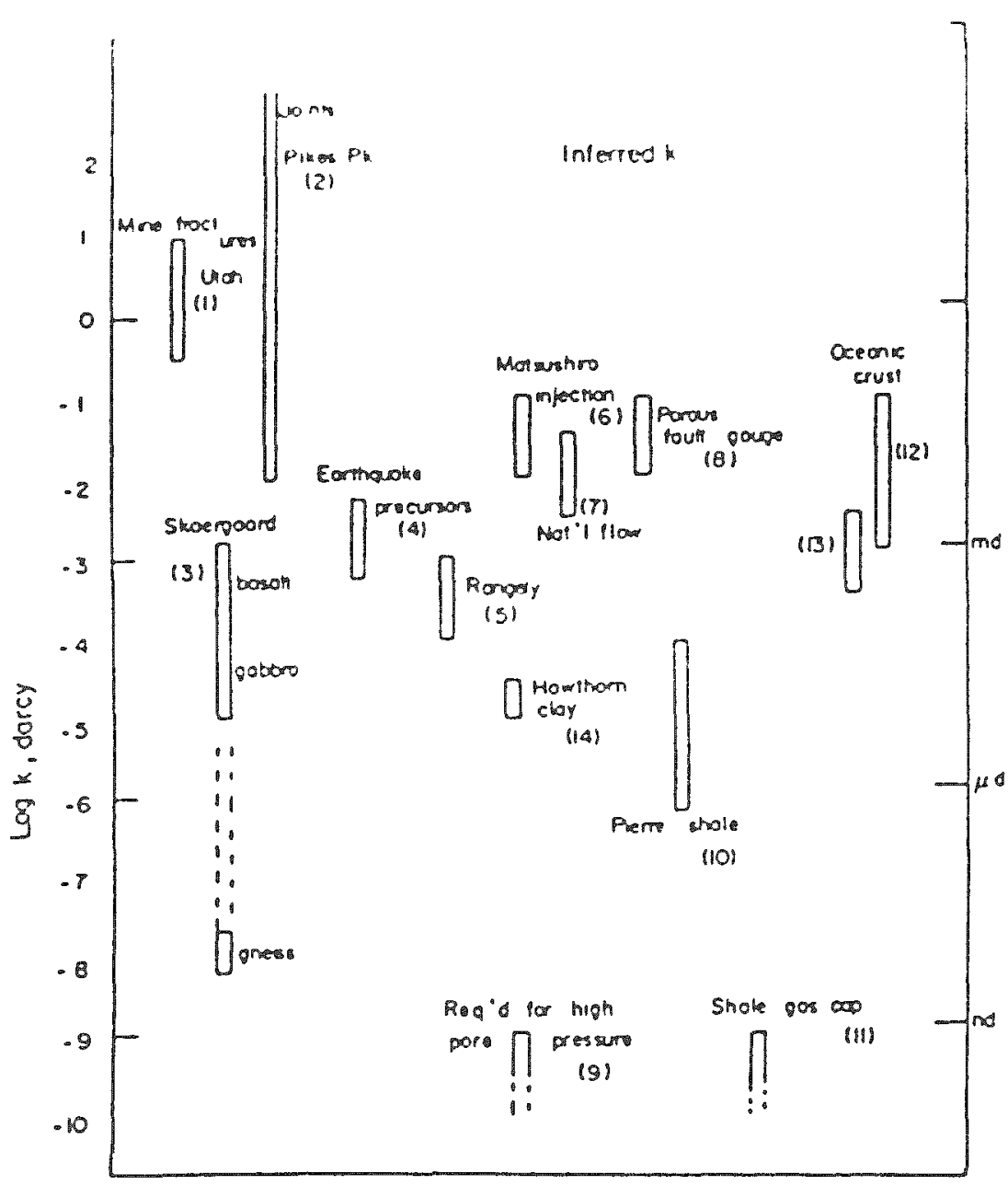

Figure 5-17. In Situ Permeabilitv Inferred from Various Large-Scale

Phenomena. From Brace, 1980.

1 From observed fracture spacing and aperture in and around Mayflower Mine, Park City, Utah

2 From measured fracture spacing and aperture at about 60 stations in the Pike's Peak granite, near Manitou Springs, Colorado

3 Based on application of transport theory to the hydrothermal system associated with crystalization of the Skaergaard intrusion, Greenland The principal input to the models was variation of 180 and exchange reactions between hydrothermal fluids and various rocks in the system. The estimates are shown for basalt host rocks (suriace to about $7 \mathrm{~km})$, intrusive gabbro $(4-8 \mathrm{~km})$ and intruded gneiss $(7-10 \mathrm{~km})$

4 Based on precursor time vs length of after shock zone for a wide variety of earthquakes

5 Based on a personal communication of $J$ Healy who observed pressure changes 025 mi from the well two hours after injection The same porosity, viscosity and compressibility were used as in 4

6 Ontake related a sequence of earthquakes at Matsushiro, Japan, with water injection at a well, the time lag was 5-10 days and the distance $5-15 \mathrm{~km}$, giving $\alpha$ of $10^{4} \mathrm{~cm}^{2}$, sec.

7 Ground-water discharge was also observed at Matsushıro some time after an earthquake The authors calculated the bulk permeability to be $10 \mathrm{md}$, assuming a porosity of 001 and viscosity of $10^{-3}$ poise

8 Based on coupled deformation-diffusion in a porous fluid-filled medium thought to model the creeping zone of the San Adrean fault

9. Upper bound estimate based on the permeability which would be required to cause pore pressure to attain Iithostatic pressure with $10^{6} \mathrm{yr}$ The estimate is based on a fixed source of pore pressure at depth

10 Based on observed water loss from the Dakota sandstone into the overlyıng Pierre shale, which is about $200 \mathrm{~m}$ thick

11 An upper bound estimate based on the sealing properties of argillaceous rocks above oil and gas reservoirs in Siberia The calculated hydraulic diffusivity is less than $10^{-9} \mathrm{~cm}^{2} / \mathrm{sec}$ We used porosity of 001 and the properties of water to obtain the value of $k$ shown

12 Based on convection theory for porous media and observed heat flow for the Indian Ocean

13. This upper bound estimate is based on reduction of heat flow due to assumed downward flow of cold ocean water in the top $5 \mathrm{~km}$ of oceanic crust in the Famous and Galapagos areas.

14. Based on an analysis of chloride contamination and water loss through a $60 \mathrm{~m}$ thick clay confining layer above an aquifer at Brunswick, Georgıa 
Figures 5-1, 5-15, and 5-17. SRP was chosen rather than other sites for which laboratory and in situ values are available (LASL, Laramie, for example) because of the larger number of measurements available.

For SRP, laboratory and in situ measurements from the same wells are compared in Figure 5-18. For the Triassic siltstones and mudstones, laboratory measurements are within about an order of magnitude of values in situ; for the crystalline basement rocks certain intervals show about the same agreement, but $k$ of the conducting zone is about $10^{3}$ greater than laboratory values.

A detailed summary of the results of five different techniques utilized at the Savannah River Plant to determine permeability of the crystalline bedrock is presented in Figure 5-19 (Marine, 1981). Laboratory tests gave values similar to those obtained from in situ tests in virtually impermeable rock. Analyses of pumping tests gave values similar to a tracer test for hydraulically transmissive rock. The hydraulically transmissive rock is about three orders of magnitude more permeable than the virtually impermeable rock. The permeability obtained from the age of the water and the inferred gradient and flow path represents a composite average of a large mass of rock consisting of both virtually impermeable rock and hydraulically transmissive rock. This value is two orders of magnitude less than the values from hydraulically transmissive rock. It is an order of magnitude greater than the average of laboratory tests and in situ tests, and it is about the same as the maximum laboratory and in situ values.

Thus, it may be inferred that fracture zones in the metamorphic rocks are not infinite in extent but terminate in virtually impermeable rock. Thus, the regional average permeability coefficient of the SRF is dominated by that of virtually impermeable rock. Thus, for this study (Marine, 1981), the laboratory measurements of peremability would provide values that are indeed applicable to calculations of regional flow within an order of magnitude.

General comparison of laboratory, in situ and inferred values of $k$ (Figure 5-1, 5-15, 5-17) suggest several important conclusions: 


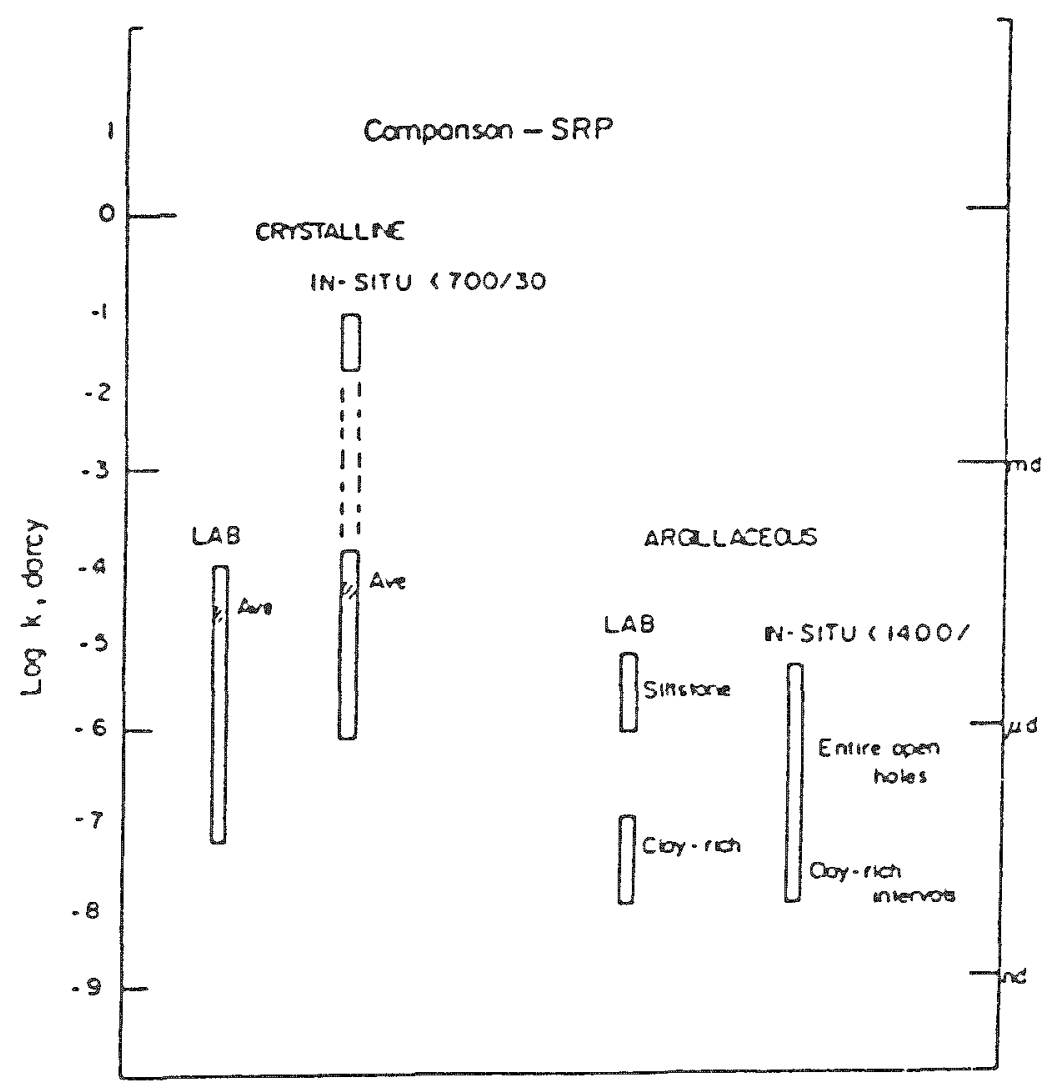

Figure 5-18. Comparison of In Situ and Laboratorv Measurements for the Same Intervals at the Savannah River Plant; Measurements for the Crystalline Rock are Given in Marine, 1967 and Argillaceous Rock in Marine, 1974. Numbers for the In Situ Values are Depth and Interval in Meters. From Brace, 1980. 


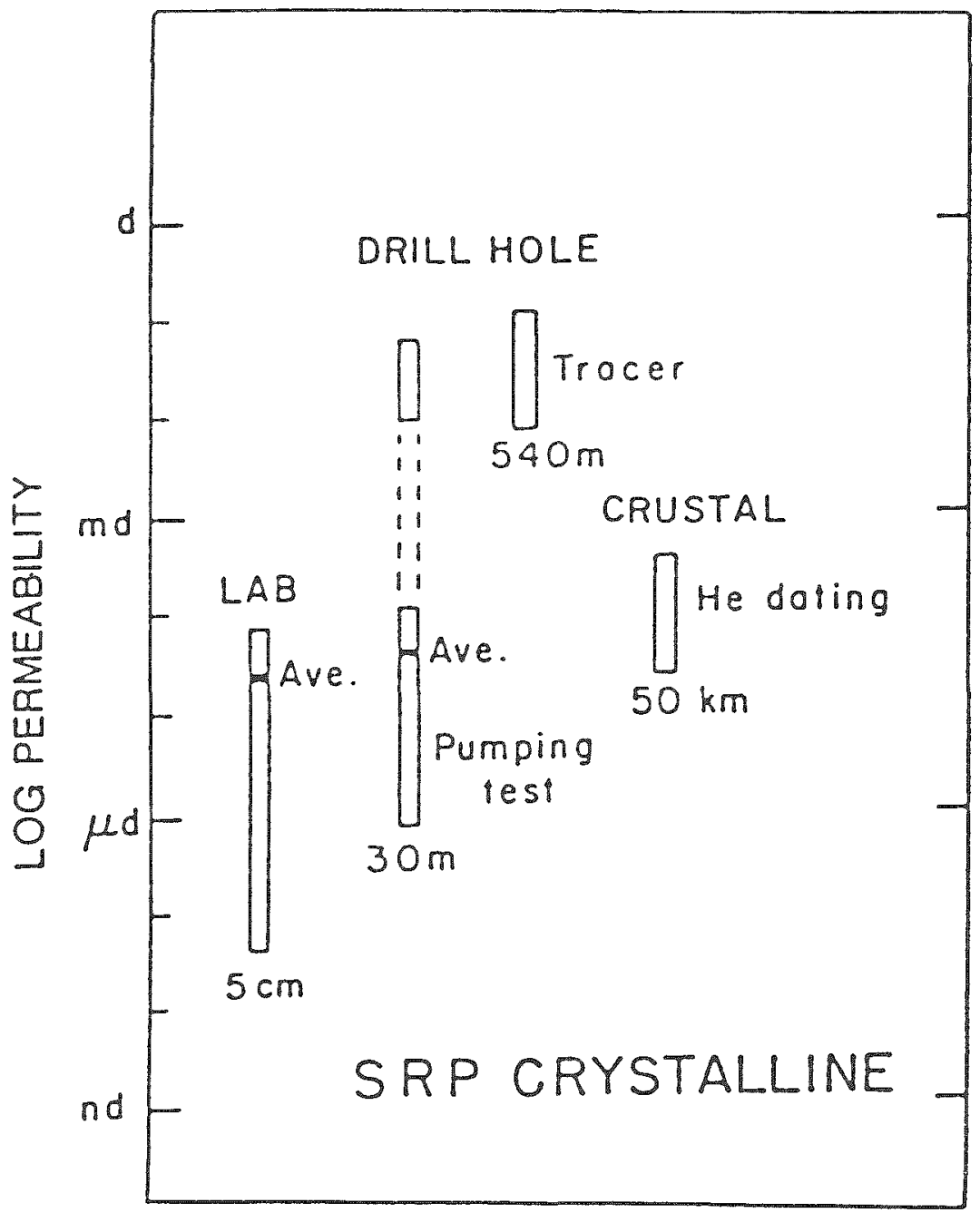

Figure 5-19. Comparison of Laboratory In Situ and Rock Mass Measurements of Permeability of Crvstalline Rock at the Savannah River Plant, Aiken, S.C. After Marine, 1981 . 
(i) For crystalline rocks, most inferred values are about the same as the more permeable zones in situ; average $k$ is 1 to 10 md. This suggests that pumping tests in wells may sample a volume of rock which is representative of much larger crustal volumes. For the Pierre shale (Figure 5-15 and 5-17), the same rock-mass is involved; inferred $k$ is within an order of magnitude of $k$ from in situ tests (Bredehoeft, 1979).

(ii) The average $k$ for crystalline rocks noted above of 1 to $10 \mathrm{md}$ is about $10^{3}$ greater than laboratory measurements for crystalline rocks, and corresponds to that of many sandstones.

(iii) For rocks of appreciable clay content, laboratory and in situ values usually agree within about a factor of 10 . Some intervals in wells also agree even for crystalline rocks (the SRP in Figure 5-18, for example).

The marked difference between laboratory and in situ $k$ of crystalline rocks noted above is usually explained by fractures (Witherspoon and Gale, 1977; Marine, 1967; Snow, 1968a; Maini and Hocking, 1979). Joints, faults, and other planar discontinuities in a rock mass are usually not sampled for laboratory measurement and yet they may represent flow paths many times more significant than those in the intact laboratory sample. A simple demonstration of this is given by comparison of several laboratory and field experiments (Figure 5-20). $k$ was measured in an intact sample and compared with that of a sample containing a natural joint (Laramie granite (Pratt et a1, 1971)) or a sawcut (the other three rocks in Figure 5-20). $\mathrm{k}$ was measured in the direction of the fracture plane and was several orders of magnitude greater than intact $k$.

This result is generally more characteristic of crystalline rocks than certain sandstones and shales. For example, the SRP and Pierre shales show close agreement between in situ and laboratory values (Figures 5-1, 5-15, 5-18). Field permeability measurements in a jointed sandstone near Rangely, $\mathrm{CO}$, showed that little if any flow of water followed the joints (Swolfs et a1, 1981). A similar conclusion was reached after hydrologic study of the 


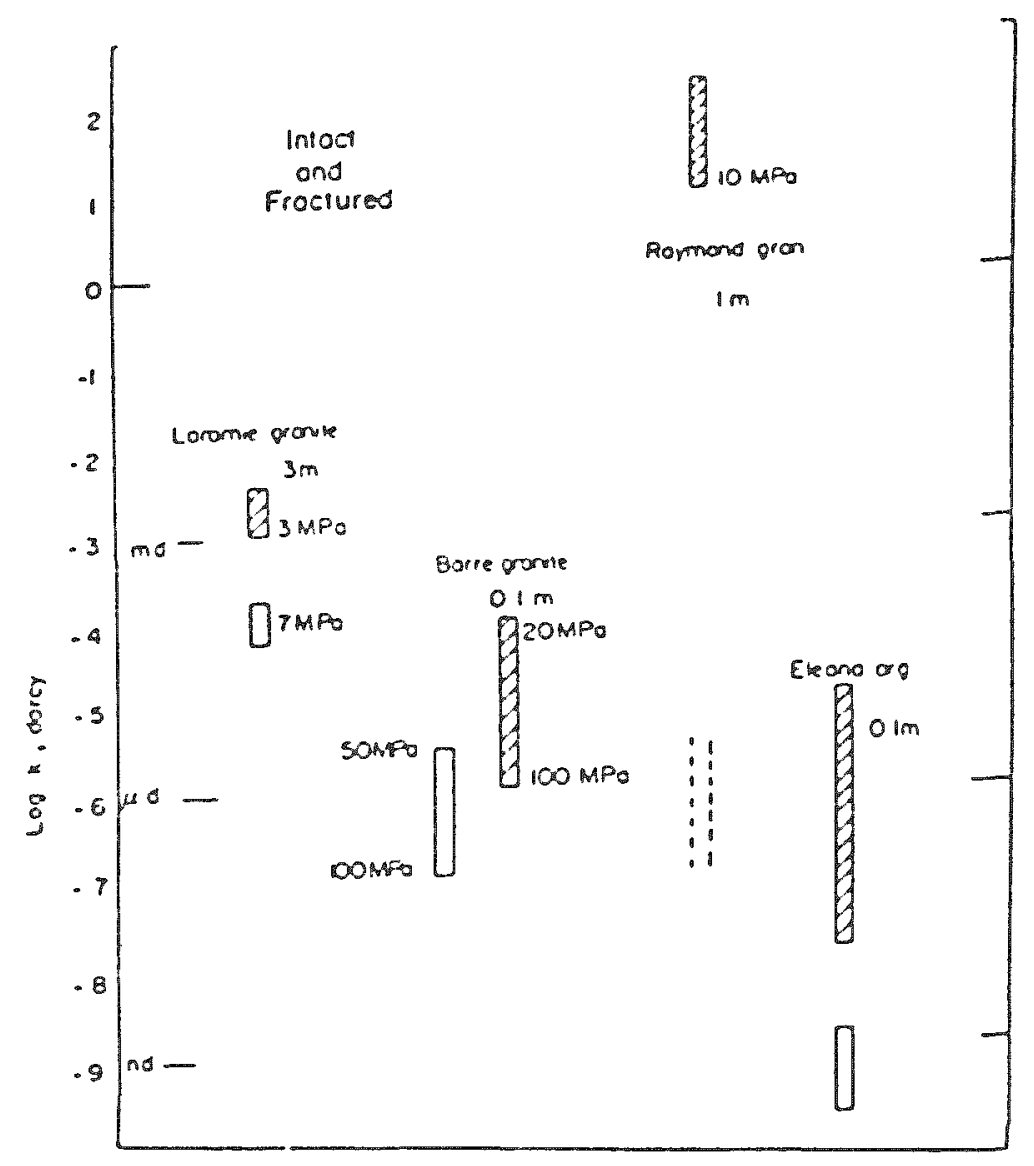

Figure 5-20. Comparison of Intact and Fractured Rocks. Cross-Matched Boxes Give $k$ Parallel with the Single Fracture or Sawcut, $k$ of Intact Raymond Cranodiorite is not Known; Tyoical Granite from Figure $5-1$ is Shown bv the Dotted Lines. From Brace, 1980. 
Navajo sandstone (Nelson, 1972; Scholz et a1, 1973). Thus, fractures may play a minor hydrologic role for certain argillaceous rocks and sandstone; the reasons are probably different. $k$ of intact sandstone is already in the millidarcy range; fractures add little (Brace, 1978). For shale with a high clay content, fractures probably seal at modest depths owing to plasticity. The Eleana argillite (Figure 5-10) is nearly half lithic fragments and thus may not behave like typical shale. 


\subsection{INTRODUCTION}

Obviously the ease of fluid flow, expressed as permeability, depends on interconnected porosity, both fracture and matrix. However, the exact relationship between $k$ and $\eta$ is far from obvious. One thing is clear, though, permeability does not correlate directly with $\eta$. For example, the matrix permeabilities of granite and shale are about the same, whereas porosity of shale is usually 10 percent or greater and porosity of granite is typically less than half a percent. Or consider sandstone and shale; porosities are comparable, whereas permeabilities differ by as much as six orders of magnitude. Or, a few parts in $10^{5}$ of fracture porosity increase permeability of typical crystalline rocks by three orders of magnitude. Theory suggests that the missing element is pore dimension. Two different cases have been studied, planar fractures, and isotropic matrix flow in rocks like sandstone and granite. Pore width plays a vital, although mathematically different role, in each.

\subsection{FRACTURE FLOW}

\section{2 .1 Theory}

Laminar flow in a viscous incompressible fluid in a fracture has been studied by many workers starting with Boussinesq (1868). Lomize (1951), Polubarinova-Kochina (1962), Snow (1965), Romm (1966), Louis (1969), and Bear (1972) are only a few of the investigators that have derived the basic equations describing flow through a fracture. If the flow is laminar and one adopts the analogy of parallel planar plates to represent the fracture surfaces, these workers have shown that the permeability of a fracture set with an aperture $b$ and spacing, $J$ is given by

$$
k=\frac{b^{3}}{12 J}
$$

$\mathrm{Eq} \cdot 5.6$ 
If the flow is steady and isothermal, the flux, $q$, per unit drop in head, $h$, can be developed from Darcy's law and may be written in simplified form as

$$
\frac{q}{h}=c(b)^{3}
$$

$\mathrm{Eq} \cdot 6.1$

Equation 5.6 is the basis for what is often called the "Cubic 1 aw" for flow in a fracture. One must bear in mind that this equation has been derived for an "open" fracture" i.e., the planar surfaces remain parallel and thus are not in contact at any point.

\subsubsection{Experimental Test of the Cubic Law}

In his comprehensive treatise on flow in fractured rock, Romm (1966) presented the results of very careful laboratory studies on flow phenomena in fine $(10$ to $100 \mu \mathrm{m})$ and superfine $(0.25$ to $4.3 \mathrm{\mu m})$ fractures. His superfine fractures were made of optically smooth glass and were carefully constructed so as to be open fractures. He demonstrated the validity of the cubic law for laminar flow in both fine and superfine fractures using various fluids and also verifled the presence of a boundary laver $0.015 \mu \mathrm{m}$ in thickness. He concluded that laminar flow in a fracture obeys the cubic law at least down to apertures of $0.2 \mu \mathrm{m}$. The critical Reynolds number at the transition from laminar to turbulent flow as found to be 2400 . This same critical value has also been reported by Lomize (1951) and Louis (1959).

Sharp (1970) performed flow tests in the laboratory with a natural rock fracture in a hard granite porphyry whose matrix permeability was extremelv small. He started the flow test from a so-called "closed" condition which was achieved by placing the fracture in a horizontal position so that it would "close" under the weight of the upper half of the rock sample. Water flow through the fracture in this "closed" condition indicated the aperture was about $270 \mu \mathrm{m}$, and flow tests were then conducted by jacking the fracture open unt 1 a maximum aperture of $1540 \mathrm{\mu m}$ was reached. Sharp (1970) and Sharp and Maini (1972) proposed an empirical flow law for natural fractures that was based on the "effective" aperture, which is the difference in the opening 
from the initial condition, and the net flow rate obtained from a calculation of the measured flow rate minus that observed uder the initial "closed" condition. They disput the validity of the cubic law and have suggested that for their particular conditions the exponent in Equation 6.1 should be 2 . In reviewing these results, Gale (1975) has pointed out that the cubic law is still valid if one correlates their flow rates with the apertures that were actually present.

While all of these investigations have been concerned with open fractures, one may encounter many situations in the field where the fractures are not open. Us'lally, fracture surfaces have some degree of contact and the effective aperture will depend upon the normal stresses acting across the discontinuity. Under these conditions, flow is still possible but since part of the flow path is now blocked by asperities, will the cubic law still hold? This is an important question in many flelds where flow through fracture systems must be considered.

Witherspoon et al (1979) studied fractured samples of basalt, granite, and marble. Matrix permeabilities were so low that they could be neglected. The samples were prepared with radial and straight-flow geometries for the flowing fluid, which was filtered water at ambient conditions. Details of the sample preparation and laboratory procedures were given by Iwai (1976). One of the most critical problems was that of determining the fracture aperture. Figure 6-1 shows an example of flow rates as measured with the straight flow granite sample when normal stresses up to $17 \mathrm{MPa}$ were employed in an attempt to close the fracture. The effect of repeated loading cycles was to reduce the flow rate per unit head difference, $q / h$, to a minimum of $5.33 \times 10^{-10} \mathrm{~m}^{2} / \mathrm{sec}$, but the fracture could not be closed completely Assuning that Equation 6.2 is valid for nearly closed fracture such as this, the residual aperture was computed to be $6.7 \mu \mathrm{m}$ under these conditions.

The reduced aperture at any stress level, $b_{d}$, could be determined by reference to the maximum fracture deformation, $\Delta D_{\mathfrak{m}}$ (See Figure $6-2$ ), using

$$
\begin{array}{ll}
\mathrm{b}_{\mathrm{d}}=\Delta \mathrm{D}_{\mathrm{m}}-\Delta \mathrm{D} & \mathrm{Eq} \cdot 6.2
\end{array}
$$

Deformations were carefully measured during loading and unloading cycles so that Equation 6.2 could be used regardless of the effects of hysteresis which are clearly evident on Figure $6-1$. 


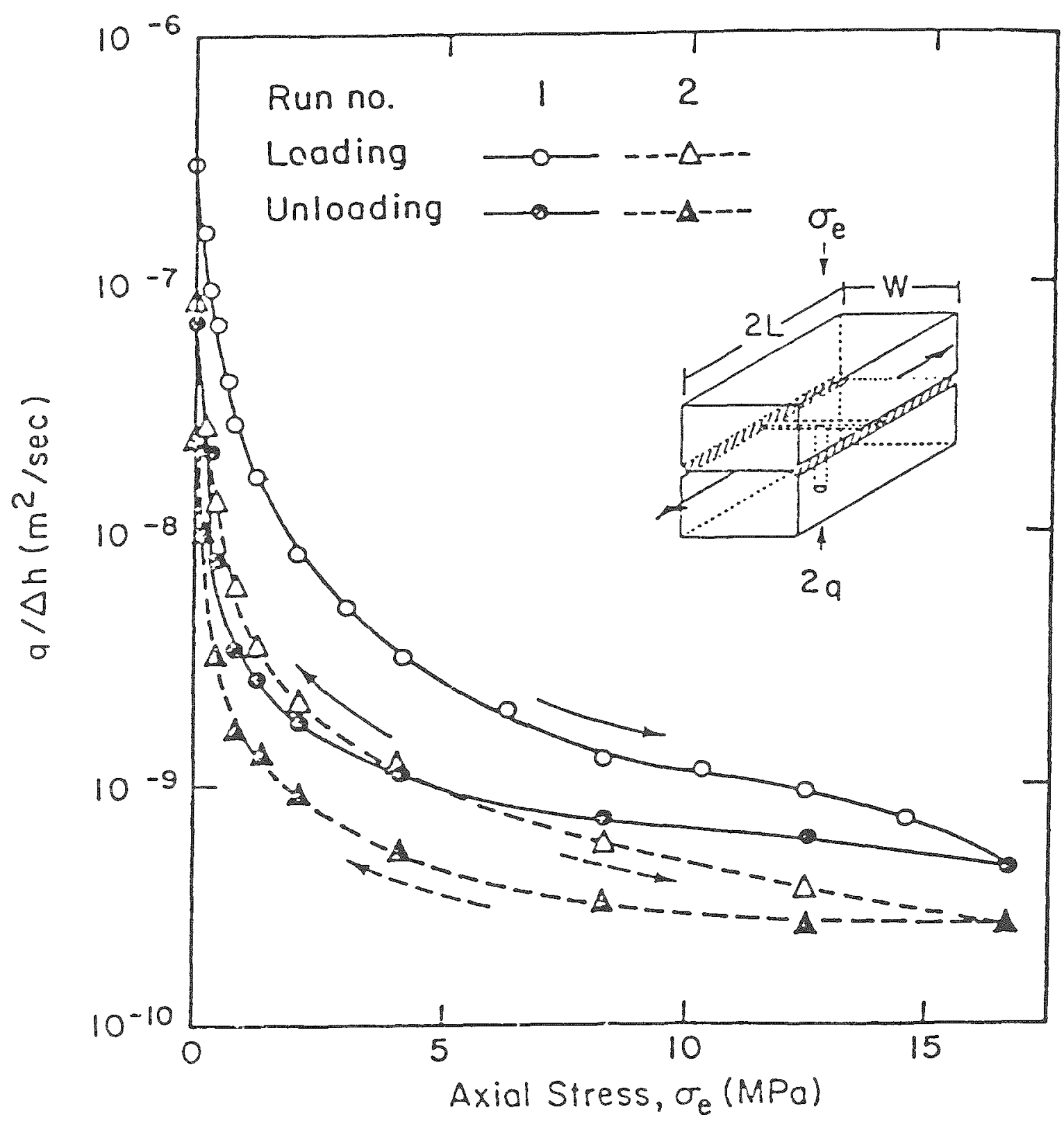

Figure 6-1. Effect of Cvclic Loading on Permeability of Tension Fracture in Grante with Straight Flow (after Iwai, 1976). 
At any given stress, the experimentally determined quantities were the reduced aperture, the flow rate, and the difference in hydraulic head. For a given aperture, $\mathrm{q}$ was observed to be proportional to $\Delta \mathrm{h}$ under the experimental conditions (Iwai, 1976), and thus Darcy's law holds.

The reduced aperture could not be used directly in Equation 6.1 to check the validity of the cubic law because the measured flow rates depend on the true aperture, $b$, which could not be measured directly. As shown on Figure 6-2, the true aperture is the sum of the reduced and residual values, i.e.,

$$
\begin{array}{ll}
b=b_{d}+b_{x} & E q \cdot 6 \cdot 3
\end{array}
$$

Having determined values for the residual aperture at maximum normal stress, Witherspoon et al (1979) then examined how well the experimental data agreed with the cubic law over the range of flow rates employed. Figure 6-3 shows results for the granite with straight flow and for basalt for radial flow. Clearly the cubic law is being closely followed for these two geometries for the rough fracture surfaces. It is followed whether the fracture is open or closed and it is independent of path of loading or the hysteresis that is so evident in the behavior under stress (Figure 6-1). The investigations covered apertures ranging from 25 to 4 um and normal stress of up to $20 \mathrm{MPa}$. Permeability was uniquely defined by the Eracture aperture and one could predict changes due to stress as long as there were no shear movements. The controlling factor is $(b)^{3}$ and therefore slight changes in aper can easily dominate any other change in pore geometry (Witherspoon et al, 1979).

In a11 of the above, and in natural fractures as we11, b represents some averaged or effective aperture. Supposing the actual form of the rough surfaces of a fracture were known; could $\mathrm{k}$ be calculated? Several recent studies have begun to address this question including those of Gangi (1981), Walsh (1981), Witherspoon et al, (1981) and Neuzil and Tracey (1981). The different theories presented in these studies appear highly promising, but as yet lack experimental verification. 


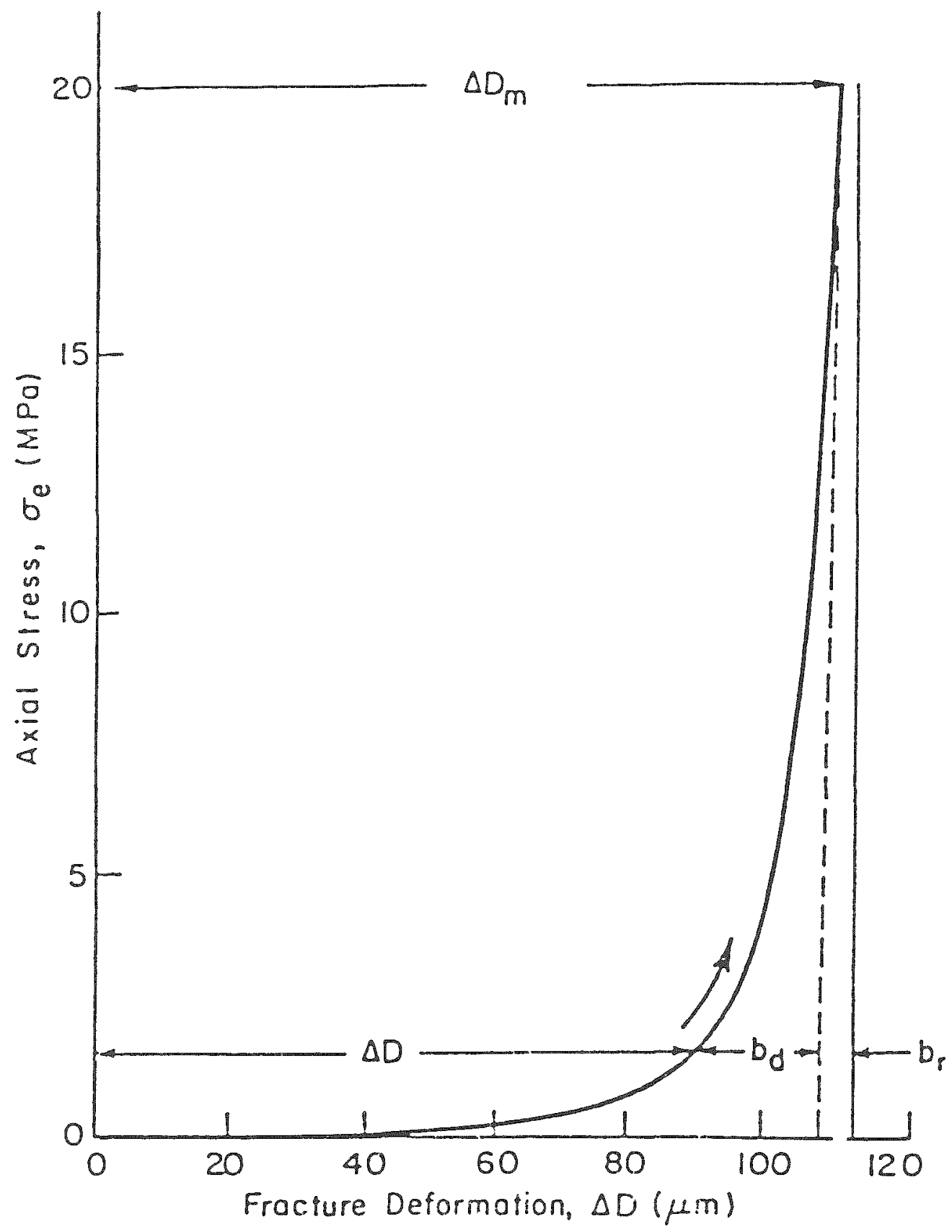

Figure 6-2. Mechanical Properties of Fracture 1'sed in Determining Changes in Aperture with Stress. (From Iwai, 1976) 

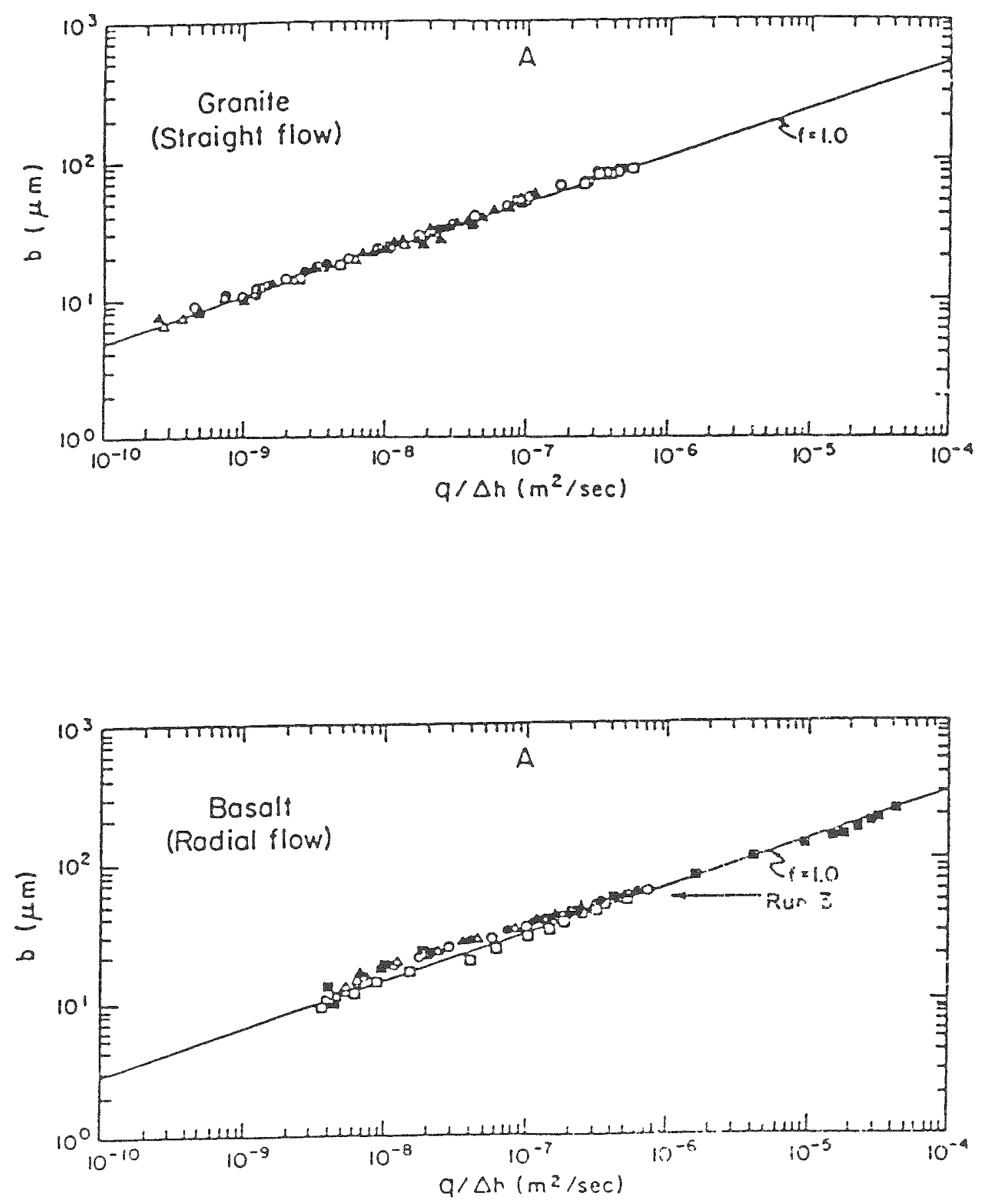

Figure 6-3. Observed Fracture Flow Per Unit Head as a Function of Observed Aperture for Single Fracture. (Witherspoon, et a1, 1979) 


\subsection{MATRIX FLOW}

\section{3 .1 Theory}

Based on Poiseuille's law, fluid flow and electrical conductivity in isotropic porous saturated rocks are related by (Hubbert, 1956; Wyllie and Spangler, 1952; Brace et al, 1968).

$$
k=\left(m^{2} / k_{0}\right) F^{-2} \eta^{-1}
$$

Eq. 6.4

where $k$ is permeability, $k_{0}$ is a shape factor which can vary between 2 and 3 , and $n$ is porosity. m is hydraulic radius, which is the volume of the interconnected pores $\eta$, divided by their surface area. $F$ is the formation factor, the ratio of resistivity of fluid-saturated rock to resistivity of fluid alone. $\eta$ here is probably equivalent to the flow porosity of Norton and Rnapp (1977).

For a wide range of rocks, the empirical Archie's law holds (Brace et a1, 1965; Gonten and Whiting, 1967):

$$
F=n^{-r}
$$

$\mathrm{Eq} \cdot 6.5$

where $r$ is a constant close to 2. Combining (1) and (2)

$$
k=\left(m^{2} / k_{0}\right) n^{3}=\left(m^{2} / k_{0}\right) F^{-1.5} \quad E q \cdot 6.6
$$

Thus, to obtain permeability, $k$, we need either hydraulic radius and porosity or hydraulic radius and formation factor.

\subsubsection{Experimental Tests of the Theory}

The theory has been tested for two granites and several sandstones (Brace, 1971). For these rocks, both $k$ and either $F$ or $n$ had been measured, and petrographic or SEM observations provided an estimate of hydraulic radius, $m$. 
For Westerly granite, Hadley (1976) used the scanning electron microscope to obtain dimensions of a representative sample of 344 cavities, whose width distribution is shown in Figure 6-4.

Hydraulic radius, from the definition given above, is $d / 4$ for a tube of circular cross-section of diameter, $d$, and $a / 2(1+a / h)$ for a rectangular slot of length $\ell$ and width a. For slot-like pores of any aspect ration, $a / \ell$, m ranges from a/4 to a/2. Many of the throughgoing cavities in unstressed crystalline rocks are sloclike in form (Montgomery and Brace, 1975), with aspect ratios of 0.1 or less and therefore with hydraulic radii of about $a / 2$. Returning to the cavities in Westerly granite, (Figure 6-4), Madden (1976) has argued that for a network of different conducting channels the geometric mean most correctly characterizes the bulk conductance. The geometric mean cavity width for westerly granite is seen to be about $0.2 \mu \mathrm{m}$, which would be equivalent to an $m$ of $0.1 \mu \mathrm{m}$. Even with the large uncertainty in $k_{0}$ in (3), namely, \pm 20 percent, this observed $m$ is quite close to the value $(0.15 \pm$ $0.02 \mu \mathrm{m}$ ) predicted from measured $k$ and $F$ (Brace et al, 1968). Or turning things around, measured $m$ and $F$ would have enabled us, using Equation 6.7 , to predict $k$ correctly to about a factor of three (Table 6-1).

The Sherman granite, also referred to as the Laramie granite (Norton and Knapp, 1976; Pratt et al, 1976) is fairly coarse-grained and contains quart $z$, potash feldspar, plagioclase and biotite. One prominent joint set spaced about 1 meter is evident in the field; the joints are parallel with cracks up to $1 \mathrm{~cm}$ long visible in hand specimen. We will term these visible cracks macrocracks to distinguish them from a much smaller set of cracks, called microcracks, apparent under the SEM. Porosity of small cores is somewhat variable owing probably to the macrocracks. Values for six samples ranged from 1.7 to 4 percent; mean porosity was 2.7 percent.

Permeability of a $2.5-\mathrm{cm}$-diameter sampled was $0.10 \pm 0.02 \mathrm{md}$ paralled with the macrocracks, at a confining pressure of $0.7 \mathrm{MPa}$. Resistivity at the same confining pressure for $0.3 \mathrm{ohm}-\mathrm{m}$ pore water gave $F$ of $880 \pm 80$. The density distribution of cavity apertures as viewed under the SEM contrasts with that of Westerly granite, in that there is a hint that two distribution curves have been superimposed with peaks near 12 and $1 \mu \mathrm{m}$; these might correspond to macrocracks and microcracks, respectively. Clearly the larger size has been dominant here, particularly since cavities of this size make 


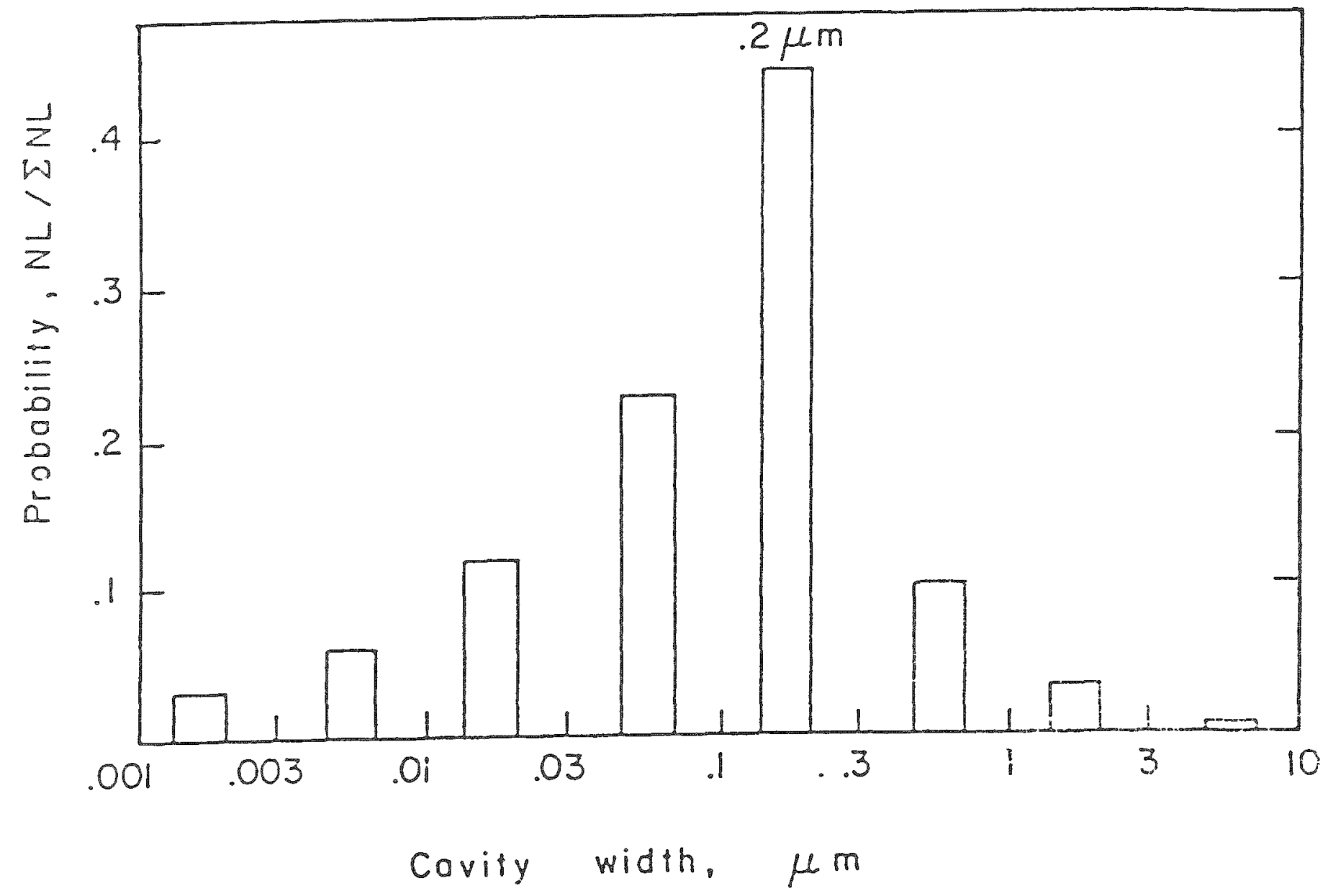

F1gure 6-4. Density Distrubution of 344 ravitv Widths for Westerlv
Granite, Showing the Probabilitv of Encountering a
$\frac{\text { Cavity Belonging to the Width Range Indicated. See }}{\text { Madden (1976) for an Explanation of the Distribution }}$
for Cracks Less than .01 $\mu \mathrm{m}$.


TABLE 6-1. Calculated and Observed Permeability

\begin{tabular}{|c|c|c|c|c|c|}
\hline \multirow[b]{2}{*}{ Rock } & \multirow[b]{2}{*}{$\mathrm{F}$} & \multirow{2}{*}{$\begin{array}{c}\mathrm{m}, \mu \mathrm{m} \\
\text { Observed } \\
\end{array}$} & \multicolumn{2}{|c|}{$\mathrm{k}, \mathrm{md}$} & \multirow[b]{2}{*}{ Reference } \\
\hline & & & Calculated & Observed & \\
\hline \multicolumn{6}{|l|}{ Westerly granite } \\
\hline $50 \mathrm{MPa}$ & 3,100 & 0.1 & $2.3 \times 10^{-5}$ & $6.3 \times 10^{-5}$ & $\begin{array}{l}\text { Brace et al, } \\
1968\end{array}$ \\
\hline $0.4 \mathrm{GPa}$ & 16,300 & 0.1 & $2 \times 10^{-6}$ & $4 \times 10^{-6}$ & $\begin{array}{l}\text { Brace et al, } \\
1968\end{array}$ \\
\hline Sherman granite & 880 & 6 & 0.6 & 0.10 & \\
\hline Berea sandstone & 11.7 & 7 & 490 & 890 & $\begin{array}{l}\text { Wyllie and } \\
\text { Rose, } 1950\end{array}$ \\
\hline Pyrex 1 & 4.4 & 0.38 & 6.2 & 8.1 & $\begin{array}{l}\text { Wyllie and } \\
\text { Rose, } 1950\end{array}$ \\
\hline Pyrex 2 & 6.2 & 12 & 3700 & 3900 & $\begin{array}{l}\text { Wyllie and } \\
\text { Rose, } 1950\end{array}$ \\
\hline Alundum & 11.5 & 2.2 & 50 & 63 & $\begin{array}{l}\text { Wyllie and } \\
\text { Rose, } 1950\end{array}$ \\
\hline \multicolumn{6}{|l|}{ Nichols Bluff } \\
\hline Sandstone & 12.5 & 4.2 & 160 & 230 & $\begin{array}{l}\text { Wyllie and } \\
\text { Rose, } 1950\end{array}$ \\
\hline Eocene sandstone & 13 & 4.4 & 160 & 340 & $\begin{array}{l}\text { Wyllie and } \\
\text { Spangler, } 1950\end{array}$ \\
\hline Penn. sandstone 1 & 20 & $4 \cdot 1$ & 75 & 120 & $\begin{array}{l}\text { Wyllie and } \\
\text { Spangler, } 1950\end{array}$ \\
\hline Penn. sandstone 2 & 13 & 5.5 & 260 & 620 & $\begin{array}{l}\text { Wyllie and } \\
\text { Spangler, } 1950\end{array}$ \\
\hline
\end{tabular}

$k$ is given in millidarcies; $1 \mathrm{md}=10^{-11} \mathrm{~cm}^{2}$ 
most of the porosity. Using an m of $6 \mu \mathrm{m}$, calculated $\mathrm{k}$ is $0.6 \mathrm{md}$, close to the measured value (Table 6-1).

The Sherman granite is of particular interest owing to three distinct types of cavity associated with joints, macrocracks and microcracks. We can compare permeability of all three, treating each as though it were independent. Field pumping measurements (Pratt et al, 1976) gave 2.2 md for the jointed rock; the 0.1 md reported here reflects the macrocracks, and 0.0006 md would be the value just due to the microcracks (using a mean $m$ of $1 \mu m$ ).

We next tested Equation 6.3 using published values of $k, F$, and $m$ for a number of sandstones and ceramics. In these studies (Wyllie and Ross, 1950; Wyllie and Spangler, 1952), $k$ and $F$ have been measured in the usual way, and m from the phase displacing pressure. Their values of $m$ are reported here for two sintered ceramics, Pyrex and Alundum, and several porous rocks, along with the measurements of $k$ and $F$ for these materials. The value of $k$ shown in the forth column of Table 6-1 has been calculated from Equation 6.6 using $k_{0}$ of 2.5 .

Wyllie and Spangler (1952) used a more direct method to measure m. Pore geometry of several sandstones was obtained from enlarged photomicrographs of thin sections. Porosity measured this way agreed closely with values obtained by immersion. Measurements for three typical rocks are given in Table 6-1.

Calculated and measured permeabilities are next compared in Figure 6-5. The uncertainties in the various parameters have been estimated as follows. Except for granite, the probable errors in measured $k$ and $F$ are probably less than \pm 10 percent, and $m$, less than \pm 15 percent. The uncertainty in $k_{0}$ is at least \pm 20 percent. In Figure $6-5$, calculated $k$ has been assigned $a \pm 50$ percent error and measured $k, a \pm 10$ percent error, with the following exception. For granite, the errors we reported (Brace et al, 1968) for $k$ and $F$ are about \pm 10 percent, but the uncertainty in $m$ (the geometric mean from Figure 6-4) is probable \pm 50 percent. The uncertainty assigned calculated $k$ for granite in the figure was a factor of 3.

Agreement between calculated and measured $\mathrm{k}$ (Table 6-1, Figure 6-5) seems fairly good, although observed $k$ is typically greater than calculated $k$ by as much as a factor of 5 . Considering the 10 orders of magnitude range of $k$, this may be an acceptable uncertainty. 


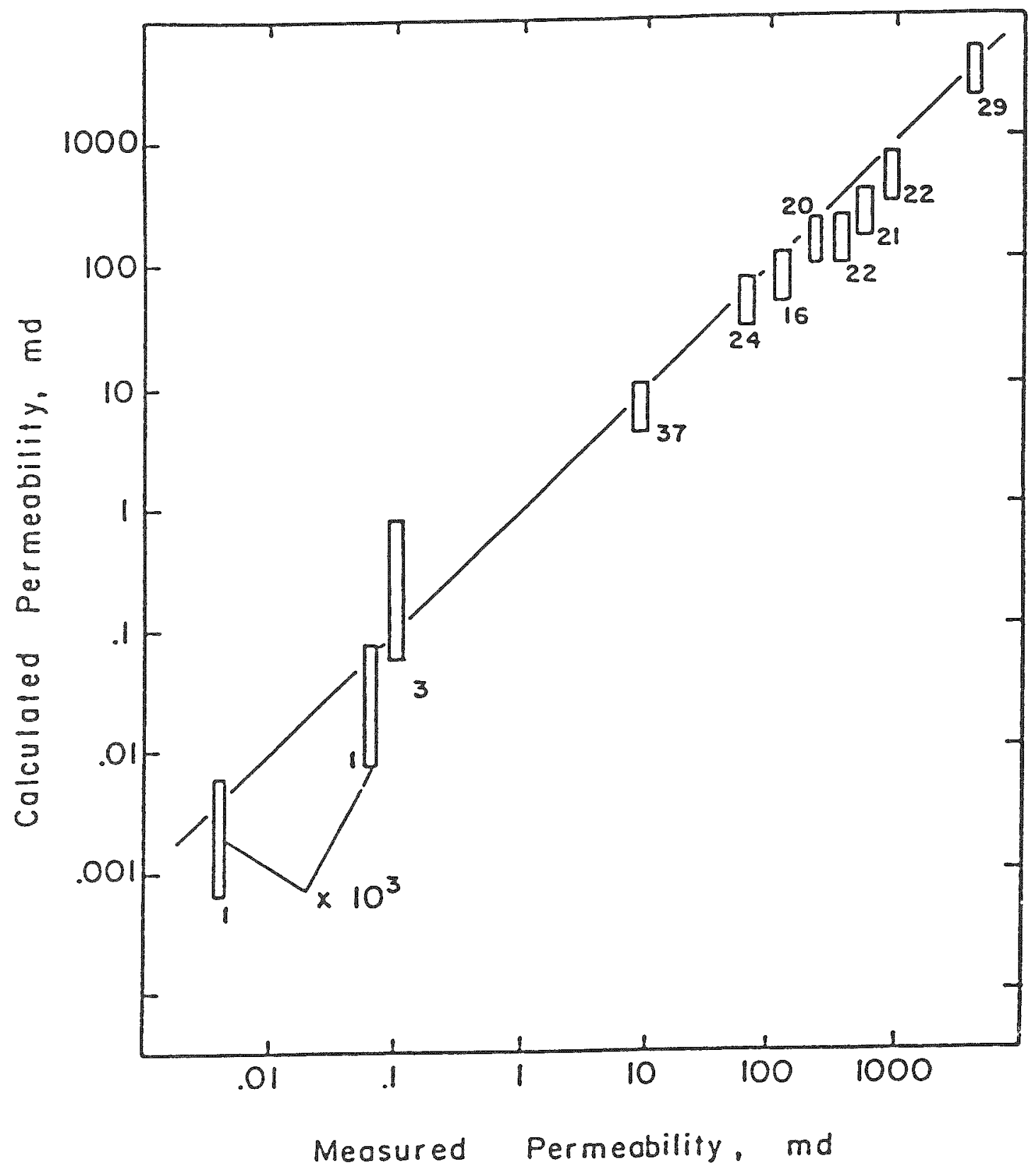

Figure 6-5. Comparison of Calculated and Measured Permeabilities. The Data are Taken from Table 6-1, and the Sma11 Number for each Rock Refers to its Porosity. Lowermost Two Points have been shifted a Factor of $10^{3}$ for Convenience. The Unut is the Millidarcie, $10^{11} \mathrm{~cm}^{2}$. 


\subsection{CONCLUSIONS}

We might summarize the foregoing as follows. Two cases have been successfully analyzed: (1) flow through isotropic porous rock, and (2) flow through rough parallel fractures. For porous rock, the following expression for permeability relationship is widely applicable:

$$
k=\frac{m^{2}}{k_{0}} \eta^{3}
$$

where $k_{0}$ is a dimensionless constant which can vary between 2 and 3.

$\eta$ is interconnected porosity and $m$ is one quarter of the diameter of a cylindrical pore and half the aperture of a flat rectangular slow.

For a fracture set with spacing, $J$,

$$
k=\frac{b^{3}}{12 J}
$$

Eq. 5.6

But $b / J$ is fracture porosity, $\eta_{F}$, so that

$$
k=\frac{b^{2}}{12} \quad n_{F}
$$

$\mathrm{Eq} \cdot 6.7$

Comparison of Equation 5.6 and 6.7 clearly shows the difference in the role played by porosity in the two cases.

Some understanding of the dominating influence of fractures can be galned by comparing Equation 5.6 and 6.7 using reasonable estimates of porosity and aperture. Consider first jointed crystalline rock. From Snow's work (1968a), mean values of aperture were $100 \mathrm{\mu m}$ and fracture porosity $10^{-5}$. For the matrix, take $\eta$ as $3 \times 10^{-3}$ and pore width of $1 \mathrm{~km}$. Then fracture permeability, using Equation 5.6 will be $10^{6}$ times permeability through the matrix. For rocks like sandstone where $n_{I}$ of $10^{-1}$ and $b$ of 100 to 1000 hm are more appropriate, flow through fractures would be subordinate.

Equations for permeability such as Equation 5.6 and 6.7 may have useful practical applications. Inexpensive determination of permeability could be made in, say, a borehole, if porosity and pore size, or fracture aderture 
were known. Porosity is currently logged in some cases, based on resistivity and other characteristics. Pore and, particularly, fracture size is more difficult. However, new methods of whole wave analysis seem promising for the latter (Palllet, 1981). When avallable as a wreline logging method, rapid and inexpensive estimation of permeability may become possible. 
Bandis, S., 1980. Experimental Studies of Scale Effects on Shear Strength and Deformation of Rock Joints, Ph.D. Thesis, University of Leeds.

Bear, J., 1972. Dynamics of Fluids in Porous Media, Elsevier, New York.

Bianchi, L., and D. T. Snow, 1969. "Permeability of Crystalline Rocks Interpretated from Measured Orientations and Apertures of Fractures". The Arid Zone Research of India, Jodphur (Rajasthan), Annals of Arid Zone, Vol. 8, No. 2, pp. $231-245$.

Bjornnson, A., 1976. "Electrical Resistivity of Layer 3 in the Icelandic Crust", Greinar V, 1-22, Visindefelag Islendinga.

Bousinesq, J., 1858. Jou. de Liouville 13, Vol. 13, D. 227.

Brace, K. F., 1965. "Some New Measurements of Linear Compressibility of Rocks", J. Geophys. Res., Vol. 70, No. 2, pp. 391-398.

Brace, W.F., 1971. "Resistivity of Saturated Crustal Rocks to $40 \mathrm{~km}$ Rased on Laboratory Measurements", in The Structure and Physical Properties of the Earth's Crust, Ed. John Heacock, ed., Geophysical Monograph Series, Vo1. 14, pp. 243-255, Amer. Geophys. Union.

Brace, W. F., 1977, "Permeability from Resistivity and Pore Shade," J. Geophys. Res. 82, p. 3343.

Brace, W.F., 1978. "A Note on Permeability Changes in Geologic Materials Due to Stress", PAGEOPH, Vo1. 116, pp. 627-633.

Brace W.F., 1980. "Permeability of Crystalline and Argillaceous Rocks", Int. Jour. Rock Mech. Min. Sci. and Geomechanics Abstr, Vo1. 17, DD. $241-251$. 
Brace W. F., A. Orange, T. M. Madden, 1965. "The Effect of Pressure on the Electrical Resistivity of Water Saturated Crystalline Rocks", J. Geophy. Res. Vol. $70(22)$, p. 5669.

Brace, W. F., and A. S. Orange, 1968. "Electrical Resistivity Changes in Saturated Rock during Fracture and Frictional S1iding", J. Geophys. Res., Vo1. 73, No. 4, pp. 1422-1445.

Brace, W.F., J. B. Walsh, and W. T. Grango, 1968. "Permeabilitv of Granite Under High Pressure", J.Geophys. Res., Vol. 73. No.6, pp. 2225-2236.

Bredehoeft, J. D., and B. B. Hanshaw, 1968. "On the Maintenance of Anomalous Fluid Pressures: in Thick Sedimentary Sequences", Geol. Soc. Amer. Bull., Vol. 79, pp. 1097-1106.

Carlsson, A., and T. 011son, 1977. "Variations of Hydraulic Conductivity in Some Swedish Rock Types", Rockstore 1977 (Stockholm), Vo1. 2, pp. 85-91.

Casse, F. J., and H. J. Ramey, Jr., 1979. "The Fffects of Ternperature and Confining Pressure on Single-Phase Flow in Consolidated Rocks", J. Petrol. Tech., Vol. 31, No. 8, pp. 1051-1059.

Charles, R. W., 1978. "Experimental Geothermal Loop: I, 295 C Study", Los Alamos Scientific Lab. Rept. LA-7334-MS.

Charles, R. W., 1979. "Experimental Geothermal Loop: II, 200 C Study", Los Alamos Scientific Lab. Rept. LA-7734-MS.

Childs, E. C., 1969. Introduction to Physical Basis of Soil-water Phenomena, Wley, New York, 593 pp. 
Cooper, H. H., J. D. Brededhoeft, and I. S. Papadopulos, 1967. "Response of a Finite Diameter Well to an Instantaneous Charge of Water", Water Res. Res., Vol. 3, pp. 263-269.

Danesh, A., C. Ehlig-Economides, and H.J. Ramey, Jr., 1978. "The Effect of Temperature Level on Absolute Permeability of Unconsolidated Silica and Stanless Stee1", Trans. Geothermal Resource Council, Vo1. 2, pp. 137-139.

Davis, S. N., and R. J. M. Dehiest, 1966. Hydrogeology, 2nd Ed., John Wiley, New York.

Dehiest, R. J. M., Ed., 1969. Flow Through Porous Media, Academic Press, New York.

Dehiest, R. J. M., 1965. Geohydrologv, John Wiley, New York.

Dreyer W., 1958, "Uber die Genauigkeit der Porositatsbestimmung aus Absolut und Raumdichte", Tonind. Ztg. Keram Rundschau V. 82, p. 72-79.

Duffy, T. A., 1980. Final Report The Salt Block 1 Test: Experimental Deta1 1 s and Comparison with Theory, SAND79-7050, Sandia Laboratories, Albuquerque, $M$.

Gale, J. E., 1975. A Numerical Field and Laboratory Study of Flow in Rocks with Deformable Fractures, Ph.D. Thesis, University of Calıfornia, Berkeley.

Gale, J. E., and P. A. Witherspoon, 1979. An Approach to the Fracture Hydrology at Stripa: Preliminary Results, Tech. Info. Report. No. 15, Lawrence Livermore Laboratory, LBL-7079.

Gangi, A. F., 1981. "The Variation of Mechanical and Transport Properties of Cracked Rock with Pressure". Proceedings of the 22nd U.S. Symposium on Rock Mechanics, Massachusetts Institute of Technologv.

Gloyna, E. F. and T. D. Reynolds, 1961. "Permeability Measurements of Rock Salt", J. Geophys. Res., Vol. 66, pp. 3913-3921. 
Gonten, D. and R. I. Whiting, 1967. "Correlations of Physical Properties of Porous Med1a", J. Cos. Petr. Engrs., Vol. 7, No. 3, pp. 266-272.

Hadley, K., 1976. "Comparison of Calculated and Observed Crack Densities and Seismic Velocities in Westerly Granite", J.Geophys. Res., Vol. 81, No. 20, pp. $3484-3494$.

Hantush, M. S., 1956. "Analysis of Data from Pumping Tests in Leaky Aquifers", Trans. Am. Geophysics Union, Vo1. 37, pp. 702-714.

Heard, H. C., D. Trimmer, A. Duba, and B. Bonner, 1979. Permeability of Generic Repository Rocks at Simulated in situ Conditions, Lawrence Livermore Lab. Rept. ICRL-82609, 12 pp.

Hubbert, M. R., 1956. "Darcy Law and the Field Equations of Flow of Underground Fluids," Trans. Amer. Inst. Min. Metal Engr., Vo1. 207, pp. $222-239$.

Iwal, K., 1976. Fundamental Studies of Flu1d Flow through a Single Fracture, Ph.D. Thesis, University of California, Berkeley.

Jacob, C. D. and S. W. Lohman, 1952. "Nonsteady Flow to a Well of Constant Drawdown in an Extensive Aquifer", Trans. Am. Geol. Union, Vol. 33, pp. 559-559.

Keller, G. V., 1960. "Physical Properties of Tuffs of the Oak Spring Formation, Nevada", U.S. Geol. Surv. Prof. Paper 400R, pp. 396-400.

La1, Chia-Shing, 1971. Fluid Flow Through Rock Salt Under Various Stress States, Ph.D. Thesis, Michigan State University.

Lin, $h ., 1978$. Measuring the Permeability of Eleana Argi11ite from Area 17, Nevada Test Site, Using the Transient Method, Lawrence Livermore Lah. Rept. UCRL-52604. 
Lockner, D., D. Bartz, and J. Byerlee, 1978. "Permeabilitv Changes during Flow of hater through Granite Subjected to a Temperature Gradient", Summaries, 4 th Workshop, Geothermal Reservoir Engineering, Stanford University.

Lomize, G. M., 1951. Filtratsiya v Treshchinovatykh Porodakh. (Flow in fractured rocks), Gosenergoizdat, Moscow.

Louss, C. and Y. M. T. Maini, 1970. "Determination of in situ Hydraulic Parameters in Jointed Rock", 2nd Congress International Society for Rock Mechanics, Belgrade, Vol. 1.

Louss, C., 1969. A Study of Groundwater Flow in Jointed Rock and Its Influence on the Stability of Rock Masses, Imperial College Rock Mechanics Research Report No. 10.

Madden, T. R., 1976. "Random Networks and Mixing Lars", Geophysics, Vo1. 41, pp. $1104-1125$.

Marine, I. W., 1967. "The Permeability of Fractured Crystalline Rock at the Savannah River Plant Near Aiken, South Carolina", U. S. Geol. Survev Prof. Paper 575-B, Pp. B203-B211.

Marine, I. W., 1974. "Geohydrology of Buried Triaasic Basement at Savannah River Plant, South Carolina", Am. Ass. Petro. Geol. Bul. Vol. 58, pp. 1825-1837. 
Montgomery, C. W. and W. F. Brace, 1975. "Micropores in Plagioclase", Contrib. Minera1. Petrol, Vo1. 52, pp. 17-28.

Mordecai, M. and L. H. Morris, 1971. "An Investigation into the Changes of Permeability Occuring in a Sandstone when Failed under Triaxial Stress Conditions", in Dynamic Rock Mechanics (12th Sympos. Rock Mechanics, Rolla, Mo., 1970), Ed. George B. Clar, Chap. 11, Port City Press, Inc., Baltimore, p. 221 .

Morrow, C. and W. F. Brace, 1981. "Flectrical Resistivity Changes in Tuffs due to Stress", J. Geophys. Res., Vol. 8, B4, pp. 2929-2934.

Mundi, E. and J. Wallace, 1973. "On the Permeability of Some Fractured Crystalline Rocks", Bul1. Ass. Eng. Geol., Vol. 10, pp. 229-312.

Nekut, A., J.E. P. Gonnerney, and A. F. Juckles, 1977. "Deep Crustal Electrical Conductivity; Evidence for Water in the Lower Crust", Geo. Physc. Res. Let., Vol. 4, pp. 239-242.

Nelson, R. A., 1972. "An Experimental Study of Fracture Permeability in Porous Rock", Proc. Sympos. on Percolation Theory in Fissured Rock, ISRM Paper $2 A 6$, Stuttgart, Germany.

Neuzi1, C. E. and J.V. Tracy, 1981. "Flow Through Fractures", Water Resource Research, Vol. 17, pp. 191-199.

Norton, D. and R. Knapp, 1977. "Transport Phenomena in Hydrothermal Systems: The Nature of Porosity", Amer. J.Sci., Vol. 297, pp. 913-936. Onle, E. L., 1951. "The Influence of Permeability on Ore Distribution in Limestone and Dolomite", Econ.Geol, Vol. 46, pp. 667-706.

Ohtake, M., 1974. "Se1smic Activity Induced by Water Injection at Matsushiro, Japan", J. Phys. Earth, Vol. 22, pp. 163-176. 
Pallett, F., 1981. "A Comparison of Fracture Characterization Techniques Applied to Near Vertical Fractures in a Limestone Reservoir", SPWAL, 22nd Logging Symposium.

Papadopulos, S. S., 1967. "Nonsteady Flow to a well in an Infinite Anisotropic Aquifer", in Proceedings Dubrovnik Symposium on Hydrologv of Fractured Rocks, Int. Assoc. Sci, Hydrol. Pub1.73, Vol. I, pp. 21-31.

Peterson, E. and P. Lagus, 1981. "In Situ Permeability Testing of Rock Salt", Proc. Penetration Sealing Field Testing Workshop, D"Appolonia Project, NM79-137h-2, Santa Fe, NM.

Pickens, J. F. and G. E. Grisak, 1981. "Scale-Dependent Dispersion in a Stratified Granular Aquifer," Water Resources Research, Vol.17, pp. 1191-1211.

Piwrnski1, A. J. and R. Netherton, 1972. "An Experimental Investigation of the Permeability of Kayenta and St. Peter Sandstones to Hypersaline Brine in the Temperature Interval 70 to $90 \mathrm{C}$ at $10.3 \mathrm{MPa}$ Confining Pressure", Lawrence Livermore Lab. Rept. UCRL-52382.

Polubarinova-Kochina, P. Ya., 1962. Theory of Groundwater Movement, translated by J. M. R. Dewiest, Princeton, New Jersey, Princeton University Press.

Potter, J. M., 1978. Experimental Permeability Studies at Elevated Temperature and Pressure of Granitic Rocks, Los Alamos Scientific Lab. Thesis LA-7224-T.

Pratt, H. R., H. S. Swolfs, W. F. Brace, A. D. Black, and J. h. Handin, 1977. "Elastic and Transport Properties of an In Situ Jointed Granite", Int. J. Rock Mech. Min. Sci. Vo1. 14, pp. 35-45.

Raven, K. G., and J. E. Gale, 1977. "Subsurface Containment of Solid Radloactive Waste: A Study of the Surface and Sub-Surface Structural Ground Water Conditions at Selected Underground Mines and Excavations." Division of Energy and Mines Resources, ERM/GSC-RW, Internal Report 1/77, ottawa, 105 pp. 
Rice, J. R. and D. A. Simons, 1976. "The Stabilization of Spreading Shear Faults by Coupled Deformation-Diffusion Effects in Fluid-Infiltrated Porous Mater1a1s", J.Geophys. Res., Vo1. 81, pp. 4322-5334.

Rootare, H. M. and C. F. Prenzlow, 1967. "Surface Areas from Mercury Porosimeter Measurements", J. Phys. Chem., Vol. 71, pp. 2733-3736.

Romm, E. S., 1966. Filtratsionnye Svioistva Treschinovatykh Gornvx Porod (Flow Characteristics of Fractured Rocks), Nedra, Moscow.

Rubey, W. W. and M. K. Hubbert, 1959. "Role of Fluid Pressure in Mechanics of Overthrust Faulting", Geo1. Soc. Amer. Bu11., Vol.70, pp. 175.

Sche1degger, A. E., 1974. Physics of Flow through Porous Media, 3rd Ed., Univ. Turonto, Oxford Univ. Press, Jondon, $313 \mathrm{pp}$.

Scholz, C. H., L. R. Sykes, and Y.P. Aggarwal, 1973. "Earthquake Prediction: A Physical Basis", Science, Vol. 181, pp. 803-810.

Science Applications, Inc., 1980. Hydrologic Studies, Summary Report, RHO CPFF-708.

Scott, R. F., 1963. Principles of Soil Mechanics, Addison-hlesley Publ. Co., Inc., Reading, Mass.

Sharp, J. C., 1970. Fluid Flow through Fissured Media, Ph.D. Thesis, University of London. Imperial College of Science and Technology.

Sharp, J. C. and Y.N. T. MainI, 1972. "Fundamental Considerations on the Hydraulic Characteristics of Joints in Rocks", Proceedings Symposium on Percolation Through Fissured Rock, International Society for Rock Mechanics, Stutgart, No. T1-F.

Snow, D. T., 1965. A Parallel Plate Model of Fractured Permeable Media, Ph.D. Thesis, University of California, Berkeley. 
Snow, D. T., 1968(a). "Rock Fracture Spacings, Openings, and Porosities", I. Soll Mech. and Found. Div. A.S.C.E., Vol. 94, pp. 73-91.

Snow, D. T., 1968(b). "Hydraulic Characteristics of Fractured Metamorphic Rocks of Front Range and Implications to the Rocky Mountain Arsenal kell", Colo. Sch. Mines Quartly., Vol. 63, pp. 167-199.

Snow, D. T., 1969. "The Frequency and Apertures of Fracture in Rock", J. Rock Mech. Min. Sci., Vol. I, pp. 23-42.

Somerton, W. H. and A. K. Mathur, 1976. "Effects of Temperature and Stress on Flu1d Flow and Storage Capacity of Porous Rocks", Proc., 17th Sympos. Rock Mechanics, Paper 2 A2, 8 pp..

Somerton, W. H., I. M. Soylemezogula, and R. C. Dudley, 1975. "Effects of Stress on the Permeability of Coal", Int. J. Rock Mech. Min. Sci., Vol. 12, p. 129 .

Stesky, R. M, and W. F. Brace, 1973. "Flectrical Conductivity of Serpentinized Rocks to $6 \mathrm{bk}^{\prime \prime}, \mathrm{J}$. Geophys. Res., Vol.78, po. 7514-7621.

Stuart, W., F. Brown, and E. Rhodehame1, 1954. Ground Water Investigations of the Marquette Iron Maning District, Mchigan Geol. Survey Div. Tech., Report 3, 92 pp.

Summers, R., K. Wnkler, and J. D. Byerlee, 1978. "Permeability Changes during the flow of Water through Westerly Granite at Temperatures of $100 \mathrm{C}$ to 400 C", J. Geophys. Res., Vol. 83, pp. 339-344.

Sutherland, H. J. and S. P. Cave, 1980. "Gas Permeability of SENM Rock Salt", Int. J. of Rock Mech. and Mining, Vol. 17, pp. 281-288.

Swolfs, H. S., C. E. Brechtel, K. F. Brace, and H. R. Pratt, 1981. "Field Mechanisal Properties of a Jointed Sandstone", in Mechanical Behavior of Crustal Rocks, SGU Monograph 24. 
Thackston, J., 1981. "Hydrogeologic Field Investigations Paradox Basin, Utah", Proc. Penetration Sealing Field Testing horkshop, D'Appolonia Project, NM79-137h-2, Santa Fe, NM。

Thayer, R. E., A. Bjornsson, L. Alvarez, and J. F. Hernance, 1981. Magma Genesis and Crustal Spreading in the Northern Neovolcanic Zone of Iceland: Telluric-magnetotoelluric Constraints", Geophys. J.R.Astr. Soc., Vol.65, pp. 423-442.

Theis, C. V., 1935. "Relationship between the Lowering of the Piezometeric Surface and the rate and Duration of Discharge of a Well Using Ground-Water Storage", Trans. Amer. Geophys. Union, Vol. 16, DP. 519-524.

Villas, R. N. N., 1975. Fracture analysis, Hydrodynamic Properties and Mineral Abundance in the Altered Igneous Wall Rocks of the Mayflower Mine, Park Crty District, Utah, Ph.D. Dissertation, University of Utah, 254 pp.

Voegele, M. D., E. Hard1n, D. Lingle, M. Board, and N. Barton, 1981. "Site Characterization of Joint Permeability using the Heated Block Test", R. Mech. Proceeding of the 22nd U.S. Symposium.

Voegele, M. D., R. McCa1n, M. Gronseth, and H. Pratt, 1980. "In Situ Permeabllity Measurements for an Underground Compressed Air Storage Proiect", in Doe and Schwartz, ed. Well Testing in Low Permeability Environments, Proc. 3 rd Invitational Well Testing Symposium, Berkeley, LBL 12076, pp. 45-60.

Walton, W. C., 1970. Groundwater Resource Evaluation, Mcfraw-Hill.

Wang, J., C. F. Tsang, T. N. Narasimhan, and P. A. Witherspoon, 1977. "Transient Flow in Tight Fractures", Proc. Ist Invitational Well Testing Symposium, Lawrence Berkeley Laboratory.

Wawersik and D. W. Hannum, 1980. "Mechanical Behavior of New Mexico Rock Salt in Triaxial Compression up to $200 \mathrm{C}^{\prime \prime}$, J. Geophys. Res., Vol. 85, pp. $891-900$. 
Weinbrandt, R. M., H. J. Ramey, Jr. and F. J. Casse, 1975. "Effect of Temperature on Relative and Absolute Permeability of Sandstone", Soc. of Petro1. Engrs. J., pp. 376-384.

Wilson, C., T. Doe, J. Long, and P. A. Witherspoon, 1979. "Permeabilitv Characterization of Nearly Impermeable Rock Masses for Nuclear haste Repository Sitıng", presented to OECD Symposium on Well Testing in Low Permeability Rock, Paris.

Witherspoon P. A. and J. E. Gale, 1977. "Mechanical and Hydraulic Properties of Rocks Related to Induced Seismicity", Fngg. Geologv, Vol.11, (1) pp. 23-55.

Witherspoon, P. A., C. H. Amick, J. E. Gale, and R. Iwai, 1979. Observations of a Potential Size-Effect in Experimental Determination of the Hydraulic Properties of Fractures, Lawrence Berkeley Laboratory Rept. LBL-8571.

Witherspoon, P. A., Y. W. Tsang, J. C. Long, and J. Noorishad, 1981. "New Approaches to Problems of Flurd Flow in Fractured Rock", Proceedings of 22nd U.S. Symposium on Rock Mechanzcs, Massachusetts Institute of Technology.

holff, R. G., 1981. "Porusity, Permeability, Distribution Coefficients and Dispersivity", Ch. 4 in Touloukiem, Y.S., Judd, W. R., and Roy, R. F., eds., Physical Properties fof Rocks and Minera1s, McGraw-Hi11/CINDAS Data Services on Material Propertıes, Vol II-2, McGraw-Hill, New York, Pp. 45-81.

Wyllie, M. R. J. and W. D. Rose, 1950. "Application of the Rozeny Equation to Consolidated Porous Media", Nature, Vo1.165, p. 972.

Wyllie, M. R. J. and M. B. Spangler, 1952. "Application of Flectrical Measurements to Problems of Fluid Flow in Porous Media", Bul1. Amer. Assoc. Amer. Assoc. Petrol. Geolog., Vol. 36, Pp. 359-402. 
Zoback, M. D. and J. D. Byerlee, 1975. "The Effect of Microcrack Dilatancy on the Permeability of Westerly Granite", J.Geophys, Res., Vol. 80, D. 752.

Zoback, M. D. and J. D. Byerlee, 1976a. "A Note on the Deformational and Fluid Flow Behavior of Crushed Granite", Int. J. Rock Mech. Min. Sci., Vol. 13, p. 291.

Zoback, M. D. and J. D. Byerlee, 1976b. "Effect of High-Pressure Deformation on Permeability of Ottawa Sand", Amer. Assoc. of Petrol. Geol. Bul1., Vol. 60, D. 1531 . 


\section{APPENDIX}

SYMBOLS

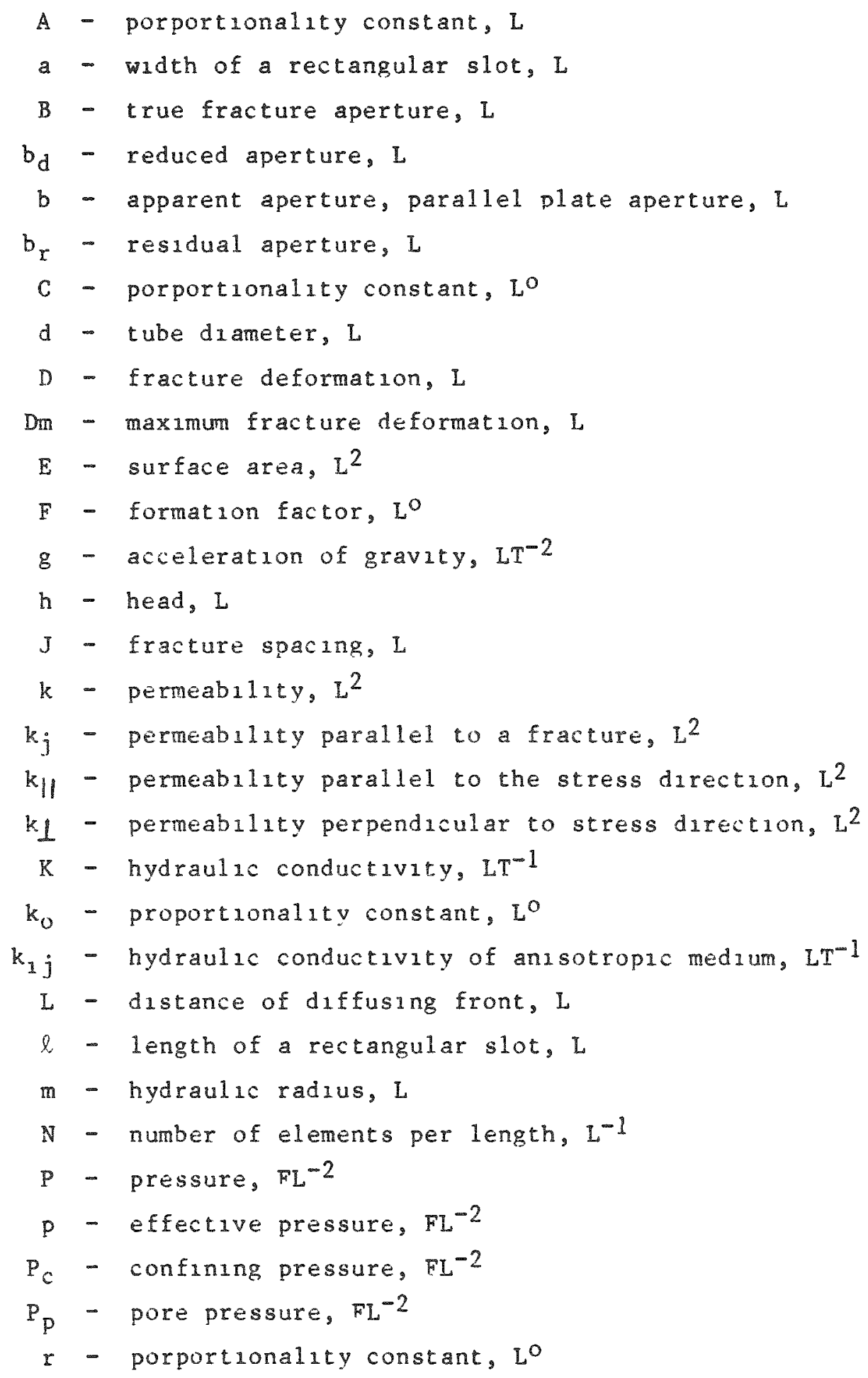



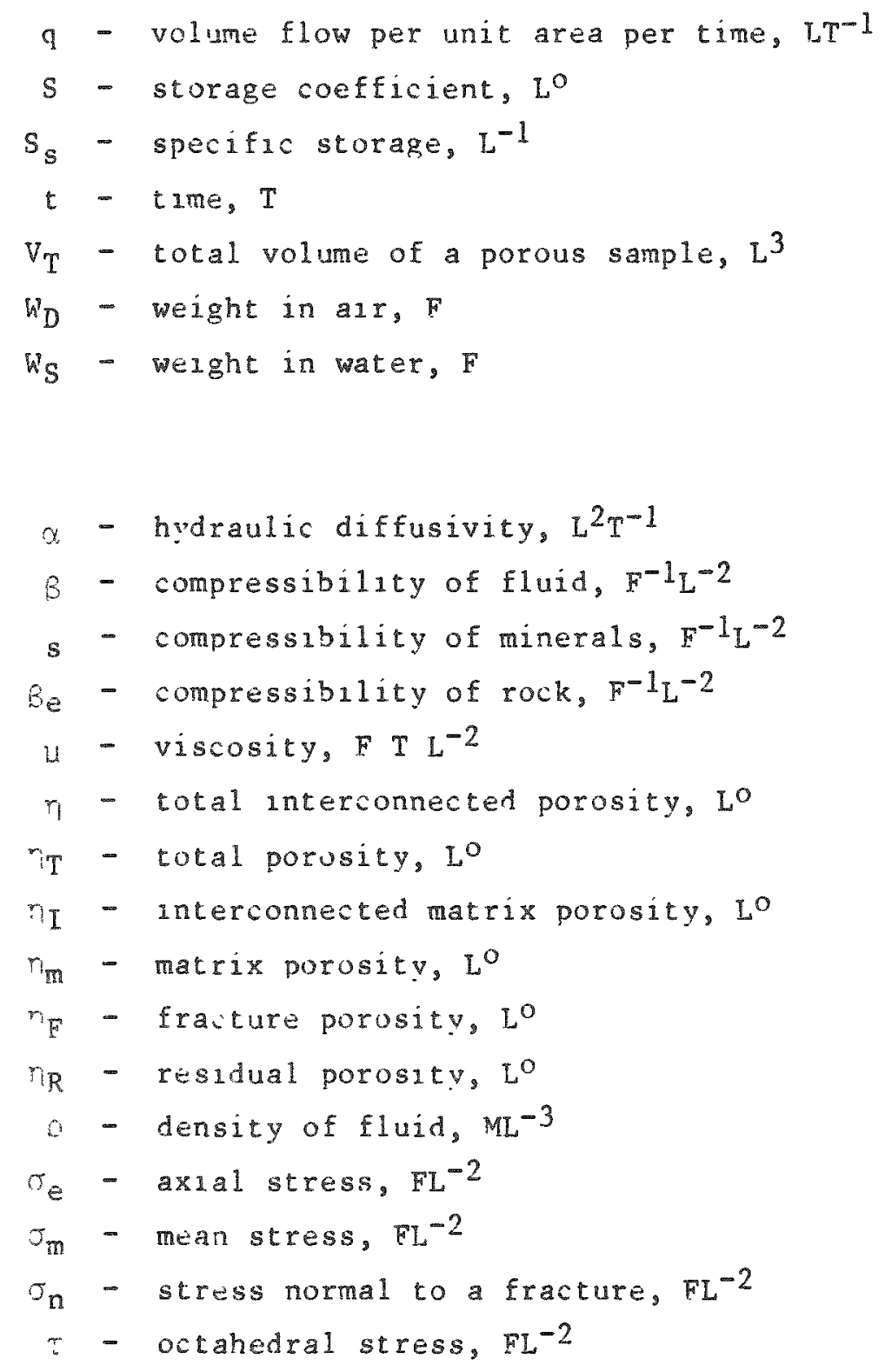

UNITS

Permeability, as used hereln, has dimensions $L^{2}$; the preferred unit is darcy.

1 darcy (d) $10^{-8} \mathrm{~cm}^{2} \approx 10^{-4} \mathrm{ft}{ }^{2}$

The darcy unit is widely used in soil and rock mechanics and hydrology. 


\section{$87 / 6$}

Hydraulic conductivity, $\mathrm{K}$, is also in common use. For water under standard conditions

$$
1 \text { darcy } \approx 10^{-3} \mathrm{~cm} / \mathrm{sec} \approx 10^{-5} \mathrm{~m} / \mathrm{sec} \approx 3 \mathrm{ft} / \mathrm{day}
$$

When transient flow is involved, it is customary to discuss hydraulic diffusivity, $\alpha$. This can be related to permeability, $k$, if porosity, $n$, viscosity, $\mu$, and compressibility, $B$, are known by

$$
\alpha=\mathrm{k} / \mu \cap \beta
$$




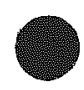


DISTRIBUTION LIST

TMUR D. LITLE INC CHARLES R. HADLOCK

ASSESSMENT BRANCH

ROBERT B. LYON

ATKINS RESEARCH \& DEVELOPMENT $T$ T . AROYD

ATOMIC ENERGY OF CANADA LTD ANN QUINPY

AUSTRALIAN ATOMIC ENERGY COMMISSION

BASALT WASTE ISOLATION PBOIECT RICHARDT, WILDE

BECHTEL GROUPINC A. A. NORMAN

BENDIX MIELD ENGINEERING CORP BHL GRAHAM CHARLES A. JONES

BROOKHAVEN NATIONAL LABORATORY HELEA TODOSOW 12 ?

BUNDESANSTALT FUR GEOWISSENSCHAFTEN UND ROHSTOFFE HELMUT VEAZLAFF

RUNDESMINISTERIUM FUR TORSCHUNG ROLF.PETER RANDL

BUPEAU OF ECONOMIC GEOLOCY WHLIAM L. FISHER

CENTRE D INPORMATIQUE GEOLOGIQUE GHISLAIN DE MARSILY

CORNELL UNIVERSTTY IOHV BIRD

DAPPOLONIA CONSULTNG ENGINEERS INC LISA R DONOHLE

DEPT OF THE ENVIRONAENT

5. FFATES

FDISON FIECTRIC INSTIUUTE

R. [ L. STANFORD

ELECTRIC POWER RESEARCM INSTITUTE CHAIM BRALN ROBLRT WHIIAMS

ERTEC WESTERN INC KENNETH WIISOS

CLORGIA INSTITUTE OF TECHNOLOGY GEOTFREY G. 1 CHHOLZ

GEOTRANS

JAMES MERCER

HAHAN-MEITNER-INSTITUT KIALS ECKART MAASS

HANTORD FNGINEERING DEVELOPMENT LABORATORY ALBERT G. BLASEMITZ

MARVAED UNIVEESTTY DADE W. MOELLER

INSTITUT FUR TIEELAGERUNG H. GIES KLAUS RUHA

IASTITUTE OF GEOLOCAL SCIENCES NEII A. CHAPMAN

INTEEA ENVIRONMENTAL CONSULTANIS INC F. J. PEARSON. JR ROBERT WILMS

IAPAN ATOMIC ENERGY RESEARCH INSTITUTE TARO ITO

JOINT RESEARCH CENTIE

KBS ERANCESCO GIRARDI

LAR5 B. NILSSON

MERNEORSCHUNGSZENTRUM KARLSTUHE

$\mathrm{CM}$

K. D. ClOSS

AWIRENCE REREELEY LARORATORY

PALL A. WITHERSPOON
LAWRENCE LIVERMORE LABORATORY

THOMAS I, WOLERY

LAWRENCE HIVERMORE NATHONAL

LABORATORY

W. G. SUTCLIFFE

TECHNICAL INFORMATION DEPARTMENT L-53

IOS ALAMOS NATIONAL LABORATORY B. CROWE BRUCER. ERDAL

LOWENSTEIN, NEWMAN, RTIS \& AXELRAD MICHAEL A. BAUSER

NATIONAL ACADEMY OF SCIENCES JOHA T. HOLLOWAY PETER B. MYERS

NATIONAL BOARD FOR SPINT NUCLEAR

FUEL, KA RABRANSLENAMDEN NILS RYDELL

NATIONAL BUREAU OF STANDARDS WILLIAM P. REED

NATIONALE GENOSSENSCHATT FUID DIE LAGERUNG RADIOAKTIVER ABEALLE MARLIES KLHN

NEW MEXICO ENVIRONMENTAL EYALUATION GROUP

ROBERTH. VEILL

NUS CORP

W. G. BELTER

JOSEPH J. DINLNNO BARRY N. NAFT

OAK RIDGE NATIONAL LAEORATORY DAVID C. KOCHER

ORGANIZATION FOR ECONOMIC COOPERATION AND DEVELOPMENT I.P. OUVIER

PACIFIC NORTHWEST LARORATORY DON I BRADLEY H C. BURKHOLDER CHARLES T MIRCAID MAXR. KREITER R. WILLIAM NELSOA R JEFF SER $\triangle E$

PHYSIKALISCH-TECHNISCME BUNDESANSTALT PETER BRENNECKE

PRERCETON UNIVERSITY GEORGEF. PINDER

RE/SPEC INC PAULF. GNIRK

ROCKWEL HANFORD OPERATIONS R. A. DEIU L. R. FITCH

ROYAL INSTITUTE OE TECHNOLOGY IVARS NERETNIEKS

SANDIA NATIONAI LABORATORIES

NANCY C. FINLEY

R. 1 HUNTER

I. KEITH IOHNSTONE

R W. LYNCH

MARTIN A. MOLECKE

JAMES T. NEAL

SCOTT SINANOCK

IYNA D. TYLER

MIPP CENTRAL FILES

SCIENCE APPIUCATIONS INC JEFFREY ARBITAL

STANFO RO UNIVETSITY KONRAD B. KRAUSKOPF

STONE WESTER ENGINETEING CORP J. PECK

TEXAS ENEETY 舀 NATURAL RESOURCES

ADVISORY COUNCIS CAROL KINC
THE ANALYTIC SCIENCES CORP JOHN W. BARILETT

U.K. DEPT. OF THE ENVIRONMENT RADIOACTIUE WASTI MANAGEMENT DIVISION

U.S. AMMY COFS OF ENGIEETS ALAN BUCK

U.S. DEPARTMENT OF ENERG DONALDL. VIEIH

U.S. DEPT OF ENERGY - ALBUQUERQUE OPERATIONS OFFICE R. LOWER? IOSEPH M. MCGOUGH

U.S. DEPT OF ENERGY - CHICACO OPERATIONS OFFICE

D. BRAY PUBLIC READING ROONA

U.S. DEPT OF ENERGY - DALLAS SUPPORT OFFICE

CURTISE. CARLSON, IR

U.S. DEPT OF ENERGY - DIVISION OF WASTE REPOSTTORY DEPLOYMENT

W. WADE BALLARD, IR

W. BENAETT

C. R COOHFY 2 ,

WARREN EISTER

THOMAS P LONGO RALPH STEIN

U.S. DEPT OR ENERCY - MEADQUARTERS PLBIIC READING ROON

U.S. DEPT OF ENERGY - IDAHO OPERATIONS OPFICE

PLBLIC READING ROON

J. H. SALO

IOHAB. WHITSETT

U.S. DEPT OF ENERGY - NEVADA OPERATIONS OFFICE

M.P. KLNICH

PLBUIC PIATHNG ROONA

U.S. DEPT OF ENERGY - NWTS MARJORIF POPOVICH

U.5. DEPT OF EAERCY - NWTS PROGRAM OFFICE

T BALLLELI

M BLANCHARD

L. A. CASTY

R. LAHOII

L. R. MCCLAIV

1. O. AEFF

K. K.WL

R C. WLNDERLICH

U.S. DEPJ OF ENERGY - OAK MIDGE OPERATIONS OFFICE

PLBBIC READING ROON

U.S. DEPT OF ENERGY - RICHLAND

OPERATIONS OFFICE

O. L. OLSON

PUBLIC READING ROOM I SCHREIBER

U.S. DEPT OR ENERGV - SAN FRANCISCO OPERATIONS OFEICE

ENERGY RESOLRCES CENTER PUBLIC READING ROOA

U.S. DEPT OF ENERGY - SAVANAAH RIVER OPEEATIONS OFFCE REGIRA T. HARRIS

U.S. DEPT OF ENEREY - TECHNICAL INFORMAIION CENTER (27)

U.S. ENVIRONMENTAL PROTECTION ACENCY DIVISION OF CRITERIA \& STANDARD DAN LGAN 
U.S. GEOLOGICAL SURVEY - COLUMBUS

A M. LA SALA.JR.

US. GEOLOGICAL SURVEY - DENVER JESS $M$ CLEVELAND W. SCOTT KEYS

U.S. GEOLOGICAL SURVEY - MENLO PARK IACOB RUBIN

U.S. GEOLOGICAL SURVEY - RESTON IOHN ROBERTSON DAVID B. STEMART

U.S. NUCLEAR REGULA TORY COMMISSIOA 1. CALVIN BELOTE

PATRICIA A. COMELLA
EARICOF. CONTI

MICHAEL C. CULLINGFORD

I.) DAVIS

F. L. DOYLE

FREDERICK FORSCHER

PAUL F. GOLDBERG

HIGH-LEVEL WASTE LICENSING BRANCH

HICH-LEVEL WASTE TECHNICAL LIBRARY

IAMES C. MALARO

JOHN B. MARTIN I3!

IOHN C. MCKINLEY

HUBERT MILLER

EDWARD O'DONMEL

R. JOHN STARMER
UNIVERSITY OF CALIFORNIA

THOMAS H. PIGFORD

VANDERBUET UNIVERSITY

FRA

WOODWARD-CLYDE CONSULTANTS

TERRY A GRA IT 